JOSÉ ROBERTO DE SOUZA

\title{
ANÁLISE ESTRUTURAL DE ENRIJECEDORES À FLEXÃO DE GEOMETRIA COMPLEXA UTILIZADOS EM OPERAÇÕES
} OFFSHORE

\author{
Dissertação apresentada à Escola \\ Politécnica da Universidade de São \\ Paulo para obtenção do título de Mestre \\ em Engenharia
}


JOSÉ ROBERTO DE SOUZA

\title{
ANÁLISE ESTRUTURAL DE ENRIJECEDORES À FLEXÃO DE GEOMETRIA COMPLEXA UTILIZADOS EM OPERAÇÕES
} OFFSHORE

\author{
Dissertação apresentada à Escola \\ Politécnica da Universidade de São \\ Paulo para obtenção do título de Mestre \\ em Engenharia \\ Área de Concentração: \\ Engenharia Mecânica de Projeto e \\ Fabricação
}

Orientador: Prof. Dr. Roberto Ramos Jr. 


\section{FICHA CATALOGRÁFICA}

Souza, José Roberto de

Análise estrutural de enrijecedores à flexão de geometria complexa utilizados em operações offshore / J.R. de Souza. -São Paulo, 2008.

$78 \mathrm{p}$.

Dissertação (Mestrado) - Escola Politécnica da Universidade de São Paulo. Departamento de Engenharia Mecânica.

1. Estruturas offshore (Operação) 2. Método dos elementos finitos 3. Modelos analíticos I.Universidade de São Paulo. Escola Politécnica. Departamento de Engenharia Mecânica II.t. 
DEDICATÓRIA

À Lilian, esposa amada.

Incentivadora e companheira. 


\section{AGRADECIMENTOS}

O autor deseja expressar seu agradecimento:

Ao Departamento de Engenharia Mecânica da Escola Politécnica da Universidade de São Paulo, pelo apoio e oportunidade de realização deste trabalho.

Ao Prof. Dr. Roberto Ramos Jr., a quem o autor teve o privilégio de ter como orientador neste trabalho, pelas sugestões, insights e críticas.

Aos membros da banca do exame de qualificação, Prof. Dr. Celso Pupo Pesce e Prof. Dr. Clóvis de Arruda Martins, pela avaliação assertiva e pelas sugestões propostas naquela ocasião.

A todos os colegas e amigos que de alguma forma colaboraram para a realização deste trabalho. 


\section{RESUMO}

Os enrijecedores à flexão - ou bending stiffeners - contemplados neste trabalho são componentes estruturais auxiliares utilizados em linhas flexíveis em suas conexões com unidades flutuantes em sistemas de produção de petróleo offshore. A configuração destes acessórios deve conferir à instalação uma variação gradual da rigidez à flexão próximo ao ponto de fixação da linha flexível à unidade flutuante, diminuindo sua curvatura e suavizando o campo de tensões, evitando assim que a linha ultrapasse a curvatura máxima estabelecida em projeto. $\mathrm{Na}$ análise estrutural destes acessórios, diversas simplificações geométricas são consideradas e, em geral, os modelos propostos partem de uma geometria cônica simples. Na prática, entretanto, é comum a existência de unidades que envolvem até quatro diferentes seções. Este trabalho apresenta uma análise estrutural estática destes componentes complexos por meio de um modelo linear elástico, analiticamente formulado, que resulta em uma equação diferencial não-linear de segunda ordem com coeficientes variáveis. O problema matemático de valor de contorno é então solucionado numericamente com um código desenvolvido em Matlab ${ }^{\circledR}$, usando uma função interna baseada no método de colocação - em oposição ao método de tiros, freqüentemente usado em trabalhos anteriores. Finalmente, soluções previamente obtidas por outros autores com modelos analítico-numéricos e com elementos finitos são utilizadas para validar as soluções aqui obtidas, seguidas de uma análise paramétrica da geometria complexa de novos enrijecedores à flexão, além de breve discussão sobre análise dimensional e questões normativas relacionadas ao projeto destes acessórios.

Palavras-chave: enrijecedores à flexão. modelos analíticos. elementos finitos. análise dimensional. 


\begin{abstract}
The bending stiffeners discussed in this work are ancillary structural components installed on flexible lines at their connections with floating units in offshore oil production systems. The configuration of these accessories must provide the installation with a gradual variation of the bending stiffness near the line's attaching point, smoothing the curvature and the stress field of the compliant structure therein fixed, thus avoiding exceeding its designed structural bending limit. In the structural analysis of these accessories, several geometric simplifications are considered and, in general, the proposed models start from a simple conic geometry. In practice, however, bending stiffeners' geometries are not so simple. Indeed, units consisting of four different sections are common. This work presents a parametric static structural analysis of these complex components by means of an analytically formulated linear elastic model, which results in a second order non-linear differential equation with variable coefficients. The ensuing mathematical boundary value problem is then solved numerically

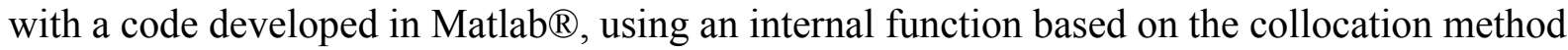
- as opposed to the shooting method, frequently used in previous works. Finally, solutions obtained previously by other authors, with analytical-numerical and finite element models, are used to validate the solutions obtained herein, followed by a parametric analysis of the complex geometry of new bending stiffeners, besides brief related dimensional analysis and normative discussions.
\end{abstract}

Keywords: bending stiffeners. analytical models. finite element method. dimensional analysis. 


\section{LISTA DE ILUSTRAÇÕES}

Figura 1 - Plataforma continental: campos e profundidades. 14

Figura 2 - Recordes obtidos pela Petrobras em lâmina d'água de poço em produção. 15

Figura 3 - Plataforma semi-submersível, movimentos e linhas flexíveis. 16

Figura 4 - A: Bell mouth; B: Restritor de flexão; C: Enrijecedor à flexão. 16

Figura 5 - Diagrama de um sistema típico de produção. 17

Figura 6 - Diagrama de corpo livre e equilíbrio do elemento de cabo. 19

Figura 7 - Comparação entre comprimentos de flexão. 21

Figura 8 - Diagrama de forças e equilíbrio do elemento de cabo. Boef e Out (1990). 22

Figura 9 - Geometria do enrijecedor à flexão analisado por Boef e Out (1990). 23

Figura 10 - Arranjo e geometria do modelo analisado por Lane et al. (1995). 24

Figura 11 - Arranjo típico de enrijecedor à flexão. 31

Figura 12 - Áreas críticas em relação à fadiga de um enrijecedor à flexão. 31

Figura 13 - Detalhe de área da capa interna: região típica de descolamentos entre o corpo de poliuretano e a capa metálica. 31

Figura 14 - Arranjo de enrijecedor à flexão para "I-Tubes". 32

Figura 15 - Enrijecedor à flexão de geometria complexa. 32

Figura 16 - Enrijecedores à flexão simples.

Figura 17 - Enrijecedores à flexão complexos. $\quad 34$

Figura 18 - Navio-tanque acoplado a uma monobóia. 35

Figura 19 - Instalação típica em "catenária direta”. 36

Figura 20 - Equilíbrio de um elemento infinitesimal. 37

Figura 21 - Transposição da força $F$ da seção $s=L$ para uma seção genérica $s$.

Figura 22 - Enrijecedor à flexão de geometria simples. 43

Figura 23 - Comparação de resultados analíticos para curvatura. $\quad 44$

Figura 24 - Comparação de resultados analíticos para deslocamento. 44

Figura 25 - Comparação de resultados para curvatura: bvp4c e MARC® PATRAN®. 45

Figura 26 - Comparação de resultados para curvatura: bvp4c e ABAQUS®. 46

Figura 27 - Barra em balanço carregada lateralmente por uma força concentrada. $\quad 49$

Figura 28 - Modelo e protótipo. 51

Figura 29 - Enrijecedor de geometria complexa. 56 
Figura 30 - Efeito da variação do parâmetro $L_{4}$ na curvatura do conjunto. 58

Figura 31 - Efeito da extensão cilíndrica $L_{4}$ na curvatura do conjunto com $F=F_{\min } . \quad 59$

Figura 32 - Perspectiva do enrijecedor especificado na Tabela 7.

Figura 33 - Efeito da variação do parâmetro $L_{2}$ na curvatura do conjunto. 61

Figura 34 - Efeito da variação do parâmetro $L_{3}$ na curvatura do conjunto. 62

Figura 35 - Efeito da variação do parâmetro $D_{2}$ na curvatura do conjunto. 63

Figura 36 - Efeito da variação do parâmetro $D_{1}$ na curvatura do conjunto. 65

Figura 37 - Efeito da variação do parâmetro $d_{2}$ na curvatura do conjunto. 66

Figura 38 - Efeito da variação do parâmetro $E_{\mathrm{BS}}$ na curvatura do conjunto. 67 


\section{LISTA DE TABELAS}

Tabela 1 - Geometrias analisadas pelos autores citados na revisão bibliográfica.

Tabela 2 - Enrijecedor 1. Extraído de Boef e Out (1990).

Tabela 3 - Enrijecedor 2. Extraído de Lane et al. (1995).

Tabela 4 - Matriz dimensional para barra uniforme em balanço.

Tabela 5 - Matriz dimensional para estudo estático de enrijecedores.

Tabela 6 - Matriz dimensional para estudo estático de enrijecedores, considerando seu peso próprio.

Tabela 7 - Enrijecedor à flexão hipotético. 


\section{LISTA DE SÍMBOLOS}

API densidade relativa de um óleo, definido pelo American Petroleum Institute:

${ }^{\circ} \mathrm{API}=\left(141,5 \div\right.$ densidade relativa da amostra à temperatura de $\left.60^{\circ} \mathrm{F}\right)-131,5$

0xy eixos coordenados e sua origem

$F \quad$ força aplicada

$T$ força de tração

$V \quad$ força cortante

M momento fletor

$L \quad$ comprimento ou posição em $s$

$s \quad$ comprimento de arco

$f, w$ forças distribuídas por unidade de comprimento

E constante (de proporcionalidade) elástica do material; módulo de Young

I momento de inércia de área (plana)

D diâmetro

$\alpha, \theta$ ângulos

$\kappa \quad$ curvatura

$R \quad$ raio de curvatura

$E I_{P} \quad$ rigidez à flexão da linha flexível

$E_{B S} \quad$ módulo de elasticidade do material do enrijecedor à flexão

$\kappa_{\text {lim }} \quad$ curvatura máxima de projeto da linha flexível

$\delta \quad$ deslocamento

* $\quad$ se não definidos no texto, subscritos indicam posição em $s$ 


\section{SUMÁRIO}

1 INTRODUÇÃO

2 REVISÃO BIBLIOGRÁFICA

3 PROJETO DE ENRIJECEDORES À FLEXÃO 29

4 MODELOS: 33

4.1 CONSIDERAÇÕES GERAIS 33

4.2 DESCRIÇÃO DO PROBLEMA REAL 33

4.3 MODELO FÍSICO - MATEMÁTICO 36

4.4 SOLUÇÕES E COMPARAÇÕES 41

5 ANÁLISE DIMENSIONAL 47

5.1 CONSIDERAÇÕES GERAIS 47

5.2 ANÁLISE DIMENSIONAL E TEORIA DA SEMELHANÇA 48

6 ANÁLISE PARAMÉTRICA 56

6.1 CONSIDERAÇÕES GERAIS 56

6.2 LEVANTAMENTO DOS ADIMENSIONAIS DO PROBLEMA 57

6.3 INFLUÊNCIA DO PARÂMETRO $L_{4}$ NA RESPOSTA DO CONJUNTO 58

6.4 CONSIDERAÇÕES SOBRE O COMPRIMENTO $L_{B S}$ DO ENRIJECEDOR 60

6.5 INFLUÊNCIA DO PARÂMETRO $L_{2}$ NA RESPOSTA DO CONJUNTO 60

6.6 INFLUÊNCIA DO PARÂMETRO $L_{3}$ NA RESPOSTA DO CONJUNTO 62

6.7 INFLUÊNCIA DO PARÂMETRO $D_{2}$ NA RESPOSTA DO CONJUNTO 63

6.8 INFLUÊNCIA DO PARÂMETRO $D_{1}$ NA RESPOSTA DO CONJUNTO 64

6.9 INFLUÊNCIA DO PARÂMETRO $d_{2}$ NA RESPOSTA DO CONJUNTO 65

6.10 INFLUÊNCIA DO PARÂMETRO $E_{B S}$ NA RESPOSTA DO CONJUNTO 66

7 CONCLUSÕES

REFERÊNCIAS

APÊNDICE A - Código para Solução de Problema de Valor de Contorno em Matlab ${ }^{\circledR}$ 


\section{INTRODUÇÃO}

A produção brasileira de petróleo tem aumentado sistematicamente desde a fundação da Petrobras - empresa estatal criada em 1953 pelo governo brasileiro para controlar a produção, o refino e a distribuição do petróleo no país. Entre os 2.700 barris por dia, em 1953, e os 2.000 .000 b.p.d., no final de 2007, há uma história estimulante de desafios e conquistas importantíssimas para a economia do Brasil.

Uma dessas importantes conquistas veio com a acertada decisão da Petrobras tornada economicamente viável pelos choques de preços do petróleo de 1973 e 1979 - de lançar-se em águas mais profundas da plataforma continental brasileira no início dos anos 80, com a resultante descoberta de significativas reservas de óleo e gás, como indicado na Fig. 1.

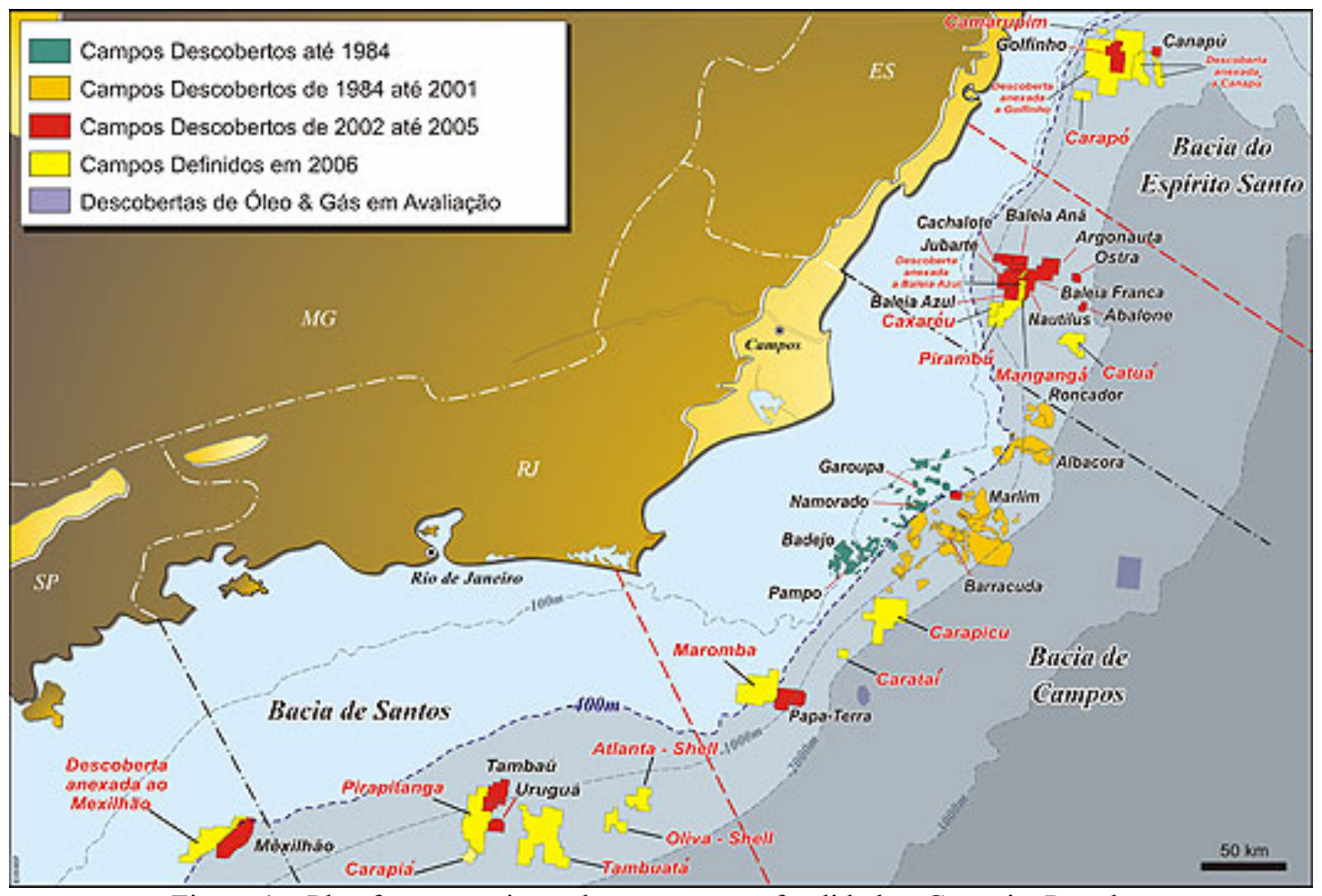

Figura 1 - Plataforma continental: campos e profundidades. Cortesia: Petrobras.

Em novembro de 2007, a Petrobras anunciou a descoberta de novas reservas na Bacia de Santos, na área denominada Tupi, em lâmina d'água que varia de $1.500 \mathrm{~m}$ a $3.000 \mathrm{~m}$. Estima-se o volume recuperável de óleo leve de $28^{\circ}$ API, em 5 a 8 bilhões de barris de petróleo e gás natural. Sua exploração é de grande interesse para o Brasil, não só pelo volume, mas também pela qualidade do óleo ali disponível. 
Em engenharia offshore utiliza-se o termo “águas profundas” para lâminas d'água maiores que $400 \mathrm{~m}$ e "ultraprofundas", para aquelas maiores que $1000 \mathrm{~m}$. O termo "hiperprofundas" é às vezes encontrado na literatura para lâminas d'água superiores a 2000m. O Brasil, através da Petrobras, é referência mundial em produção petrolífera em águas profundas. A Fig. 2 ilustra o avanço das atividades offshore da Petrobras.

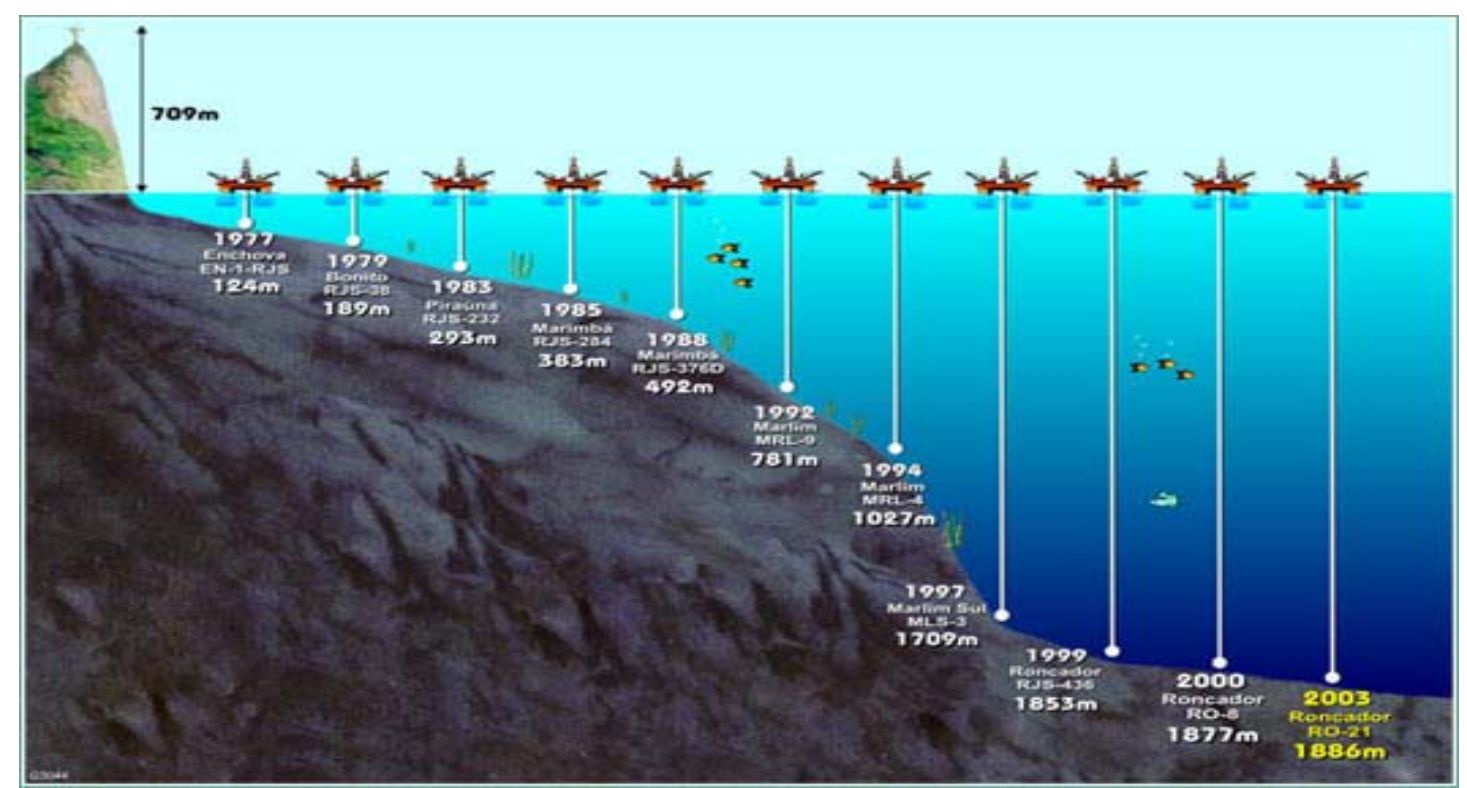

Figura 2 - Recordes obtidos pela Petrobras em lâmina d'água de poço em produção. Cortesia: Petrobras.

O uso de estruturas fixas, apoiadas no leito do oceano, não é viável ou mesmo possível em profundidades superiores a $400 \mathrm{~m}$ e o uso de sistemas flutuantes, tais como plataformas, navios-tanque, unidades de produção e armazenamento, bóias, etc., torna-se condição necessária para as atividades petrolíferas.

A ligação entre unidades flutuantes e o fundo do oceano é usualmente feita com sistemas de linhas ou tubulações que podem ser rígidas ou flexíveis, de controle ou transporte. Em grandes lâminas d'água, sistemas de tubos flexíveis apresentam várias vantagens para uso com sistemas flutuantes, em comparação com tubos rígidos: relativa facilidade de instalação, menores cargas de tração, boa acomodação ao leito do oceano e também ao movimento das unidades flutuantes.

Os tubos de transporte são usualmente chamados de "risers", metonímia para sua parte suspensa, vinda da língua inglesa. Os tubos flexíveis são estruturas compostas de várias camadas projetadas para suportar cargas radiais de pressão e axiais de tração, além das camadas de contenção do fluído transportado. 
As linhas flexíveis de controle são chamadas "umbilicais" e contêm em seu interior linhas hidráulicas e cabos elétricos para controle das unidades submersas.

Deve-se ressaltar que ambos, risers flexíveis e cabos umbilicais, possuem em geral grande rigidez axial e pequena rigidez flexional, sendo considerados muitas vezes como inextensíveis e infinitamente flexíveis em grande parte de seu comprimento.

Unidades flutuantes, por sua vez, são estruturas rígidas que estão sujeitas às marés, ondas, correntes marítimas e ventos, característicos no oceano. A Fig. 3.A ilustra uma instalação típica com linhas flexíveis visíveis próximas ao seu engastamento com a unidade flutuante, neste caso uma plataforma semi-submersível.

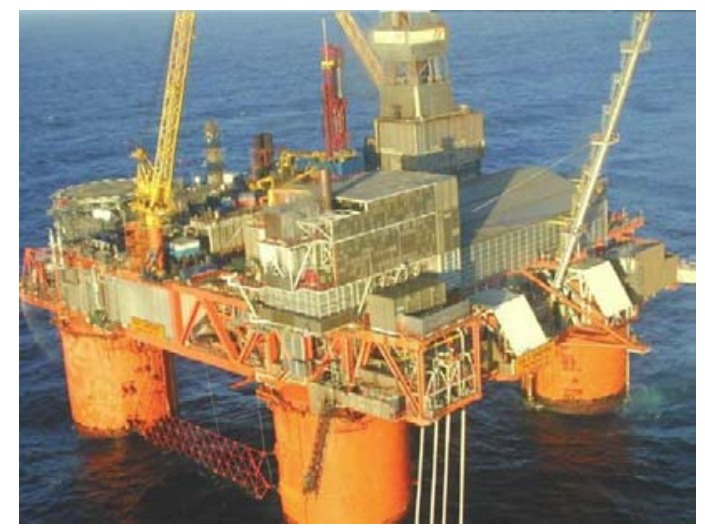

A.

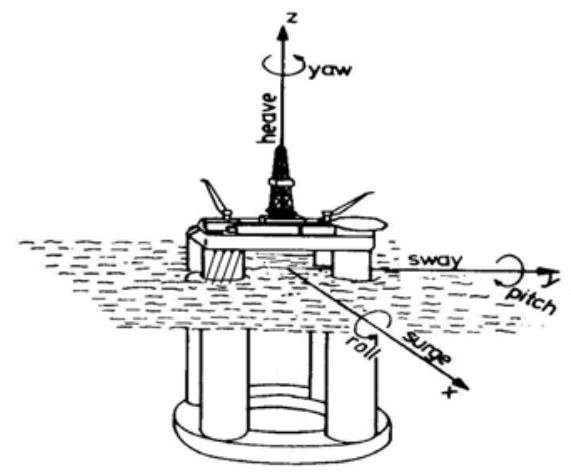

B.

Figura 3 - Plataforma semi-submersível, movimentos e linhas flexíveis. A: Cortesia: Google Imagens; B: Adaptado de Faltinsen (1990).

Os movimentos da unidade flutuante, cuja nomenclatura usual está ilustrada na Fig. 3.B, geram cargas de flexão às linhas nela engastadas e podem levá-las ao colapso se não estiverem apropriadamente protegidas com limitadores de curvatura. Em aplicações estáticas, utilizam-se restritores à flexão e, em aplicações dinâmicas, enrijecedores à flexão - como recomendado pela API RP 17B (2002). Limitadores do tipo Bell Mouth podem também ser utilizados, mas tem aplicação bastante limitada. A Fig. 4 traz exemplos destes componentes.

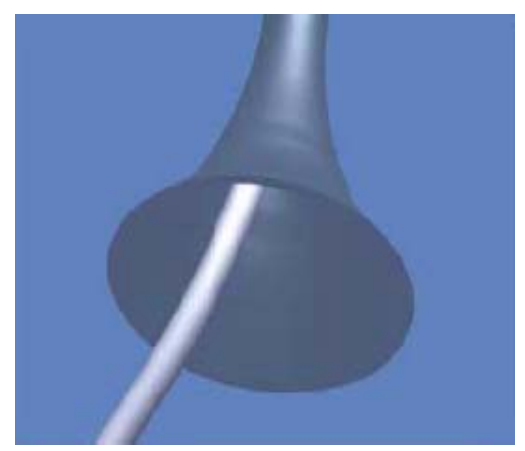

A.

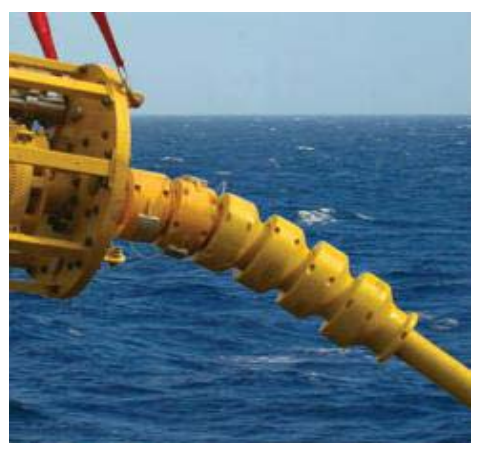

B.

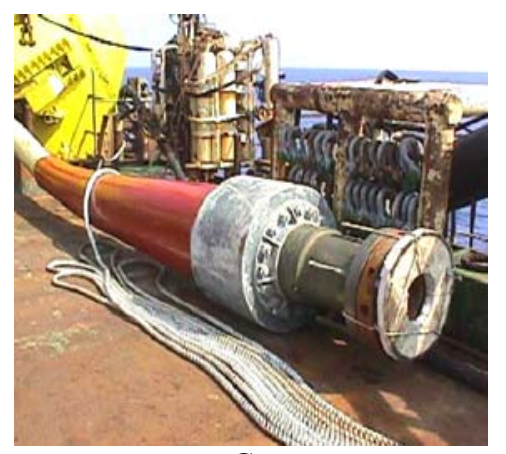

C.

Figura 4 - A: Bell mouth; B: Restritor de flexão; C: Enrijecedor à flexão. Cortesia: Dunlaw, CRP. 
Os limitadores de curvatura tipo bell mouth impedem que o tubo seja fletido além de um valor pré-determinado. Entretanto, eles geram cargas de compressão localizadas e não são aplicáveis em casos onde as cargas de flexão são elevadas, i.e., em águas profundas. Além disso, freqüentemente, o congestionamento de linhas junto ao engastamento impede sua utilização. Os restritores à flexão fornecem proteção quando os elementos intertravados fazem contato mecânico, o que ocorre apenas a partir de um determinado raio de curvatura do tubo.

Já os enrijecedores à flexão provêem suave transição da rigidez flexional, com pequena folga ("gap") entre o tubo flexível e a superfície interna do enrijecedor. Trata-se de um acessório cuja falha pode levar à ruptura da linha flexível, gerando interrupção da produção que só pode ser restabelecida depois de sua substituição. Entre despesas operacionais e lucros cessantes, o custo total da falha pode ter ordem de grandeza de milhões de dólares, além de atrasos nos cronogramas de desenvolvimento de reservatório, descumprimento de metas de produção e eventual grave agressão ao meio ambiente.

Segundo Carneval e Marinho (2006), há aproximadamente 1200 linhas flexíveis tubos de escoamento de fluido ou cabos umbilicais - em operação no Brasil. Estas linhas interconectam poços, tubos de distribuição, plataformas fixas e flutuantes, unidades flutuantes de produção e armazenamento (FPSOs) e monobóias. Em todas estas linhas são instalados limitadores de curvatura. Um exemplo de instalação típica de produção é mostrado na Fig. 5.

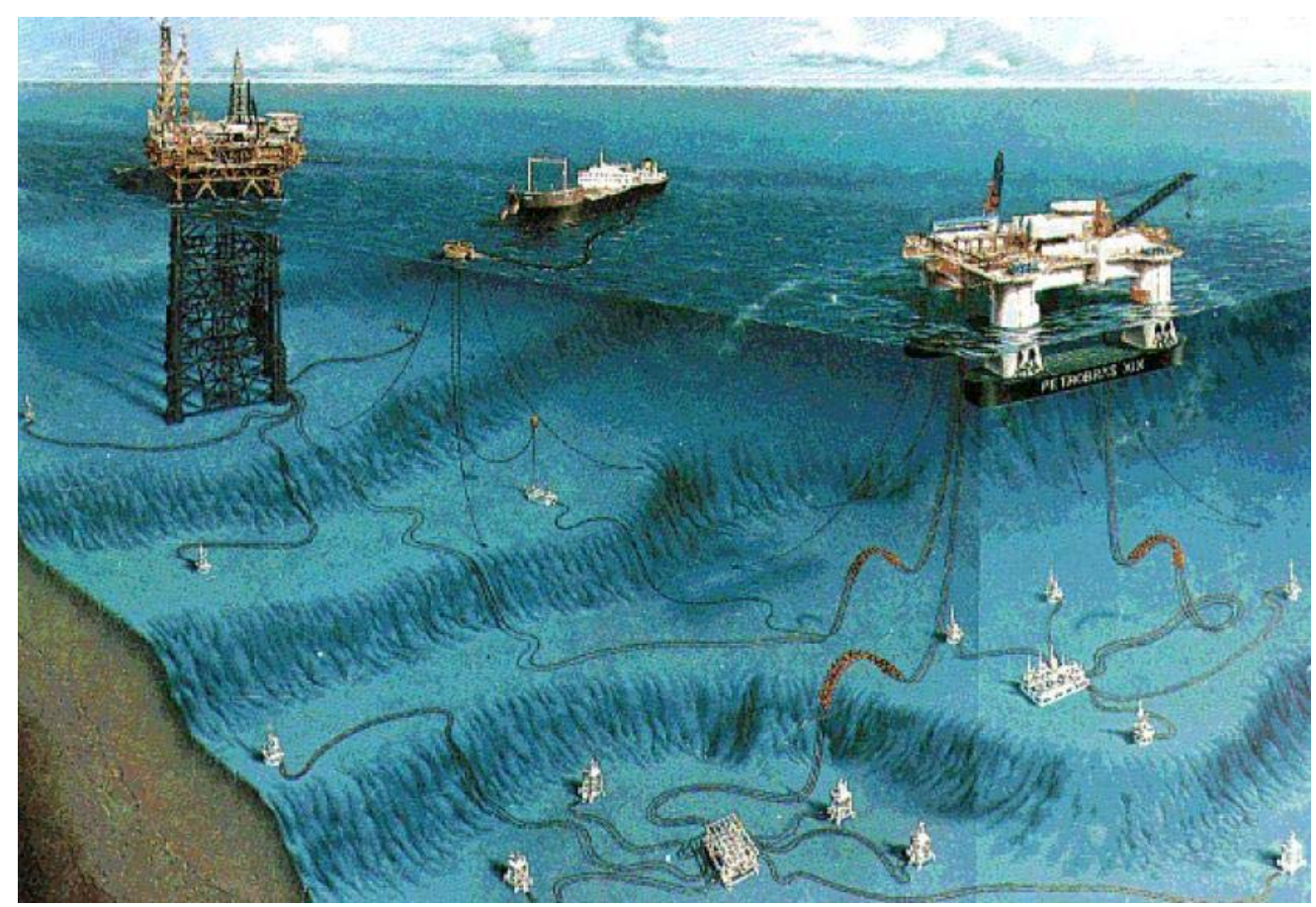

Figura 5 - Diagrama de um sistema típico de produção. Cortesia: Petrobras. 
Há na literatura vários trabalhos que lidam com o projeto estrutural de enrijecedores à flexão. Nota-se, todavia, que a geometria dos modelos propostos em tais trabalhos é bastante simplificada, particularmente naqueles com soluções analíticas, e não contemplam as geometrias mais complexas observadas em enrijecedores à flexão modernos. Além disso, Pope et al. apud Lemos (2006) registraram a falha em operação de dois enrijecedores à flexão instalados em monobóias da Petrobras. Desta forma, podemos concluir que o projeto de enrijecedores à flexão ainda carece de métodos de análise mais precisos e abrangentes.

Neste trabalho é desenvolvido um programa em Matlab® para solução do problema de valor de contorno que resulta da formulação analítica de modelos para previsão do comportamento estrutural de enrijecedores à flexão, sujeitos a carregamentos estáticos extremos. O programa é validado e então utilizado em uma análise paramétrica de enrijecedores à flexão de geometria complexa, não encontrada em outros trabalhos, com vistas ao entendimento da contribuição de cada parâmetro geométrico dessas unidades no comportamento estrutural do conjunto formado pela linha e enrijecedor à flexão.

Uma revisão bibliográfica do assunto é oferecida ao leitor no capítulo 2, a seguir.

No capítulo 3 são apresentadas considerações sobre o projeto de enrijecedores e práticas recomendadas ou especificadas pelos códigos API vigentes.

No capítulo 4 expõe-se uma revisão detalhada da formulação analítica e das hipóteses - algumas vezes implícitas - adotadas em trabalhos anteriores e confrontam-se resultados para validação do código proposto para solução do problema de valor de contorno resultante.

No capítulo 5 abordam-se aspectos da análise dimensional aplicada à avaliação estrutural de enrijecedores à flexão.

No capítulo 6 apresenta-se uma avaliação paramétrica de um hipotético enrijecedor à flexão de geometria complexa, com discussão dos resultados.

No capítulo 7 são estabelecidas as conclusões sobre os resultados obtidos e apresentadas algumas propostas para a continuidade deste trabalho.

No Apêndice A pode-se apreciar uma sugestão de implementação do código em Matlab ${ }^{\circledR}$ para solução do problema de valor de contorno resultante da formulação analítica de um modelo de enrijecedor à flexão com geometria complexa. 


\section{REVISÃO BIBLIOGRÁFICA}

Não é tão recente o estudo do problema estrutural do efeito causado pelas terminações sobre os cabos com rigidez à flexão finita, engastados em uma extremidade, e tracionados na outra. DeRuntz (1969) apresenta uma formulação geral para cabos tracionados com a hipótese de grandes deslocamentos que, não obstante a ausência de enrijecedores à flexão, reaparecerá de maneira similar nos posteriores estudos de tubos flexíveis com enrijecedores.

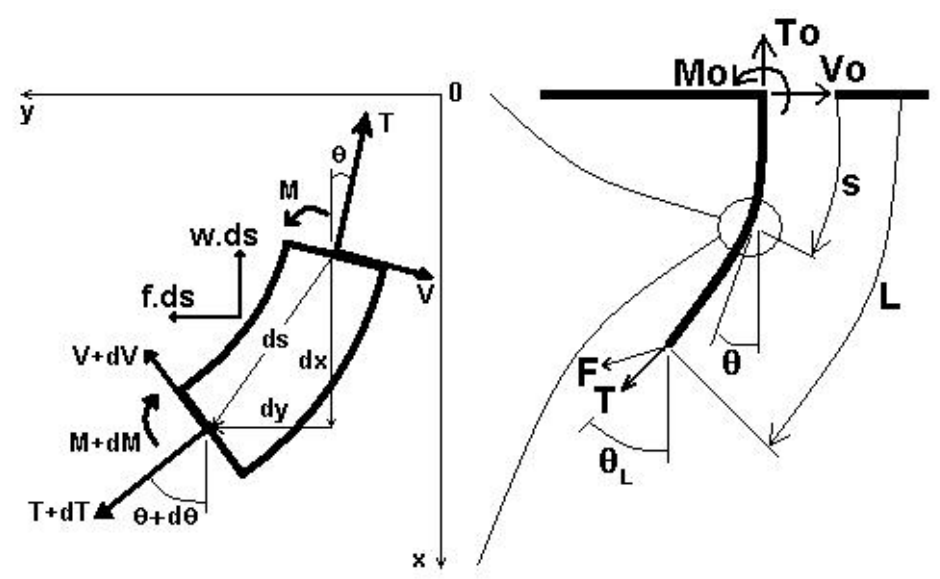

Figura 6 - Diagrama de corpo livre e equilíbrio do elemento de cabo. Adaptado de DeRuntz (1969).

Em sua análise, DeRuntz apresenta também uma definição para o termo "comprimento suficiente", observando que o momento fletor decai exponencialmente a partir da extremidade engastada dos cabos. Em suas palavras, estes resultados "não parecem ter sido notados anteriormente". O autor formula o problema ilustrado na Fig. 6 (parcialmente adaptada, com notação mais moderna) e obtém quatro equações diferenciais, eq.(1) - (4), para o caso linear elástico, e condições de contorno, eq.(5) - (8) [s.i.c.]:

$$
\begin{gathered}
\frac{d M}{d s}=-V \\
\frac{d}{d s}[T \cdot \operatorname{sen}(\theta)]+\frac{d}{d s}[V \cdot \cos (\theta)]=-f \\
\frac{d}{d s}[T \cdot \cos (\theta)]-\frac{d}{d s}[V \cdot \operatorname{sen}(\theta)]=w \\
M=\text { E.I. } \frac{d \theta}{d s}
\end{gathered}
$$




$$
\begin{aligned}
& \theta=0: s=0 \\
& \theta=\theta_{L}: T=F \\
& \theta=\theta_{L}: V=0 \\
& \theta=\theta_{L}: M=0
\end{aligned}
$$

Para o estabelecimento das condições de contorno, DeRuntz chama a atenção para o fato de que o tratamento clássico da elástica adota $M(L)=0$, o que requer $V(L) \neq 0$, levando a uma solução matemática complicada. Para evitar tal complicação, DeRuntz adota que a extremidade livre do cabo, na configuração deformada, assuma um ângulo $\theta_{L}$ em relação ao engastamento, e que a tração seja aplicada na direção de seu eixo, i.e., $V\left(l_{s}\right)=0$, hipótese válida somente para cabos "infinitamente longos".

Sendo $M_{o}$ o momento na extremidade engastada e $l_{s}$ um "comprimento suficiente" a partir daquela extremidade, para que o momento na extremidade não engastada $M(L)$ se torne suficientemente pequeno, digamos de uma razão $\Delta=M(L) / M_{o}=1 \%$, se na prática $L$ for maior que $l_{s}$, as soluções obtidas terão precisão suficiente. A eq.(9) traz o valor de $l_{s}$, sendo $T$ a tração normal à seção do cabo em $s=L$ e $\theta_{L}$ o ângulo entre $T$ e a normal ao engastamento.

$$
l_{s}=\sqrt{\frac{E \cdot I_{P}}{T}} \cdot \ln \left\{\frac{1}{\Delta} \cdot\left[1+\tan ^{2}\left(\frac{\theta_{L}}{4}\right)\right]\right\}
$$

Uma definição similar é encontrada em Pesce (1997, p. 1-5 e 3-18), para a região próxima ao ponto de contato do riser com o leito do oceano, comumente conhecido como TDP (touchdown point). A eq.(10) traz a expressão para tal "comprimento de flexão":

$$
l_{f}=\sqrt{\frac{E \cdot I_{P}}{T}}
$$

Em ambos os casos, todavia, trata-se de uma escala de comprimento dentro da qual as soluções de barra e cabo se tornam compatíveis. A Fig. 7 mostra como variam os comprimentos $l_{s}$ e $l_{f}$ conforme o nível de tração $T$ em $s=L$. Nesta figura foram considerados fixos $E I_{P}=10 \mathrm{kN} \cdot \mathrm{m}^{2}$ e $\theta_{L}=\pi / 4 \mathrm{rad}$. Pode-se verificar que as curvas de $l_{s}$ e $l_{f}$ praticamente colidem nesta situação se tomarmos $\Delta=M(L) / M_{o}=39 \%$. Contudo, se for desejável um nível de precisão maior (como, por exemplo, $\Delta=1 \%$ ), observa-se uma diferença relativamente grande entre os dois comprimentos, sendo $l_{s}$ mais conservativo que $l_{f}$. 
Sugere-se, portanto, adicionar um segmento de cabo com comprimento $l_{s}$ além do comprimento do enrijecedor para garantir resultados mais precisos na avaliação estrutural de enrijecedores à flexão.

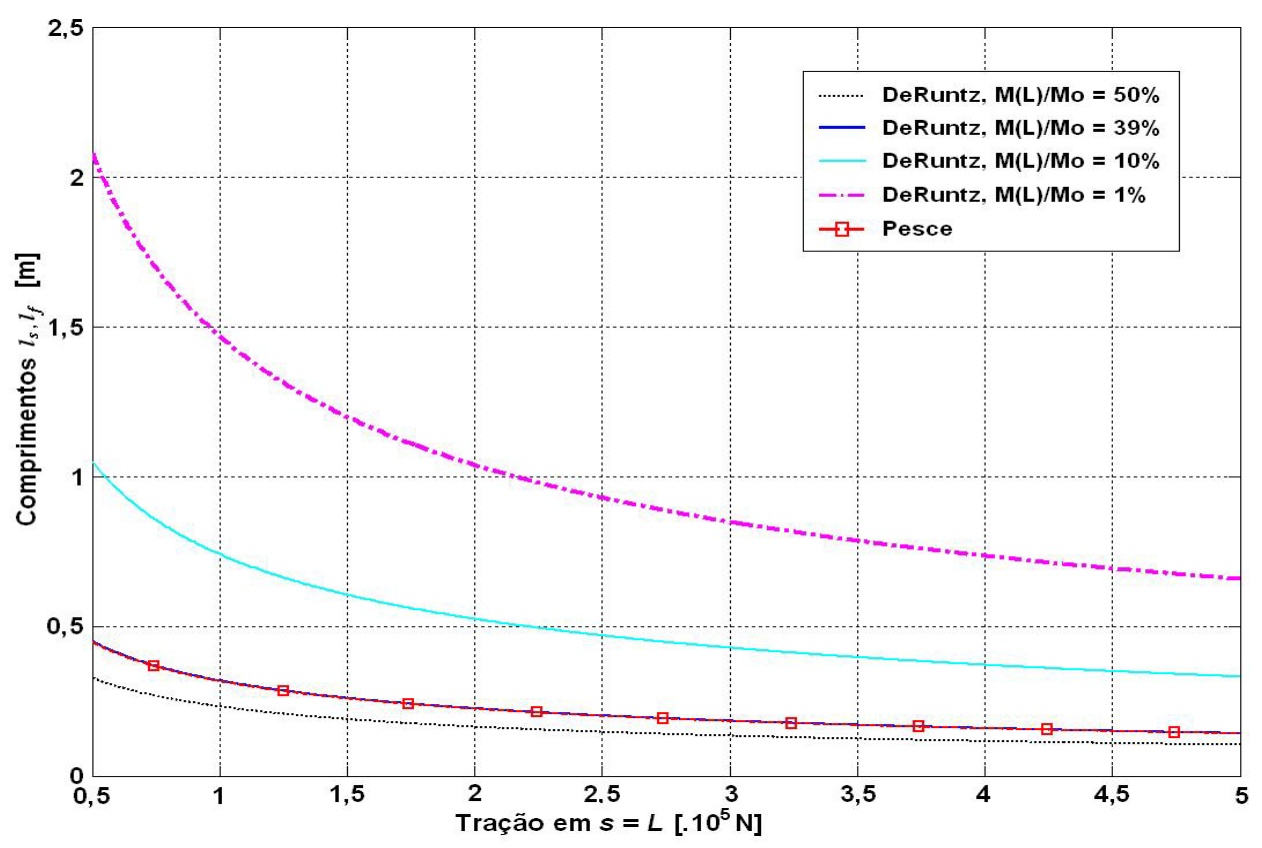

Figura 7 - Comparação entre comprimentos de flexão para $E I_{P}=10 \mathrm{kN} \cdot \mathrm{m}^{2}$ e $\theta_{L}=\pi / 4$.

DeRuntz apresenta resultados de curvatura para três casos, de complexidade crescente, todos com cabo de rigidez constante: sujeito apenas à tração; com forças externas aplicadas; e com peso próprio. Para o caso mais simples (cabo sujeito apenas à tração), de nosso interesse, traz a seguinte equação para a variação da curvatura, eq.(11):

$$
\frac{d^{2} \theta}{d s^{2}}=-\frac{T}{E . I} \operatorname{sen}\left(\theta_{L}-\theta\right)
$$

Boef e Out (1990) desenvolvem dois modelos para a análise de enrijecedores à flexão: um, analítico-numérico, baseado na teoria de barras esbeltas sujeitas à flexão pura, grandes deslocamentos e pequenas deformações e outro, discretizado com elementos finitos, considerando também deformações por cisalhamento e não-linearidade do material, resolvido com os softwares Marc $₫ /$ Patran ${ }^{\circledR}$ e dois graus de refinamento da malha tridimensional.

Sua solução analítica resulta em um conjunto de quatro equações diferenciais e quatro condições para o problema de valor de contorno, que é resolvido numericamente pelo método de "múltiplos tiros". A equação para variação da curvatura por eles obtida é reproduzida a seguir, eq.(12): 


$$
\frac{d^{2} \theta}{d s^{2}}=-\frac{d(E I(s))}{E I(s) \cdot d s} \cdot\left(\frac{d \theta}{d s}\right)-\frac{F}{E . I} \operatorname{sen}\left(\theta_{L}+\alpha-\theta\right)
$$

Boef e Out apresentam também a solução analítica "exata" para dois casos especiais: (i) rigidez à flexão constante e (ii) curvatura constante. Para o caso de rigidez à flexão constante, resulta a seguinte relação para a variação da curvatura, eq.(13):

$$
\frac{d^{2} \theta}{d s^{2}}=-\frac{F}{E . I} \operatorname{sen}\left(\theta_{L}+\alpha-\theta\right)
$$

A identificação deste resultado com a eq.(11) de DeRuntz é imediata. Boef e Out $\operatorname{adotam} M(L)=0, V(L) \neq 0$ e $\alpha(s) \neq 0$ para $0 \leq s \leq L$, mas admitem que usualmente $\alpha(L) \approx 0$, resultando em $T=F$. Sob tais circunstâncias, as eq.(11) e (13) são idênticas.

O problema analisado por Boef e Out (1990) está ilustrado na Fig. 8, onde podemos notar que o ângulo formado entre a força $F$ e a normal ao engastamento é dada por $\left(\theta_{L}+\alpha\right)$.

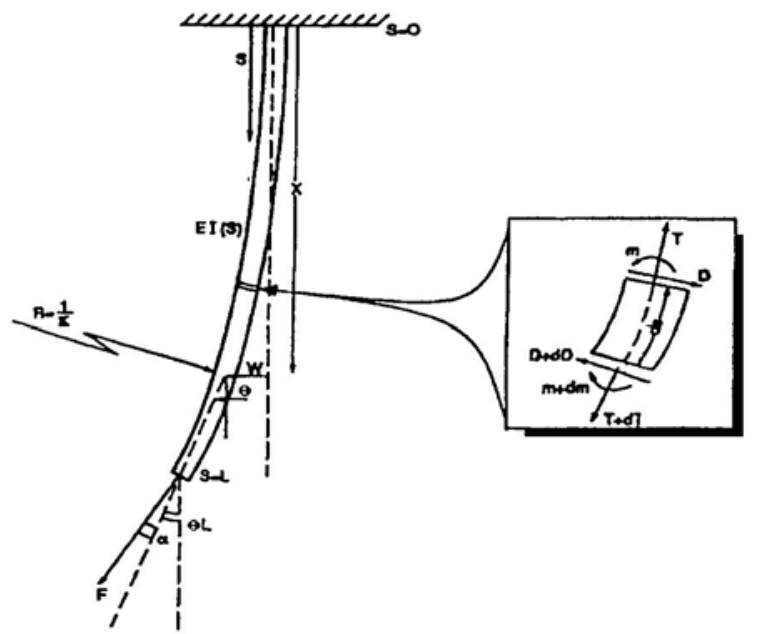

Figura 8 - Diagrama de forças e equilíbrio do elemento de cabo. Extraído de Boef e Out (1990).

A solução discretizada, por sua vez, utiliza elementos sólidos de nove nós para o enrijecedor, sendo que os nós dos vértices têm três graus de liberdade translacional cada, e o nó central, apenas um, que contabiliza a pressão hidrostática. Para o tubo, elementos de viga são empregados no eixo central do modelo e nos diafragmas radiais e circunferenciais que modelam a rigidez da seção transversal do tubo.

Os autores alertam para a incompatibilidade de deslocamentos laterais dos diferentes elementos do tubo (interpolação cúbica) e do enrijecedor (interpolação linear) e sugerem certa reserva na interpretação dos resultados. Boef e Out não fornecem informações suficientes 
sobre a modelagem do contato entre o enrijecedor e o tubo e não há ilustrações do modelo discretizado utilizado para modelagem da rigidez radial das seções transversais do tubo.

Os autores indicam que há três parâmetros de projeto para enrijecedores à flexão: seu comprimento, seu diâmetro máximo, e o módulo de elasticidade do material. Observam que o projeto de enrijecedores à flexão só pode ser otimizado, visando curvatura constante [s.i.c.], para casos específicos de carregamento, i.e. para um único par força - ângulo de aplicação desta força na extremidade não-engastada.

Boef e Out apresentam uma comparação entre os resultados de seus modelos e a solução fornecida por um fabricante (Coflexipß) para um enrijecedor à flexão cuja curvatura não deve ultrapassar $0,5 \mathrm{~m}^{-1}$ e cujo material, admitido como elástico linear, tem módulo de elasticidade de $45 \mathrm{MPa}$, obtido a partir do módulo secante em 10\% de alongamento do material. Este enrijecedor é utilizado em um riser sujeito à tração máxima de $250 \mathrm{kN}$ e ângulo máximo de rotação da extremidade de $45^{\circ}$. A Fig. 9 ilustra o modelo analisado por Boef e Out:

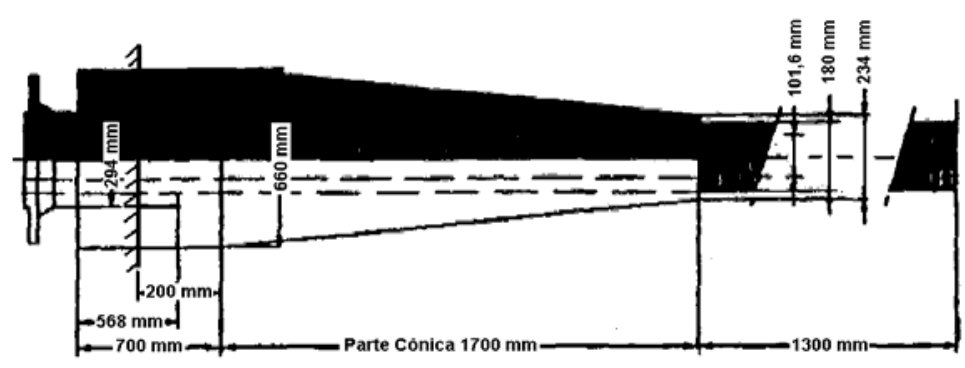

Figura 9 - Geometria do enrijecedor à flexão analisado por Boef e Out (1990).

Boef e Out concluem que o modelo analítico de barra esbelta é satisfatório para o projeto preliminar de enrijecedores e que os modelos discretizados por eles apresentados são excessivamente grosseiros e não permitem conclusões absolutas. Os autores fazem ainda algumas considerações sobre o modo de fixação do enrijecedor e sua influência nos resultados e sugerem uma analogia com o fenômeno cabo-polia para a concentração de tensões, particularmente de compressão, observada no modelo discretizado.

Lane et al. (1995) apresentam um software específico para o cálculo de enrijecedores à flexão (STIFFENER $®)$, que utiliza um modelo simplificado em três dimensões. Comparam seus resultados com dois outros, obtidos com o software comercial ABAQUS $®$. Trazem ainda considerações sobre materiais e manufatura de enrijecedores à flexão.

Segundo os autores, os parâmetros de projeto do programa STIFFENER ${ }^{\circledR}$ são: material do enrijecedor, seu comprimento, e seu diâmetro externo máximo. À semelhança de Boef e Out (1990), nota-se. 
No modelo em três dimensões proposto para o programa STIFFENER ${ }^{\circledR}$, o conjunto cônico tubo-enrijecedor é substituído por uma seção equivalente de rigidez à flexão crescente, e o tubo tem comprimento total sempre três vezes maior que a parte cônica do enrijecedor. Observa-se que este último parâmetro, apesar de arbitrado, atende à hipótese de comprimento suficiente, eq.(9), para os casos estudados.

Lane et al. (1995) indicam que a inclusão do tubo no modelo é necessária, pois a força axial nele atuante afeta a rigidez do conjunto, por afetar a rigidez do tubo flexível. No modelo do STIFFENER ${ }^{\circledR}$, o tubo é sólido e suas características devem ser ajustadas de modo a se obter a desejada rigidez à flexão, sendo a rigidez axial um subproduto deste ajuste. A inextensibilidade do tubo é apontada como justificativa para esta abordagem.

Vale notar que Lane et al. (1995) adotaram o poliuretano como material hipoelástico nos modelos de comparação construídos no ABAQUS®.

O programa STIFFENER ${ }^{\circledR}$ usa a formulação proposta por Boef e Out (1990) em seu módulo de cálculo preliminar. O módulo gerador de malha utiliza elementos sólidos de oito nós com três graus de liberdade cada e a análise é estática, e geometricamente não-linear, para um carregamento especificado pelo usuário. Características não-lineares do material, contato e detalhes da terminação não são contemplados pelo programa.

A Fig. 10 traz o arranjo analisado e relatado por Lane et al. (1995). Segundo os autores, a solução para tensões fornecida pelo programa STIFFENER ${ }^{\circledR}$ parece "suave e bem comportada", quando comparada aos modelos que consideram outras não-linearidades e apontam como grande vantagem do programa sua rapidez de computação e precisão no cálculo dos deslocamentos.
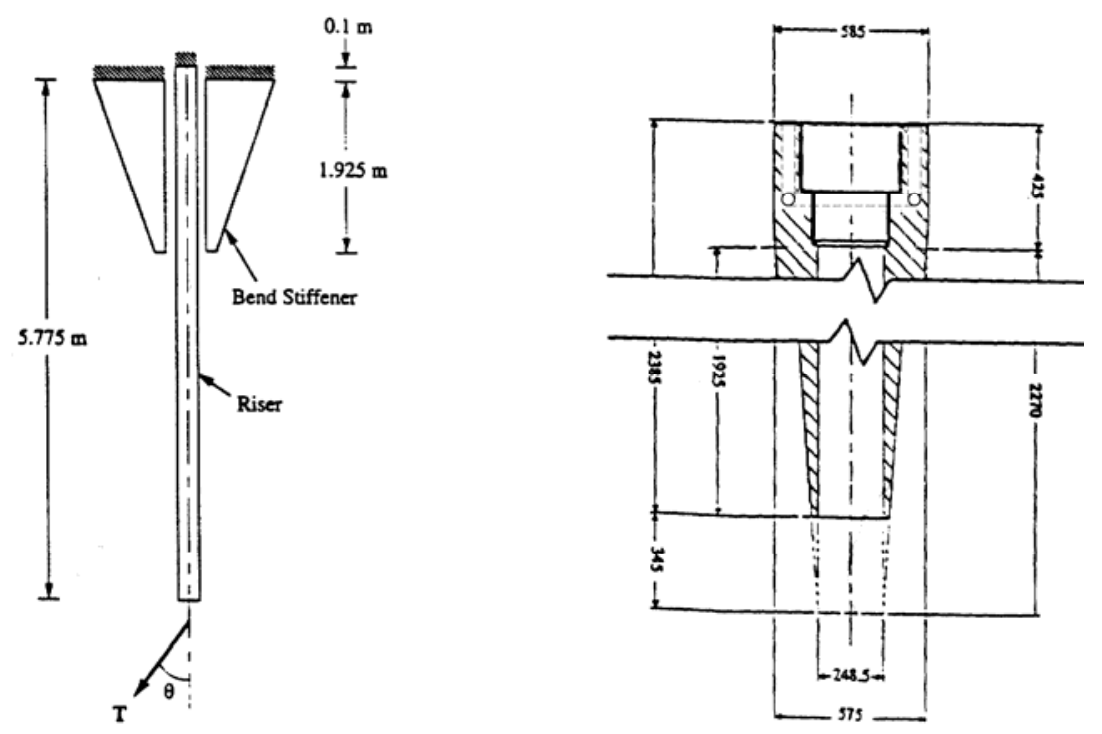

Figura 10 - Arranjo e geometria do modelo analisado por Lane et al. (1995). 
Kiepper (2004) revisa a tecnologia de enrijecedores e apresenta uma análise do conjunto tubo flexível e enrijecedor pelo método dos elementos finitos utilizando o software ABAQUS ${ }^{\circledR}$, comparando os resultados obtidos com os de um programa numérico produzido pela COPPE/Petrobras.

Entre as características do problema consideradas por Kiepper estão: grandes deslocamentos, contato entre tubo e enrijecedor, material do enrijecedor considerado linear elástico e não-linear hiperelástico. Kiepper considerou ainda a presença de um toróide interno ao corpo do enrijecedor e modelou de maneira simplificada o capacete e a luva da terminação. Fez, ainda, uma simulação numérica do ensaio de fadiga que fora realizado no Núcleo de Estruturas Oceânicas, vinculado a COPPE/Petrobras.

Kiepper modelou o conjunto ilustrado na Tabela 1, no final deste capítulo, e relata ter obtido boa concordância entre os resultados fornecidos pelo programa de elementos finitos ABAQUS ${ }^{\circledR}$, aqueles do programa numérico e, também, com os dados experimentais do ensaio de fadiga. Como sugestão para trabalhos futuros, indica a modelagem da estrutura interna de suporte, visto que esta região é suscetível à formação de trincas.

Lemos (2005) apresenta uma metodologia de análise de fadiga em risers flexíveis conectados à FPSOs e aponta o efeito da distribuição de curvaturas junto ao ponto de conexão com a unidade flutuante como essencial em tal avaliação. Sua análise envolve material linear elástico, não-linear elástico assimétrico, i.e. comportamento em tração diferente daquele em compressão, e material viscoelástico.

Lemos descreve e ilustra os risers flexíveis e seus modos de falhas, curvas S-N, mecânica da fadiga, dano acumulado, etc. Apresenta também um estudo de caso da FPSO P33, da Petrobras, e faz uma ampla discussão sobre a utilização de um "projeto baseado em resposta" aplicado à fadiga.

$\mathrm{O}$ autor faz uma análise da interface riser - enrijecedor à flexão, discorre sobre materiais poliméricos, propriedades elásticas em pequenas e grandes deformações, e comportamento viscoelástico linear. Formula, então, o problema do projeto de enrijecedores e compara os resultados obtidos. Avalia ainda questões sobre a vida útil à fadiga, com ensaios de corpos de prova e levantamento e ajuste de curvas características e de degradação do material.

Lemos resolve numericamente o problema de contorno apresentado por Boef e Out (1990) com o auxílio de pacotes matemáticos MatLab®, utilizando o método de Rosembrock (denominado ODE23S), e com o Mathcad®, utilizando o método de tiros (“shooting”) com ajuda do usuário, e verificou que o ponto de maior curvatura varia de acordo com o 
carregamento aplicado, sendo que não necessariamente o ponto de maior deformação coincide com o de maior curvatura, e que o maior momento fletor, entretanto, está sempre no engaste.

Lemos avalia também o comportamento da formulação analítica para diferentes módulos de elasticidade do poliuretano e conclui que a variação de deformação não é linear com a variação de rigidez do material [s.i.c.].

$\mathrm{Na}$ avaliação do comportamento elástico não-linear assimétrico, faz uso de uma aproximação por série polinomial com coeficientes interpolados previamente e resolve novamente o problema de valor de contorno numericamente, comparando-o com os resultados dos programas STIFFENER ${ }^{\circledR}$ (MCS International) e ANFLEX ${ }^{\circledR}$ (COPPE/Petrobras), e observa que há uma mudança razoável na distribuição de curvaturas.

Lemos reformula o problema para o caso viscoelástico linear, reescreve as equações do modelo, incluindo sua dependência com o tempo, e apresenta os resultados da aplicação de sua formulação em um programa auxiliar escrito por outro autor, com dados teóricos de uma curva de relaxação padrão.

Lemos recomenda, para trabalhos futuros, o levantamento de curvas de fadiga do poliuretano dos enrijecedores, com corpos de prova normalizados e tentativa de modelamento numérico dos detalhes de cada fabricante; recomenda também a avaliação viscoelástica nãolinear no projeto de enrijecedores à flexão, com resultados validados através de testes em escala real.

Caire (2005) apresenta os resultados de ensaios realizados para levantamento das características do poliuretano de que são feitos certos enrijecedores à flexão. Observa que não é possível se obter ajustes para curvas de tração e compressão, ambas com um mesmo modelo matemático, sendo necessário usar ajustes diferentes para modelar o comportamento assimétrico do material. Dentre os modelos analisados (Mooney-Rivlin, Yeoh, etc.), o melhor ajuste se deu com o polinomial de ordem dois.

O autor obtém também curvas e coeficientes em ensaios de fluência, mas nota que o comportamento do poliuretano é viscoelástico não-linear, sugerindo uma teoria muito mais complexa que o modelo viscoelástico linear por ele adotado e pondera que o efeito da temperatura sobre a resposta mecânica não fora avaliado.

Em seguida, reformula o problema de flexão do enrijecedor considerando o efeito do cisalhamento na deformação e compara os resultados dessa formulação com aqueles de Boef e Out (1990), concluindo que os efeitos do cisalhamento se tornam mais evidentes para carregamentos maiores, considerando um mesmo ângulo de aplicação da força. Ressalva, no 
entanto, que há divergências nos resultados de resposta da deformação no final do sistema linha - enrijecedor e os atribui ao método numérico utilizado.

Caire formula ainda o problema como linear assimétrico e não-linear assimétrico e compara resultados em um estudo de caso, concluindo que o efeito da assimetria do material também se manifesta mais claramente com o aumento do valor da força $F$.

Caire avalia o efeito da viscoelasticidade linear e propõe, finalmente, um modelo analítico para avaliação das pressões de contato entre o enrijecedor e o tubo. Conclui que uma maior folga ("gap") entre as partes resulta em maiores pressões de contato após o carregamento, observando que quanto menor o carregamento, maior a tendência das maiores pressões se localizarem na extremidade livre do enrijecedor. Sugere, para trabalhos futuros, modelos viscoelásticos não-lineares e seus efeitos combinados com cisalhamento e grandes áreas de contato, além de testes e comparações com modelos em elementos finitos.

Mbaye (2006) desenvolve um pré-processador para geração de malhas de tubos flexíveis, chamado "RiserTools", para interface com o software comercial ANSYS®, e apresenta um fluxograma para programação em Fortran usando o método de Runge-Kutta de $4^{\mathrm{a}}$ ordem para solução do problema de contorno [s.i.c.] apresentado por Lemos (2005).

Mbaye compara os resultados obtidos na solução numérica analítica com aqueles do programa ANFLEX ${ }^{\circledR}$, de propriedade da Petrobras, e nota que os valores de curvatura obtidos pelo programa ANFLEX ${ }^{\circledR}$ são aproximadamente $10 \%$ maiores que os valores encontrados pelo programa numérico. Sugere para trabalhos futuros que se implemente um pacote para geração de malha de enrijecedores à flexão no programa RiserTools.

Caire e Vaz (2007) avaliam a influência de uma hipotética resposta bi-linear do tubo flexível na relação momento-curvatura do conjunto enrijecedor à flexão-tubo flexível sob carregamentos extremos e, também, a influência da folga ("gap") entre o enrijecedor e o tubo na fadiga do conjunto.

Para o primeiro caso, a formulação analítica é adaptada de Boef e Out (1990) para avaliações paramétricas da distribuição da curvatura do conjunto em função da "curvatura crítica", com 2,5; 5; 10; e 20\% da curvatura limite, e em função da rigidez à flexão do tubo flexível, com $\mathrm{EI}_{\mathrm{ns}} / \mathrm{EI}_{\mathrm{fs}}$ igual a 100;1000; e 10000, onde os subscritos "ns" e "fs" indicam "sem escorregamento entre as camadas" e "com escorregamento total entre as camadas", respectivamente. Os resultados são comparados com modelos discretizados no software ABAQUS para casos de carregamento extremo.

Para avaliação do parâmetro "gap", os resultados de um modelo com elementos finitos são apresentados para duas opções de folga entre tubo e enrijecedor: 5 e $20 \mathrm{~mm}$. 
Os autores concluem que tanto a folga entre tubo e enrijecedor quanto o comportamento bi-linear da rigidez à flexão do tubo não influenciam expressivamente a distribuição da curvatura em carregamentos extremos. Indicam, todavia, que estes parâmetros podem ter alguma significância para carregamentos de fadiga.

Caire e Vaz concluem ainda que a presença de folga entre os componentes e a bilinearidade da rigidez do tubo levam a resultados menos conservadores. Não obstante, sugerem sua incorporação na avaliação da fadiga do conjunto.

A geometria dos conjuntos analisados pelos vários autores está ilustrada na Tabela 1, a seguir.

Tabela 1 - Geometrias analisadas pelos autores citados na revisão bibliográfica. Valores no [SI].

\begin{tabular}{lccccccc}
\hline Autores & $\mathrm{A}$ & $\mathrm{B}$ & $\mathrm{C}$ & $\mathrm{D}$ & $\mathrm{E}$ & $\mathrm{F}$ & $\mathrm{G}$ \\
\hline Boef e Out & 0,660 & 0,234 & 0,200 & 1,700 & 1,300 & 3,200 & $0,180\left(^{*}\right)$ \\
Lane et al. & 0,575 & 0,248 & $0,425(* *)$ & 1,925 & 3,850 & 5,775 & 0,248 \\
Kiepper & 0,650 & 0,180 & 0,200 & 1,700 & 3,800 & 5,700 & 0,180 \\
Lemos & 0,650 & 0,180 & 0,200 & 1,700 & 1,300 & 3,200 & 0,180 \\
Caire & 0,650 & 0,240 & 0,200 & 1,700 & 1,300 & 3,200 & $0,240\left(^{* * *}\right)$ \\
Mbaye & 0,650 & 0,180 & 0,200 & 1,700 & 1,300 & 3,200 & 0,180 \\
Caire e Vaz & 0,650 & $(* * * *)$ & 0,200 & 1,700 & 1,300 & 3,200 & $(* * * *)$
\end{tabular}

* Diâmetro interno do tubo flexível $\mathrm{d}_{\mathrm{i}}=0,1016 \mathrm{~m}$.

** Parte cilíndrica não avaliada analiticamente.

*** Para o estudo das pressões de contato e gaps, Caire utilizou $\mathrm{G}=0,210 \mathrm{~m}$ e $0,180 \mathrm{~m}$, respectivamente.

**** Caire e Vaz utilizaram gaps de 5 e $20 \mathrm{~mm}$ entre o tubo e o enrijecedor e forneceu o diâmetro interno do tubo $\mathrm{d}_{\mathrm{i}}=0,1016 \mathrm{~m}$.

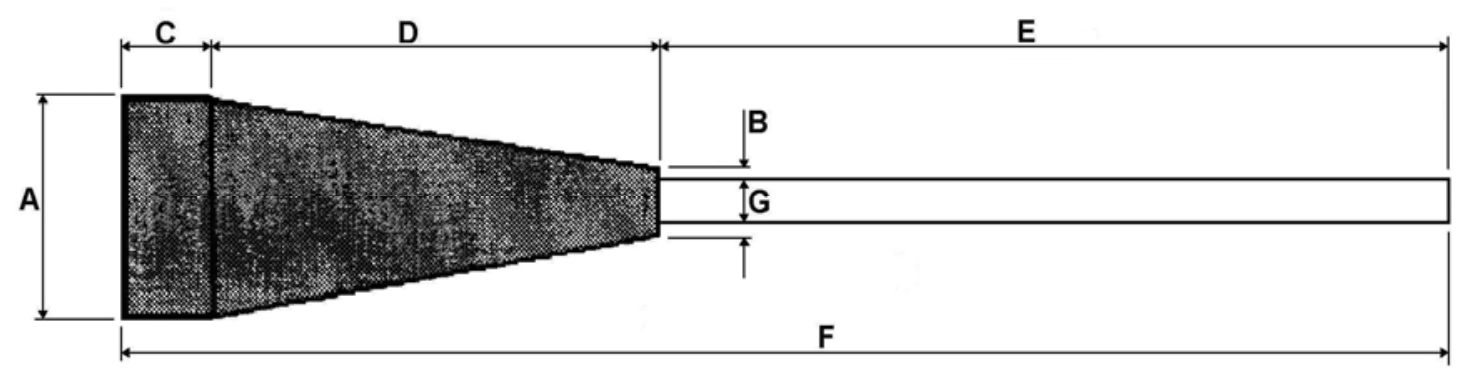

Pode-se verificar, da Tabela 1, que as geometrias analisadas pelos diversos autores que têm estudado o problema são relativamente simples, pressupondo não mais que cinco parâmetros para descrever a geometria do enrijecedor e mais um, para descrever o comprimento suficiente (ou de flexão). 


\section{PROJETO DE ENRIJECEDORES À FLEXÃO}

No Brasil, a Associação Brasileira de Normas Técnicas (ABNT) é o órgão responsável por toda normalização técnica, reconhecido como Foro Nacional de Normalização pela Resolução n. ${ }^{\circ} 7$ do CONMETRO, de 24/08/1992.

Outros órgãos também estão envolvidos, direta ou indiretamente, na normalização e regulamentação da produção petrolífera brasileira: Agência Nacional do Petróleo (ANP), Instituto Brasileiro de Petróleo e Gás (IBP), International Organization for Standardization (ISO), American Petroleum Institute (API), entre outros.

Os requerimentos de projeto de enrijecedores à flexão estão especificados no Apêndice B da API SPEC 17J/ISO 13628-11, que é suplementada pela API RP 17B/ISO 13628-2. No resumo do "19th Joint Meeting API C2/SC 17 \& ISO/TC67/SC4/WG6 Subsea Production Equipment", realizado em Galveston, Texas - E.U.A., em Março de 2006, lê-se sobre a proposta de novos códigos para projeto de "Flexible Pipe Ancillary Equipment" - API SPEC 17L1 e API RP 17L2. Entretanto, estes novos textos não estão ainda disponíveis nos sites da API ou ISO.

A API RP 2RD traz um guia para desenvolver casos de carregamento para equipamentos ligados às terminações de tubos flexíveis e a API RP 17A/ISO 13628-1 traz recomendações gerais sobre a utilização dos documentos da série 17 da API e, ainda, sobre outros aspectos do projeto de sistemas flutuantes de produção.

De maneira geral, os fabricantes mencionam que seus produtos atendem a estas normas e especificações. Não se encontraram, todavia, indicações de que tais códigos tenham sido adotados oficialmente no Brasil até o momento.

A API RP 17B não é uma especificação - é uma recomendação. Podem-se destacar ali os seguintes itens, de interesse para este trabalho:

a. Descrição de componentes auxiliares de linhas flexíveis (item 4.5);

b. Casos de cargas (load cases) (item 5);

c. Especificações para projetos de componentes auxiliares tipo bell mouth (item 7.6) e uma referência ao Apêndice B da API SPEC 17J para o projeto de bending stiffeners e bending restrictors; 
d. Especificações para os casos de carregamento, i.e. posições extremas da unidade flutuante (item 8.2.3.2): a. Condição "próxima", b. Condição “distante", c. Excursões máximas fora do plano;

e. Definição de "Tração Efetiva", Te (item 8.4.5).

Há ainda ilustrações de um enrijecedor à flexão, semelhante àquela encontrada em Lane et al. (1995) e de uma terminação de tubo flexível, onde se indica o uso de resina epóxi para fixação dos tendões helicoidais do tubo junto ao conector.

A API SPEC 17J, por sua vez, é uma especificação compulsória. Seu Apêndice B traz as seguintes especificações, de interesse para este trabalho:

B.3.4 As cargas de projeto do enrijecedor à flexão deverão ser determinadas em termos de trações efetivas e variações angulares a partir da posição média;

B.4.2 A metodologia de projeto do enrijecedor à flexão deverá levar em conta também propriedades não-lineares de materiais, em particular, Módulos de Young não-lineares;

B.4.3 A metodologia de projeto do enrijecedor à flexão deverá considerar os seguintes modos de falha:

a. descolamento ou ruptura,

b. ruptura ou rachadura no material elastomérico do enrijecedor à flexão,

c. envelhecimento do material,

d. fadiga,

e. falha na terminação;

B.4.5 A ovalização da extremidade do enrijecedor à flexão deve ser documentada e não deve interferir em seu desempenho;

B.4.9 Deve ser capaz de transferir as cargas para a estrutura de suporte com segurança;

B.5.7 O procedimento de manufatura para o enrijecedor à flexão deverá assegurar a ligação do material elastomérico aos componentes metálicos internos. A ligação deverá ser comprovadamente mais forte do que a exigência de desempenho durante toda a vida em serviço.

Note-se que os termos bonding/bond/bonded do texto original, em inglês, foram aqui traduzidos como "ligação". Entende-se que o autor do texto original tenha se referido a um tipo particular de ligações - aquelas coladas.

Além das normas acima, relacionadas especificamente ao projeto de enrijecedores, pode-se mencionar o trabalho de Lane et al. (1995), que faz uma revisão do estado da arte em 
materiais e manufatura de enrijecedores à flexão e traz ilustrações com arranjos de instalações típicas. Uma destas ilustrações, semelhante àquela encontrada na API RP 17B, está presente em alguns dos trabalhos consultados e pode ser vista na Fig. 11, reproduzida a seguir. Notese, entretanto, que se trata de um esquema representativo apenas, bastante simplificado.

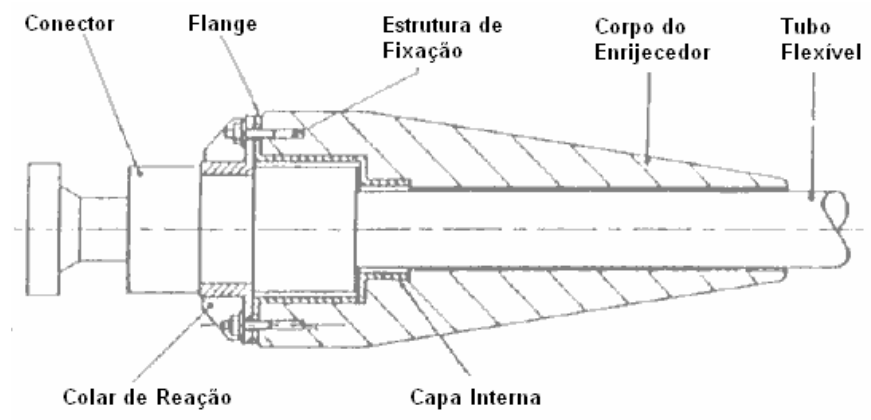

Figura 11 - Arranjo típico de enrijecedor à flexão. Extraído de Lane et al. (1995).

Considerando que os enrijecedores estarão sujeitos a cargas cíclicas e, portanto, susceptíveis à fadiga, certamente não há - ou não deveria haver - em unidades reais, certos ângulos retos e outros concentradores de tensão como aqueles observados na ilustração supracitada. As Figuras 12 e 13, a seguir, ilustram típicas regiões de falha de enrijecedores.

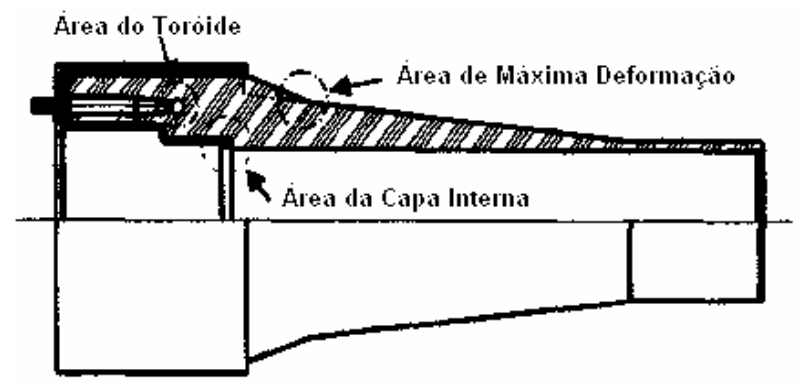

Figura 12 - Áreas críticas em relação à fadiga de um enrijecedor à flexão. Extraído de Demanze et al. (2005)

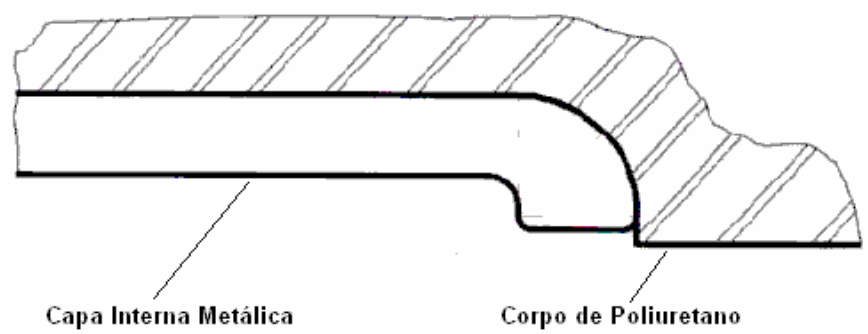

Figura 13 - Detalhe de área da capa interna: região típica de descolamentos entre o corpo de poliuretano e a capa metálica. Extraído de Demanze et al. (2005) 
Entende-se que detalhes construtivos são vantagens industriais de seus detentores e, salvo raras exceções, não estão em domínio público. Uma destas exceções é a ilustração de um enrijecedor para “I-tubes” encontrada em Lemos (2005), reproduzida na Fig. 14.

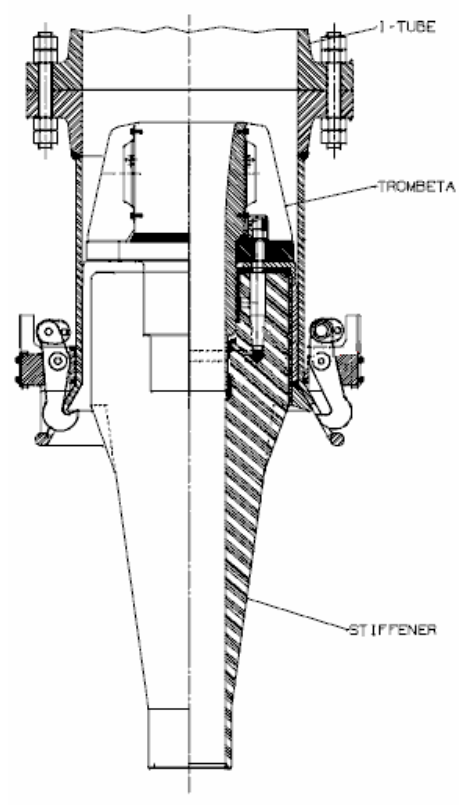

A.

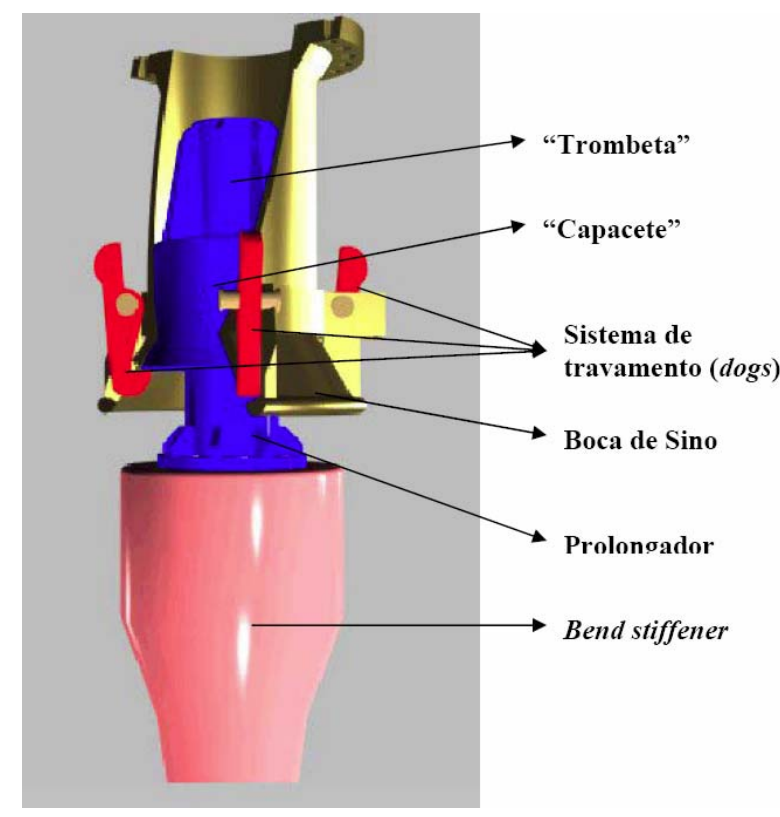

B.

Figura 14 - Arranjo de enrijecedor à flexão para "I-Tubes": A. Sem prolongador; B. Com prolongador (capa externa omitida). Extraído de Lemos (2005).

Podemos notar, a partir da Fig. 14, pelo menos quatro parâmetros para o projeto de enrijecedores que não foram contemplados em trabalhos anteriores - e que se pretende abordar neste trabalho (ref. Fig. 15):

a) O diâmetro extra $D_{2}$ na região do engastamento;

b) O comprimento do primeiro segmento de cone $L_{3}$, com maior declive;

c) O comprimento do trecho cilíndrico $L_{4}$ na extremidade não engastada;

d) O diâmetro extra $d_{2}$ na extremidade não engastada, resultante da espessura nãonula do enrijecedor naquela posição.

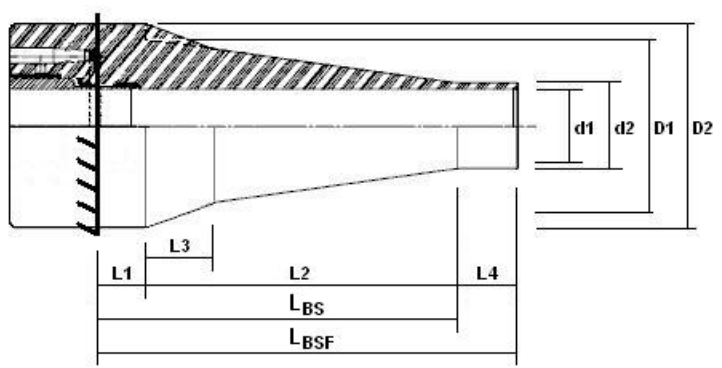

Figura 15 - Enrijecedor à flexão de geometria complexa. 


\section{MODELOS}

\subsection{CONSIDERAÇÕES GERAIS}

A solução de problemas de engenharia deve necessariamente passar por etapas "nãoexatas" até que um resultado "exato" seja alcançado. Em cada uma dessas etapas, hipóteses e simplificações são normalmente adotadas. A identificação do problema real que se quer resolver é a primeira destas etapas e requer, muitas vezes, familiaridade com o problema. Nem sempre o problema real pode ser precisamente descrito.

A partir da descrição possível do problema real deve-se propor um modelo físico contínuo ou discretizado. Entretanto, mesmo o mais refinado modelo não descreverá exatamente a realidade descrita. Note-se ainda que há uma hierarquia de possíveis modelos, sendo o melhor deles aquele que resolve o problema real mais eficientemente (menor tempo), e dentro de parâmetros de confiabilidade (erro) aceitáveis.

Precisaremos, então, de um modelo matemático e de um método - empírico, analítico ou numérico - para resolução do modelo físico proposto. No caso particular de estruturas estáticas, estabelecer-se-ão suas equações de equilíbrio, de compatibilidade e constitutivas que possibilitarão o cálculo de forças, momentos, curvaturas, deslocamentos, deformações e tensões do modelo, i.e., seu comportamento estrutural.

Citando Bathe (1996), "Está claro que todas as simplificações do modelo adotado refletem-se na resposta prognosticada. Não se pode esperar mais do que aquilo contido no próprio modelo. Assim, a escolha de um modelo físico-matemático apropriado é crucial e determina que compreensão do problema físico se pode obter com a análise.”

\subsection{DESCRIÇÃO DO PROBLEMA REAL}

O enrijecedor à flexão é uma estrutura marítima auxiliar projetada para proteger linhas flexíveis contra flexão excessiva. É composto, essencialmente, por um corpo de material polimérico ligado a peças metálicas que por sua vez conectar-se-ão à estrutura principal de fixação da linha flexível. Sua configuração deve proporcionar uma variação gradual da rigidez à flexão da instalação, suavizando a curvatura e, conseqüentemente, o campo de tensões da linha junto ao engastamento. 
A Fig. 16 reproduz ilustrações encontradas na literatura que mostram enrijecedores à flexão cuja formulação tem adotado que seus corpos têm geometria cônica simples. Já a Fig. 17 traz ilustrações de unidades com quatro diferentes seções compondo o corpo polimérico do enrijecedor à flexão.

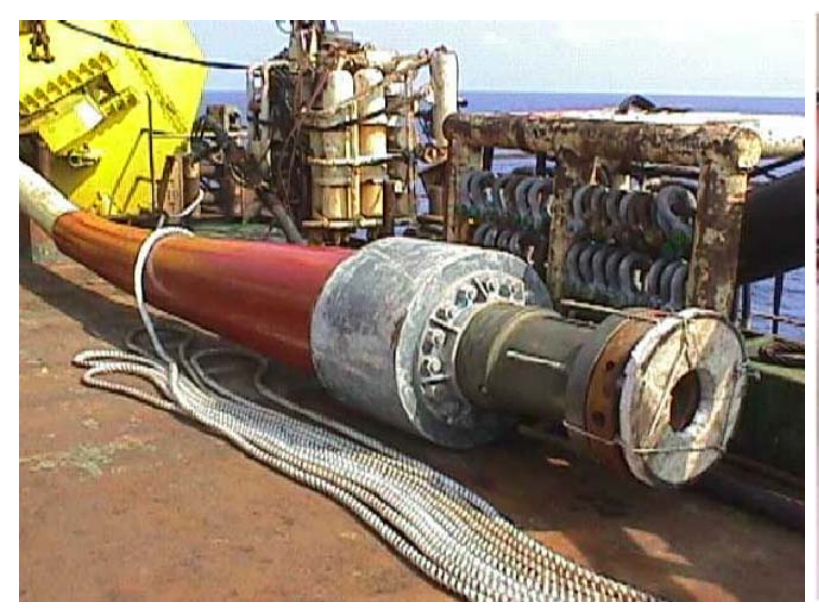

A.

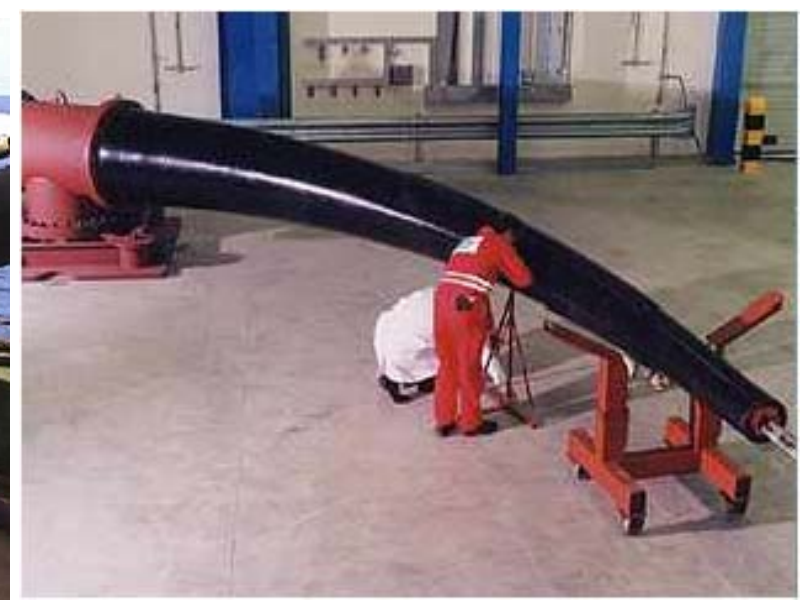

B.

Figura 16 - Enrijecedores à flexão "simples”. A. Cortesia: MSG AS; B. Cortesia: CRP.
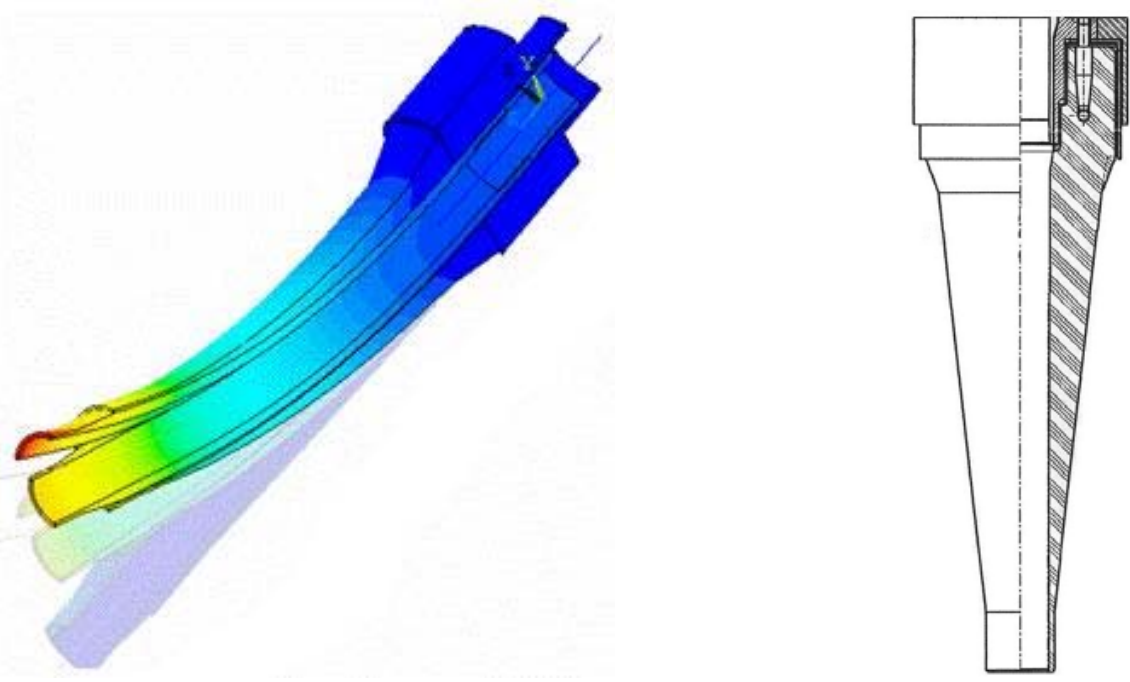

Figura 17 - Enrijecedores à flexão “complexos”. Cortesia: TechnipCRP.

O projeto de estruturas marítimas deve considerar a ação das ondas, ventos, correntezas, tremores de terra, colisões (pequenas ou grandes), explosões, etc. Usualmente, especifica-se ainda as condições de sobrevivência, resistência à fadiga e modos de falha. Uma análise completa de qualquer dessas estruturas exige um levantamento de dados estatísticos do local, características dinâmicas da instalação, etc. 
Pope et al. apud Lemos (2005, p. 213) indicam que enrijecedores à flexão falharam em serviço quando instalados em uma monobóia da Petrobras, no Campo de Marlim. Tais falhas (por fadiga) são coerentes com as dimensões e inércia características de uma bóia, cujos movimentos têm maior amplitude e freqüência que os de um FPSO, por exemplo - estando ambos sujeitos a um mesmo estado de mar. A Fig. 18 fornece um exemplo para comparação de suas dimensões. Note-se também a presença dos enrijecedores na mesma ilustração.

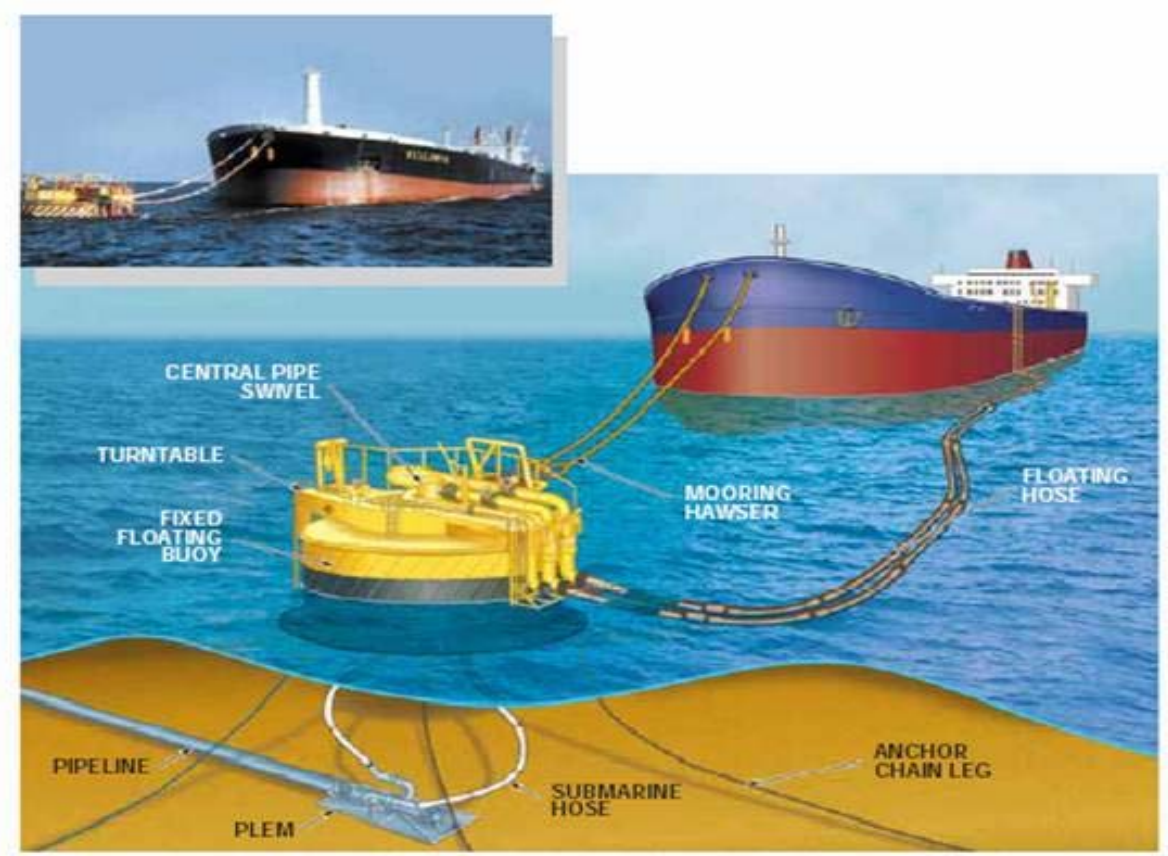

Figura 18 - Navio-tanque acoplado a uma monobóia. Cortesia: SOFEC, Inc.

Como aponta Pesce (1997), a resposta dinâmica da linha é, em sua maior parte, devida aos movimentos impostos pela unidade flutuante à terminação de topo. Fortuitamente, todavia, os carregamentos dinâmicos impostos à linha são amortecidos por forças de arrasto hidrodinâmico do próprio riser, resultando em pequenas amplitudes de oscilação da curvatura.

No que tange à dinâmica da linha, estas oscilações são “quase-estáticas" e seu efeito pode, portanto, ser quantificado de forma estática. Assim, os carregamentos associados aos movimentos da extremidade superior serão extremamente relevantes em duas situações:

a) Em condições extremas de agitação marítima;

b) No cálculo do dano acumulado para avaliação de fadiga mecânica.

Pelo exposto, conclui-se que a análise estrutural de enrijecedores à flexão pode ser conduzida para carregamentos estáticos apenas, sem prejuízo da compreensão que se espera obter em uma abordagem inicial do problema. 


\subsection{MODELO FÍSICO-MATEMÁTICO}

Inicialmente, retomemos o modelo adotado por Boef e Out (1990), o qual admite as seguintes hipóteses:

a) Barra delgada com grandes deslocamentos (Bernoulli-Euler), desprezando-se o peso próprio e quaisquer forças externas;

b) Flexão pura;

c) Seção transversal variável ao longo do comprimento do enrijecedor;

d) Desprezam-se os efeitos da força cortante;

e) Material homogêneo isótropo e com comportamento linear elástico.

O modelo físico para uma instalação típica em "catenária direta" pode ser simplificadamente ilustrado como na Fig. 19.

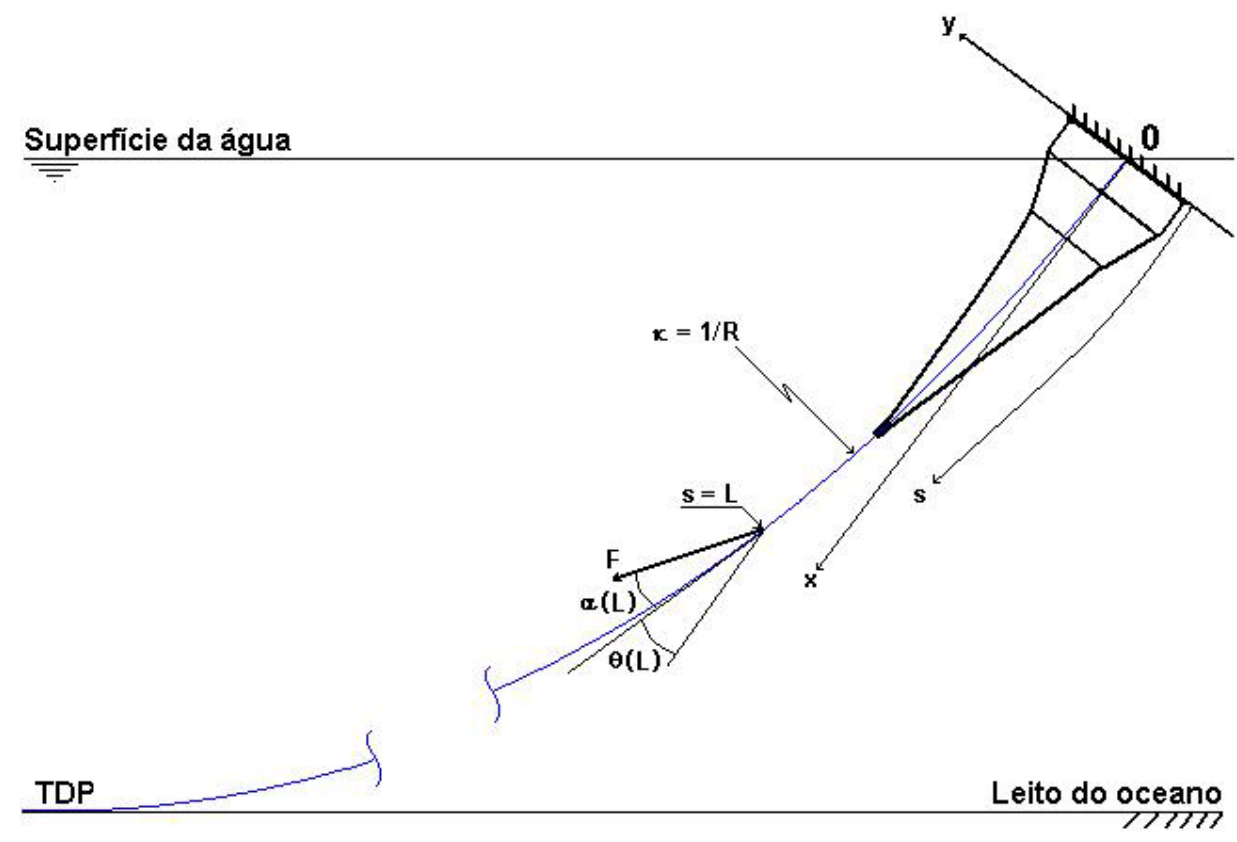

Figura 19 - Instalação típica em "catenária direta".

Seja Oxy um sistema de referência ligado à unidade flutuante de tal modo que:

a. A origem $O$ é o ponto do eixo central da linha flexível a partir do qual o comprimento de arco $s$ da linha é medido;

b. O eixo $O x$ é tangente ao eixo central da linha em $s=0$;

c. O plano Oxy é o plano de flexão da linha (admite-se, por hipótese, que a curva formada pelo eixo central da linha é uma curva plana, o que é válido para pequenos comprimentos de arco quando comparados ao comprimento total da linha); 
d. Os eixos $x$ e $y$ são orientados de tal forma que os pontos do eixo central ocupem o primeiro quadrante do sistema $O x y$ para $s>0$;

e. O sistema $O x y$ não é um sistema de referência inercial, mas pode ser aproximado como tal, dada a natureza "quase-estática" do problema.

Um elemento $d s$ da instalação está convenientemente ilustrado na Fig. 20, onde os eixos de referência $x$ e $y$ estão alinhados com as direções vertical e horizontal, respectivamente.

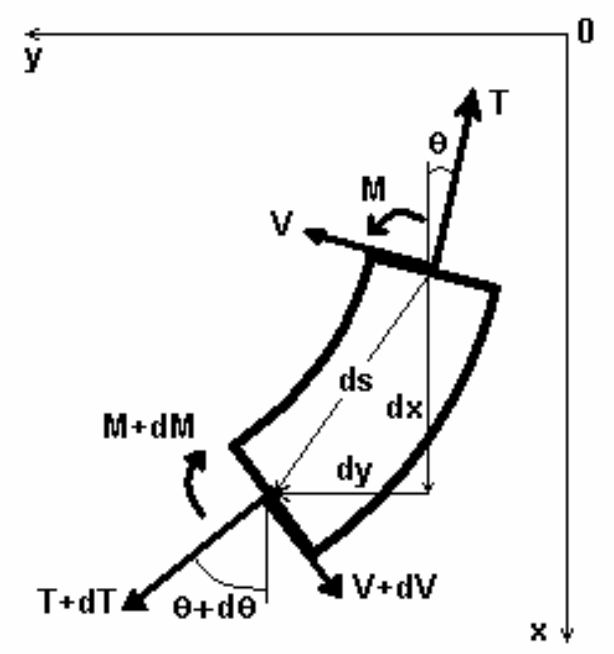

Figura 20 - Equilíbrio de um elemento infinitesimal.

Assim, temos, na direção $x$ vertical:

$$
\begin{gathered}
\sum F_{x}=0: \quad\left[T+\left(\frac{d T}{d s}\right) \cdot d s\right] \cdot \cos \left[\theta+\left(\frac{d \theta}{d s}\right) \cdot d s\right]+ \\
+\left[V+\left(\frac{d V}{d s}\right) \cdot d s\right] \cdot \operatorname{sen}\left[\theta+\left(\frac{d \theta}{d s}\right) \cdot d s\right]-T \cdot \cos (\theta)-V \cdot \operatorname{sen}(\theta)=0
\end{gathered}
$$

Mas, no limite, para $d s \rightarrow 0$, são válidas as aproximações:

$$
\begin{aligned}
& \operatorname{sen}\left[\theta+\left(\frac{d \theta}{d s}\right) \cdot d s\right] \approx \operatorname{sen}(\theta)+\cos (\theta) \cdot\left(\frac{d \theta}{d s}\right) \cdot d s \\
& \cos \left[\theta+\left(\frac{d \theta}{d s}\right) \cdot d s\right] \approx \cos (\theta)-\operatorname{sen}(\theta) \cdot\left(\frac{d \theta}{d s}\right) \cdot d s
\end{aligned}
$$


Substituindo (15) e (16) em (14), simplificando, desprezando os infinitésimos de ordem superior, dividindo por $d s$ e levando ao limite para $d s \rightarrow 0$, resulta:

$$
\frac{d}{d s}[T \cdot \cos (\theta)+V \cdot \operatorname{sen}(\theta)]=0
$$

Note-se que a eq.(17) atesta a invariância da componente vertical da resultante de forças nas seções transversais ao longo da coordenada curvilínea $s$, de acordo com as hipóteses admitidas para o estabelecimento do equilíbrio, i.e., inexistência de forças externas e peso próprio desprezado.

Analogamente, na direção $y \underline{\text { horizontal: }}$

$$
\begin{gathered}
\sum F_{y}=0: \quad\left[T+\left(\frac{d T}{d s}\right) \cdot d s\right] \cdot \operatorname{sen}\left[\theta+\left(\frac{d \theta}{d s}\right) \cdot d s\right]- \\
-\left[V+\left(\frac{d V}{d s}\right) \cdot d s\right] \cdot \cos \left[\theta+\left(\frac{d \theta}{d s}\right) \cdot d s\right]-T \cdot \operatorname{sen}(\theta)+V \cdot \cos (\theta)=0
\end{gathered}
$$

Chegando-se a:

$$
\frac{d}{d s}[T \cdot \operatorname{sen}(\theta)-V \cdot \cos (\theta)]=0
$$

Note-se que a eq.(19) atesta a invariância da componente horizontal da resultante de forças nas seções transversais ao longo da coordenada curvilínea $s$, de acordo com as hipóteses admitidas para o estabelecimento do equilíbrio, i.e., inexistência de forças externas e peso próprio desprezado.

Tomando agora o equilíbrio de momentos do elemento infinitesimal em relação à seção inferior, temos:

$$
\begin{aligned}
\sum M=0: \quad & {\left[M+\left(\frac{d M}{d s}\right) \cdot d s\right]+T \cdot \operatorname{sen}(\theta) \cdot d x-V \cdot \cos (\theta) \cdot d x-} \\
& -T \cdot \cos (\theta) \cdot d y-V \cdot \operatorname{sen}(\theta) \cdot d y-M=0
\end{aligned}
$$


Da geometria do sistema, no limite para $d s \rightarrow 0$, temos:

$$
\begin{aligned}
& \frac{d x}{d s}=\cos (\theta) \\
& \frac{d y}{d s}=\operatorname{sen}(\theta)
\end{aligned}
$$

Simplificando, dividindo (20) por $d s$, substituindo o que vai em (21) e (22) e simplificando novamente, resulta:

$$
\frac{d M}{d s}-V=0
$$

Deve-se observar que, para o estabelecimento das equações de equilíbrio (17), (19) e (23), admitimos que o versor normal à seção transversal coincide com o versor tangente ao eixo central da respectiva seção, ou seja, o efeito da distorção da seção transversal causada pela força cortante não foi considerado neste equacionamento. Com esta hipótese, teremos, após a integração das equações (19) e (17):

$$
\begin{aligned}
& T \cdot \operatorname{sen}(\theta)-V \cdot \cos (\theta)=C 1 \\
& T \cdot \cos (\theta)+V \cdot \operatorname{sen}(\theta)=C 2
\end{aligned}
$$

Considerando a condição de contorno dada por $\theta(0)=0$, teremos:

$$
\begin{gathered}
C 1=-V(0)=-V o \\
C 2=T(0)=T o
\end{gathered}
$$

Logo, aplicando a condição acima em (24) e (25):

$$
\begin{aligned}
& T \cdot \operatorname{sen}(\theta)-V \cdot \cos (\theta)=-V o \\
& T \cdot \cos (\theta)+V \cdot \operatorname{sen}(\theta)=T o
\end{aligned}
$$


Resolvendo o sistema acima para $T$ e $V$, teremos:

$$
\begin{aligned}
& T=T o \cdot \cos (\theta)-V o \cdot \operatorname{sen}(\theta) \\
& V=T o \cdot \operatorname{sen}(\theta)+V o \cdot \cos (\theta)
\end{aligned}
$$

Retomando a geometria do sistema, ilustrada na Fig. 19, teremos, na seção de aplicação da força $F$, o que segue:

$$
\begin{gathered}
T(L)=F \cdot \cos \left(\alpha_{L}\right) \\
V(L)=-F \cdot \operatorname{sen}\left(\alpha_{L}\right)
\end{gathered}
$$

Onde: $\alpha_{L}$ é o ângulo entre a força resultante $F$ e a componente normal à seção transversal, ambas em $s=L$. Note-se que o ângulo $\alpha$ varia com a coordenada $s$. Logo $\alpha=\alpha(s)$.

Usando as condições de contorno (30) em (28) e (29), resulta:

$$
\begin{gathered}
T=F \cdot \cos \left(\theta_{L}-\theta+\alpha_{L}\right) \\
V=-F \cdot \operatorname{sen}\left(\theta_{L}-\theta+\alpha_{L}\right)
\end{gathered}
$$

O resultado acima pode ser ilustrado graficamente na Fig. 21.

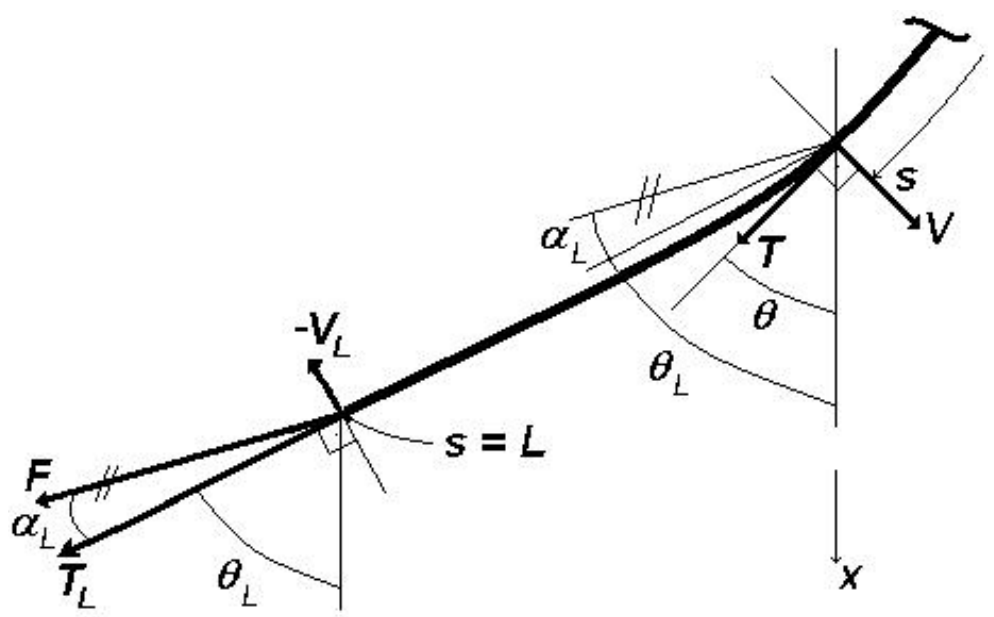

Figura 21 - Transposição da força $F$ da seção $s=L$ para uma seção genérica $s$. 
Substituindo, agora, (31) em (23), vem:

$$
\frac{d M}{d s}+F \cdot \operatorname{sen}\left(\theta_{L}-\theta+\alpha_{L}\right)=0
$$

Se admitirmos o caso de flexão pura em regime elástico linear e que as seções originalmente planas permaneçam planas e normais às fibras longitudinais da viga, teremos, como indicado em Timoshenko (1979, p.110):

$$
M=E I \cdot \frac{d \theta}{d s}
$$

Onde $E I$ é a rigidez à flexão equivalente do conjunto formado por enrijecedor (rigidez variável ao longo do comprimento) mais linha flexível (rigidez constante): $E I=[E I]_{b s}+[E I]_{p}$.

Substituindo (33) em (32), vem:

$$
\frac{d}{d s}\left[(E I) \cdot \frac{d \theta}{d s}\right]+F \cdot \operatorname{sen}\left(\theta_{L}-\theta+\alpha_{L}\right)=0
$$

Lembrando que, segundo Boef e Out (1990), análises globais indicam que $\alpha_{L}$ é usualmente bastante pequeno e pode, portanto, ser excluído do equacionamento do problema.

Explicitando, então, a derivada da primeira parcela da eq.(34), dividindo por EI, rearranjando e simplificando, resulta:

$$
\frac{d^{2} \theta}{d s^{2}}+\frac{1}{E I} \cdot \frac{d(E I)}{d s} \cdot \frac{d \theta}{d s}+\frac{1}{E I} \cdot F \cdot \operatorname{sen} \cdot\left(\theta_{L}-\theta\right)=0
$$

Observe que o problema acima formulado resulta em uma equação diferencial ordinária não-linear de segunda ordem com coeficientes variáveis, cuja solução analítica explícita não é conhecida. Logo, é preciso recorrer a métodos numéricos para sua resolução, sendo que o primeiro passo é escrevê-la como um sistema de equações de primeira ordem. Isto pode ser feito, por exemplo, com a introdução de novas variáveis, tiradas da geometria do problema, como proposto por Boef e Out (1990), eq.(36) - (39): 


$$
\frac{d \kappa}{d s}=-\frac{1}{E I} \cdot\left[\frac{d(E I)}{d s} \cdot \kappa+F \cdot \operatorname{sen}\left(\theta_{L}-\theta\right)\right]
$$

$$
\begin{aligned}
& \frac{d \theta}{d s}=\kappa \\
& \frac{d x}{d s}=\cos (\theta) \\
& \frac{d y}{d s}=\operatorname{sen}(\theta)
\end{aligned}
$$

Com condições de contorno:

$$
\begin{gathered}
s=0: x(0)=0 ; \theta(0)=0 ; y(0)=0 \\
s=L: \theta(L)=\theta_{L}
\end{gathered}
$$

\subsection{SOLUÇÕES E COMPARAÇÕES}

O sistema de equações formulado acima é, do ponto de vista matemático, um Problema de Valor de Contorno, pois as condições de contorno disponíveis não são todas para um mesmo ponto. Se o fossem, teríamos um Problema de Valor Inicial.

Há várias maneiras de se resolver o problema acima: linearização, aproximações por séries infinitas, transformação do problema de valor de contorno em problema de valor inicial equivalente, etc. Trabalhos anteriores adotaram a abordagem de redução de ordem, já obtida naturalmente na formulação, e transformação em problema de valor inicial equivalente, $\operatorname{com} \kappa$ inicialmente igual a zero para obtenção da quarta condição de contorno em $s=0$, necessária à solução, como requer um problema de valor inicial. Um algoritmo de "tiros múltiplos" que utiliza o método de Runge-Kutta de Segunda ou Quarta Ordem tem sido utilizado para obtenção dos resultados.

Algoritmos de tiros, entretanto, são instáveis em pontos de descontinuidade da função que define o perfil do enrijecedor e podem não conseguir lidar com geometrias mais complexas. Esta dificuldade foi, de fato, reportada por Caire (2005) ao tentar modelar a abrupta descontinuidade (de um valor nulo para um não-nulo) do diâmetro na extremidade do enrijecedor. 
Apresenta-se, então, neste trabalho um outro método para solução do problema formulado: a função "bvp4c", disponível no software Matlab a partir de sua versão 6.0, segundo Shampine, Kierzenka e Reichelt (2000), que se utiliza do método de colocação (interpolação). Este código permite resolver o problema original de valor de contorno sem ter que tornar $\kappa$ inicialmente igual a zero. Um esquema de implementação do código para solução de problemas de enrijecedores à flexão pode ser apreciado no Apêndice A.

Obteve-se boa concordância com os resultados de trabalhos anteriores, extraídos de Boef e Out (1990) e Caire (2005), com a utilização do programa Matlab bvp4c para o enrijecedor de geometria simples, Fig. 22, definido na Tabela 2.

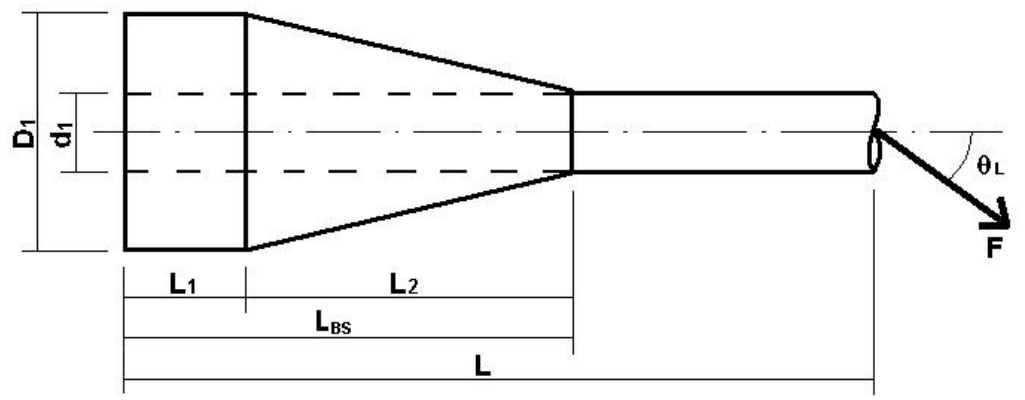

Figura 22 - Enrijecedor à flexão de geometria simples.

Tabela 2 - Enrijecedor 1. Extraído de Boef e Out (1990).

\begin{tabular}{llll}
\hline Propriedades & Símbolo & Valor & Unidade \\
\hline Rigidez à Flexão da Linha & $E I_{P}$ & 10 & {$\left[\mathrm{kN} \cdot \mathrm{m}^{2}\right]$} \\
Módulo de Young do Enrijecedor & $E_{B S}$ & 45 & {$[\mathrm{MPa}]$} \\
Comprimento Total do Modelo & $L$ & 4 & {$[\mathrm{~m}]$} \\
Comprimento da 1a Seção Cilíndrica & $L_{1}$ & 0,2 & {$[\mathrm{~m}]$} \\
Comprimento da Seção Cônica & $L_{2}$ & 1,7 & {$[\mathrm{~m}]$} \\
Diâmetro Máx. Original do Enrijecedor & $D_{1}$ & 0,65 & {$[\mathrm{~m}]$} \\
Diâmetro Externo da Linha & $d_{1}$ & 0,18 & {$[\mathrm{~m}]$} \\
Diâmetro Ext. do Enrijecedor na Extremidade Livre & $d_{2}$ & 0,18 & {$[\mathrm{~m}]$} \\
Força Aplicada em $s=L$ & $F$ & 250 & {$[\mathrm{kN}]$} \\
Ângulo entre $F$ e o eixo $x$ & $\theta_{L}$ & 45 & {$\left[{ }^{\circ}\right]$} \\
Limite de Curvatura da Linha Flexível & $\kappa_{\text {lim }}$ & 0,5 & {$[1 / \mathrm{m}]$} \\
\hline
\end{tabular}

Os resultados de curvatura obtidos com o código implementado neste trabalho, comparados aos resultados (analítico-numéricos) dados por Boef e Out (1990) e Caire (2005), validam o novo método de solução numérica proposto, como pode ser observado na Fig. 23. 


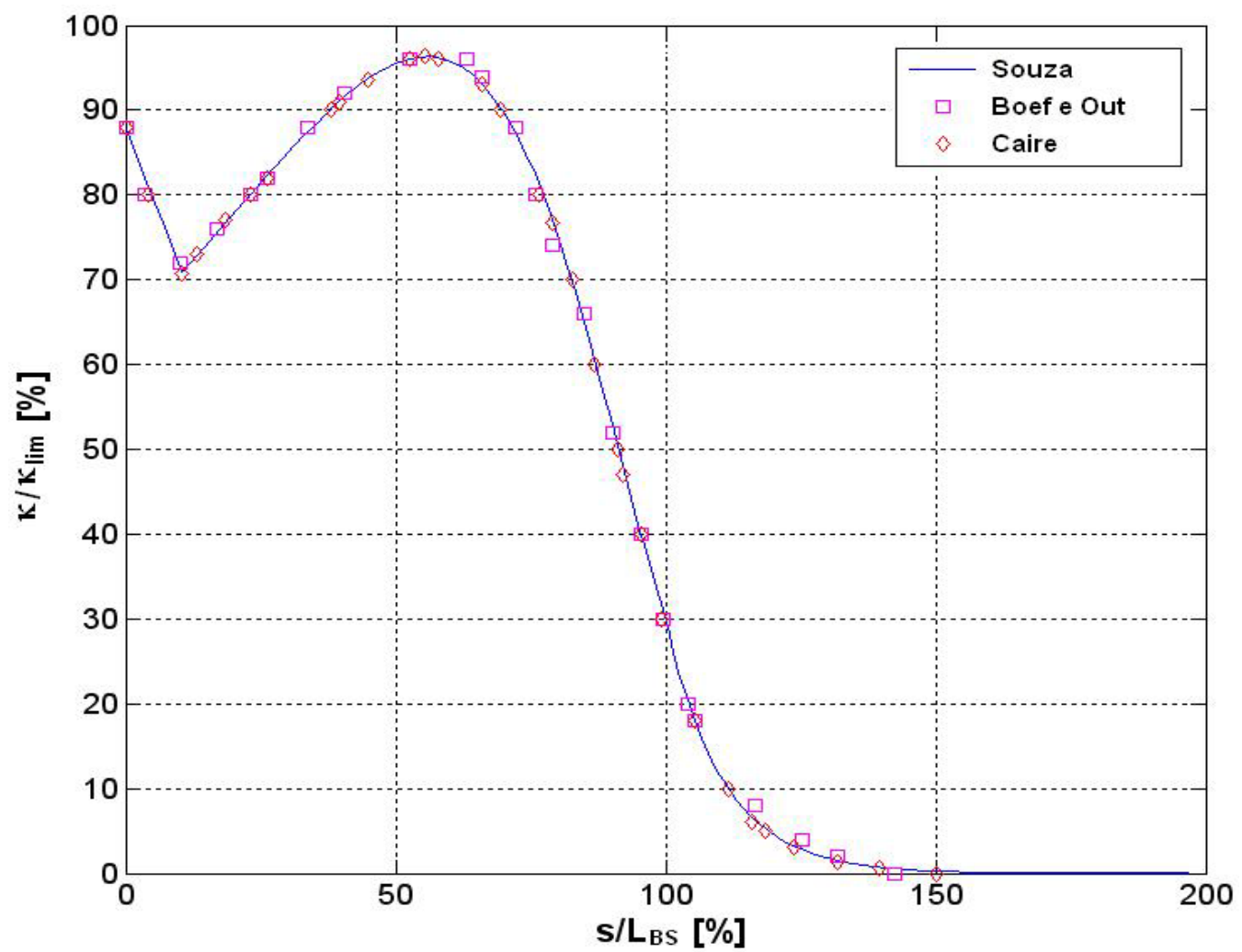

Figura 23 - Comparação de resultados analíticos para curvatura.

Os resultados para o deslocamento (elastica) podem ser apreciados na Fig. 24, onde se pode observar claramente que o código "bvp4c" recupera os resultados obtidos anteriormente com outro método analítico-numérico, por Caire (2005).

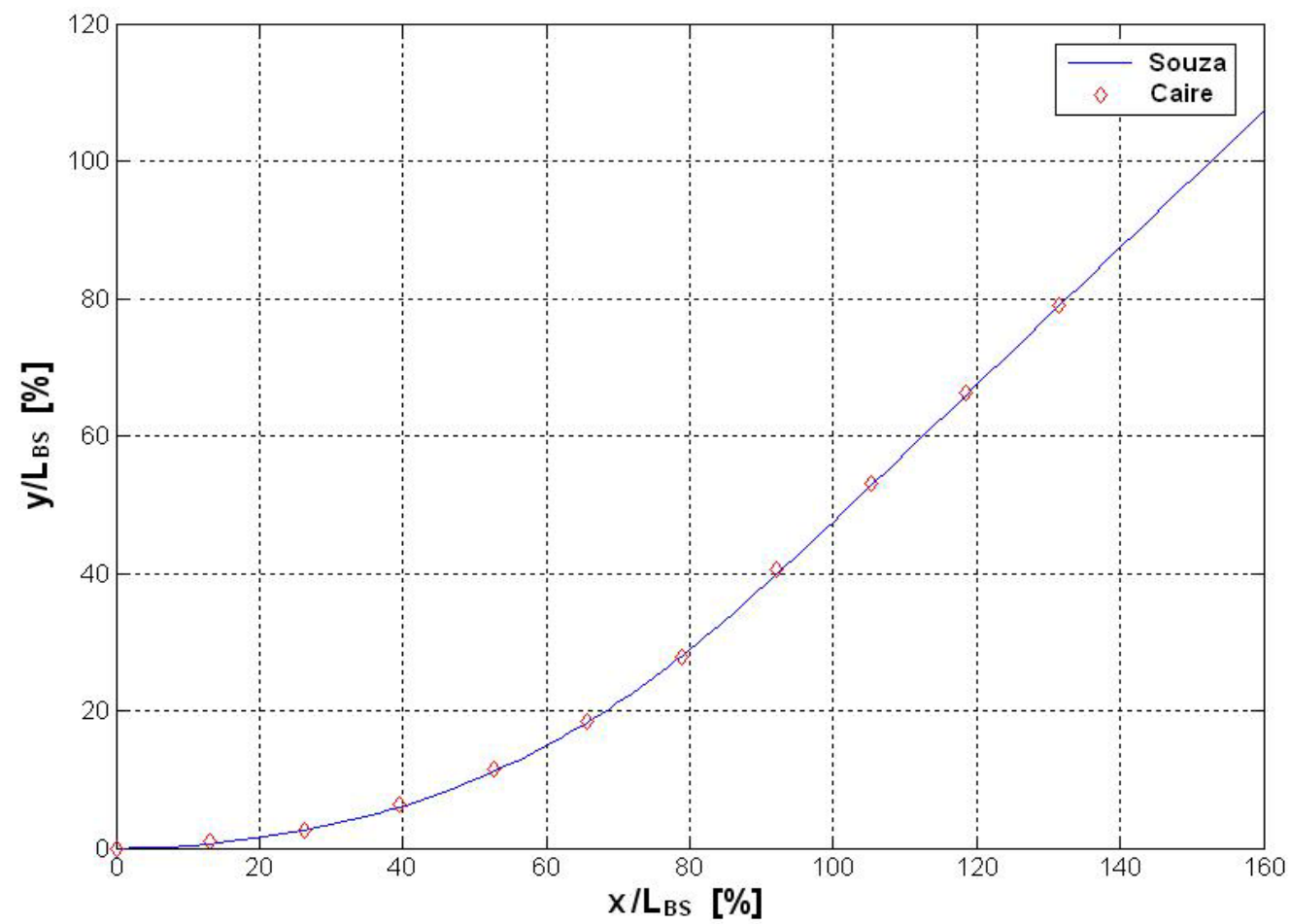

Figura 24 - Comparação de resultados analíticos para deslocamento. 
Os resultados da análise de um modelo com elementos finitos ("FEM"), resolvido com uma antiga versão dos softwares Marc ${ }^{\circledR}$ e Patran ${ }^{\circledR}$, por Boef e Out (1990), são comparados na Fig. 25 aos resultados obtidos com o código bvp4c para a mesma geometria, descrita na Tabela 2, exceto pelo diâmetro $d_{2}$, que passou a ser $d_{2}=0,234 \mathrm{~m}$.

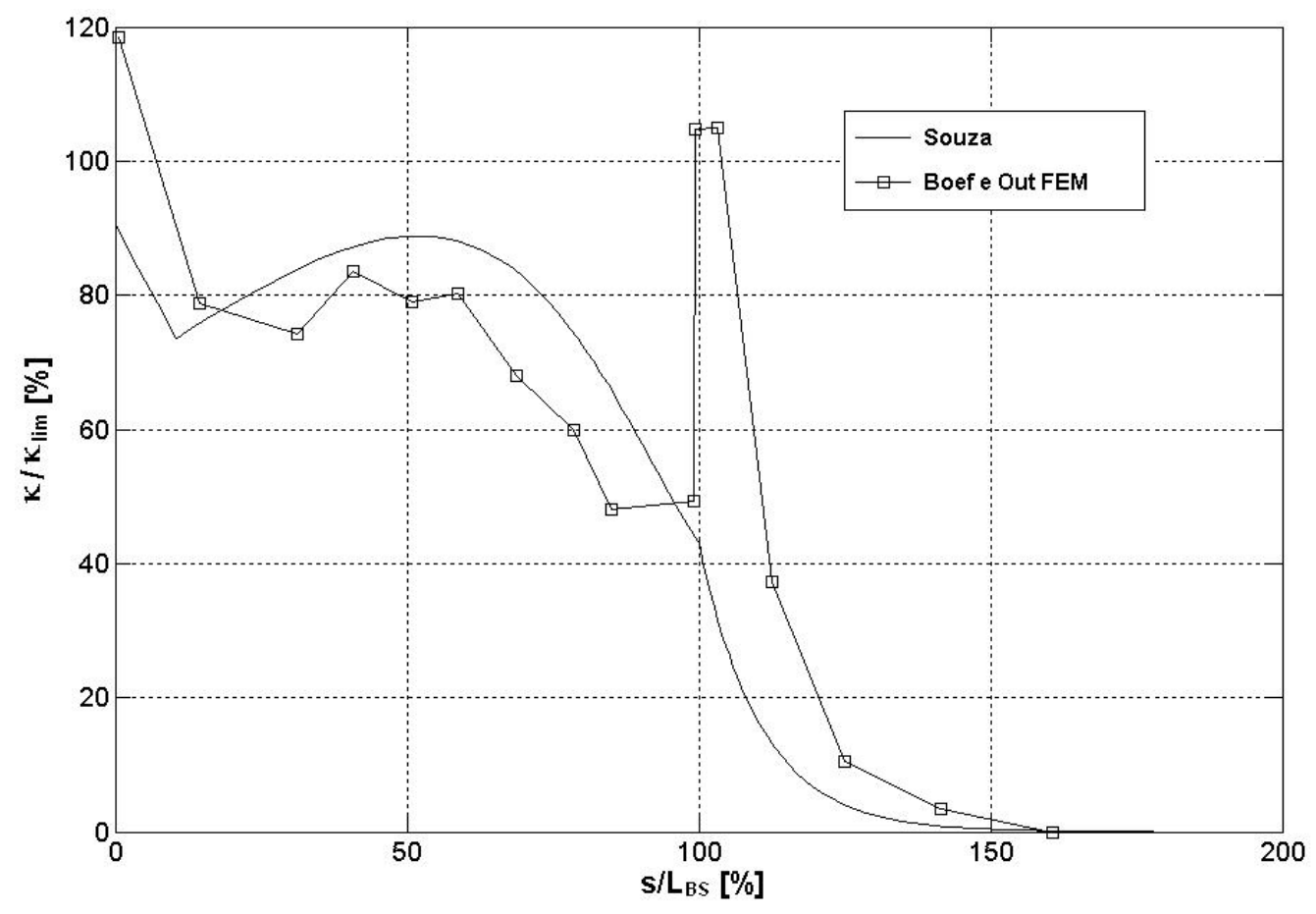

Figura 25 - Comparação de resultados para curvatura: bvp4c e MARC® PATRAN ${ }^{\circledR}$, extraído de Boef e Out (1990).

Deve-se observar que Boef e Out (1990) suspeitaram que os resultados de seu modelo com elementos finitos sobreestimaram o valor da curvatura na extremidade não-engastada em aproximadamente $50 \%$, devido à sensibilidade do código à maneira como o enrijecedor é modelado nesta área. Não obstante, o aspecto qualitativo da resposta de curvatura se mantém bastante próxima àquela calculada com o código "bvp4c". 
Tabela 3 - Enrijecedor 2. Extraído de Lane et al. (1995).

\begin{tabular}{llll}
\hline Propriedades & Símbolo & Valor & Unidade \\
\hline Rigidez à Flexão da Linha & $E I_{P}$ & 10 & {$\left[\mathrm{kNm}^{2}\right]$} \\
Módulo de Young do Enrijecedor & $E_{B S}$ & 45 & {$[\mathrm{MPa}]$} \\
Comprimento Total do Modelo & $L$ & 4 & {$[\mathrm{~m}]$} \\
Comprimento da $1^{\text {a }}$ Seção Cilíndrica & $L_{1}$ & 0,345 & {$[\mathrm{~m}]$} \\
Comprimento da Seção Cônica & $L_{2}$ & 1,925 & {$[\mathrm{~m}]$} \\
Diâmetro Máx. Original do Enrijecedor & $D_{1}$ & 0,575 & {$[\mathrm{~m}]$} \\
Diâmetro Externo da Linha & $d_{1}$ & 0,237 & {$[\mathrm{~m}]$} \\
Diâmetro Ext. do Enrijecedor na Extremidade Livre & $d_{2}$ & 0,248 & {$[\mathrm{~m}]$} \\
Força Aplicada em $s=L$ & $F$ & 133 & {$[\mathrm{kN}]$} \\
Ângulo entre $F$ e o eixo $x$ & $\theta_{L}$ & 29,4 & {$\left[{ }^{\circ}\right]$} \\
Limite de Curvatura da Linha Flexível & $\kappa_{\text {lim }}$ & 0,385 & {$[1 / \mathrm{m}]$} \\
\hline
\end{tabular}

Por fim, a Fig. 26 mostra boa concordância entre os resultados obtidos com o código aqui proposto e aqueles obtidos por Lane et al. (1995), com um modelo em elementos finitos resolvido com o software ABAQUS ${ }^{\circledR}$ para o enrijecedor definido na Tabela 3.

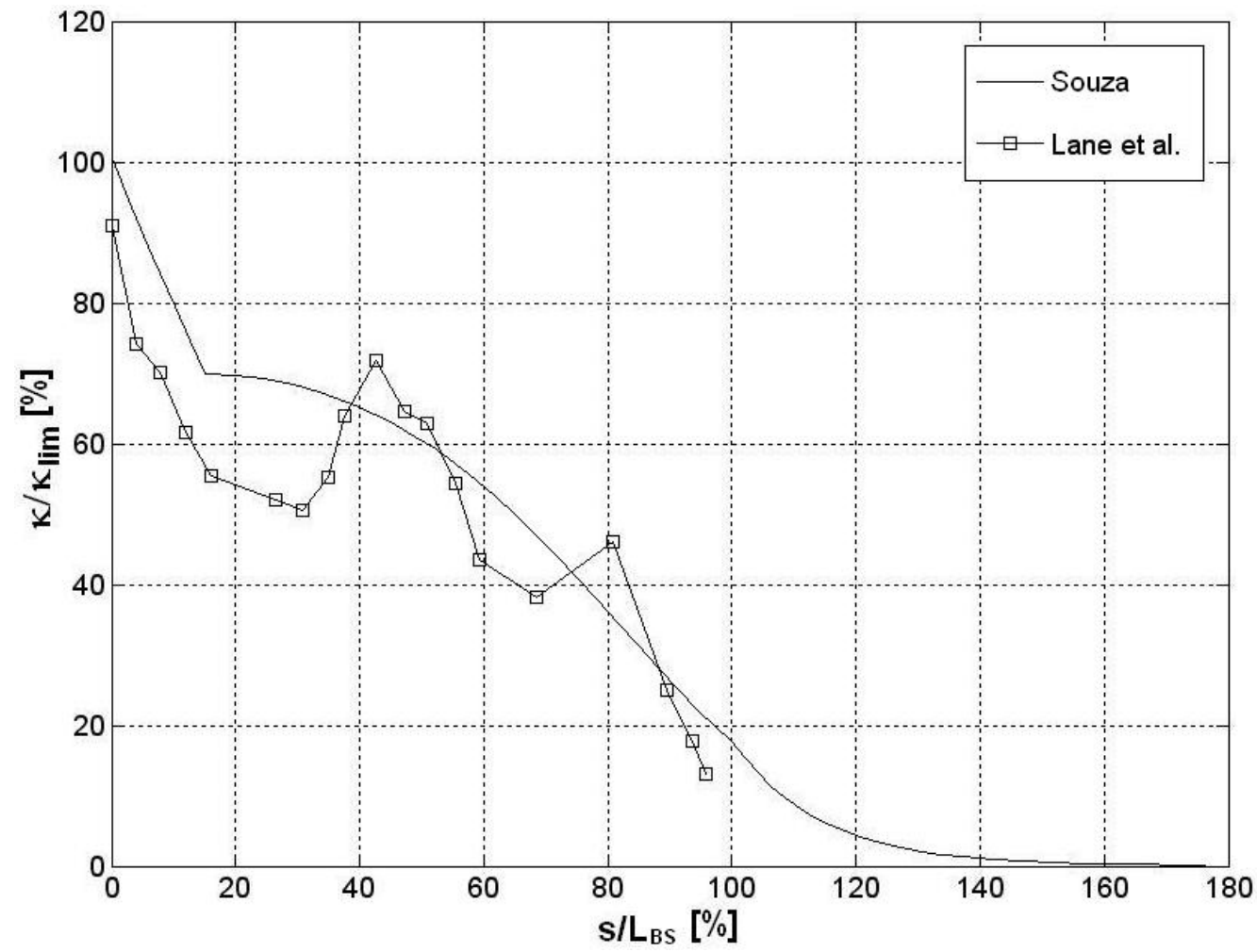

Figura 26 - Comparação de resultados para curvatura: bvp4c e ABAQUS®, extraído de Lane et al. (1995). 


\section{ANÁLISE DIMENSIONAL}

\subsection{CONSIDERAÇÕES GERAIS}

$\mathrm{Na}$ abordagem proposta neste trabalho, adota-se que o material de que é feito o corpo do enrijecedor à flexão é homogêneo e tem comportamento linear elástico, dentre outras hipóteses simplificadoras. É natural então que surja uma preocupação sobre sua aplicabilidade, uma vez que os corpos de unidades reais são usualmente feitos de material visco-elástico e sabe-se que os enrijecedores à flexão estão sujeitos a variações de temperatura, além de outras não-linearidades não consideradas neste trabalho.

Expandir os modelos matemáticos analíticos disponíveis e torná-los utilizáveis em uma maior gama de problemas, com maior precisão de análise, deu o tom aos recentes trabalhos publicados sobre o assunto. Não raro, todavia, os autores concluíram que seus modelos (não-linear elástico assimétrico e linear viscoelástico, por exemplo) avançaram na teoria, mas os resultados não foram totalmente satisfatórios. Confira, por exemplo, Caire (2005).

Se por um lado se diminuem as restrições impostas pela formulação ao comportamento do material, por exemplo, por outro, aumentam-se as incertezas das aproximações para as suas equações constitutivas, sendo que muitas vezes nenhum dos modelos disponíveis (Rivlin, Ogden, etc.) se mostra satisfatório, como aponta Lemos (2005).

Assim, como também os modelos discretizados (elementos finitos, por exemplo) dependem da difícil representação constitutiva do material, do correto modelamento do contato, etc., compreende-se o porquê das experimentações práticas com enrijecedores à flexão reais, em meio a tantos modelos físicos disponíveis: embora aparentemente simples, o problema da análise estrutural destas unidades mostra-se bastante intricado.

Por outro lado, e interessantemente, a maioria dos experimentos com enrijecedores à flexão para linhas flexíveis são feitos com os próprios protótipos e não com modelos reduzidos - o que reduziria o custo da experimentação, uma vez que os aparatos poderiam ter menor potência, etc.

Este capítulo tem por objetivo, então, apresentar ao leitor uma breve descrição do método dimensional e as razões e requisitos para se ensaiar modelos e protótipos. Além disso, todas as coordenadas dos resultados gráficos apresentados neste trabalho utilizam variáveis 
adimensionais, ao invés de variáveis físicas. A lógica deste tratamento encontra também neste capítulo sua justificativa.

\subsection{ANÁLISE DIMENSIONAL E TEORIA DA SEMELHANÇA}

Análise dimensional é uma técnica para reestruturar as variáveis dimensionais originais de um problema em um conjunto de produtos adimensionais, fornecendo informações importantes sobre possíveis combinações daquelas variáveis. Embora não seja capaz, por si só, de descobrir a formulação completa de uma lei física, a análise dimensional é uma ferramenta poderosa para o planejamento de experimentos, reduzindo significantemente sua complexidade e, com isto, o custo da análise, seja ela física ou numérica.

O teorema hoje conhecido como "teorema de П" é central à análise dimensional e foi enunciado (sem provas) pela primeira vez por Vaschy, em 1892. Foi Buckingham, entretanto, quem o provou em seu artigo, Sobre sistemas fisicamente semelhantes: ilustrações do uso de equações dimensionais, em 1914. Segundo Carneiro (1993), deve-se ao artigo de Buckingham a ampla difusão do teorema e, também, o uso da letra grega PI maiúsculo, correspondente à letra latina $\mathrm{P}$, inicial da palavra produto.

Em um sistema coerente de unidades de medida, as unidades de um pequeno número de grandezas são independentes e adotadas como unidades fundamentais ou de base. As unidades das demais grandezas, chamadas unidades derivadas, são dependentes dessas unidades fundamentais, de acordo com leis físicas ou definições. Esta dependência é expressa sob a forma de produtos das unidades fundamentais elevadas a expoentes que Fourier denominava expoentes de dimensão.

Qualquer relação funcional que exprima matematicamente uma lei natural ou um processo físico, para ter significado, deve preencher dois critérios: seus dois lados devem ter igualdade numérica e seus dois lados devem ter homogeneidade dimensional. Segundo Szirtes (1997), este último critério só foi reconhecido - ou, pelo menos, discutido - por Euler, em 1765, sendo firmemente estabelecido e formulado por Fourier, em 1822. Decorre do princípio da homogeneidade dimensional que essas relações continuarão válidas mesmo que sejam mudadas as magnitudes das unidades fundamentais.

O teorema de $\Pi$ diz que se uma relação original desconhecida é representada por $f\left(x_{1} ; x_{2} ; \ldots ; x_{n}\right)=0$, onde os $x_{i}$ são as variáveis do problema, ela pode ser transformada em uma nova função $\phi\left(\Pi_{1} ; \Pi_{2} ; \ldots ; \Pi_{n-m}\right)$ de $n-m$ grupos adimensionais $\Pi_{\mathrm{j}}$, sendo $m$ o número de unidades fundamentais estritamente necessárias para descrever o fenômeno. Estes grupos 
adimensionais são produtos de potências das variáveis originais, denominados "números П"; $m$ é o posto da matriz dimensional.

As variáveis que figuram nas equações desses grupos adimensionais podem ser variáveis (independentes e dependente), parâmetros, constantes físicas específicas ou constantes físicas universais. São geralmente variáveis dimensionais, cujos valores numéricos dependem das unidades de medida adotadas, mas algumas delas podem ser adimensionais, como, por exemplo, o "coeficiente de Poisson". Estes, todavia, não precisam figurar na matriz dimensional.

A matriz dimensional é uma forma conveniente de arranjar as variáveis do problema físico de forma a facilitar a obtenção dos produtos de potências que formarão os números П: suas linhas são compostas pelas grandezas fundamentais escolhidas e suas colunas correspondem aos expoentes das respectivas dimensões que formam cada uma das variáveis.

Para exemplificar, tomemos o caso de deflexão de uma barra de seção circular uniforme em balanço sujeita a uma carga transversal concentrada conforme ilustrado na Fig. 27.

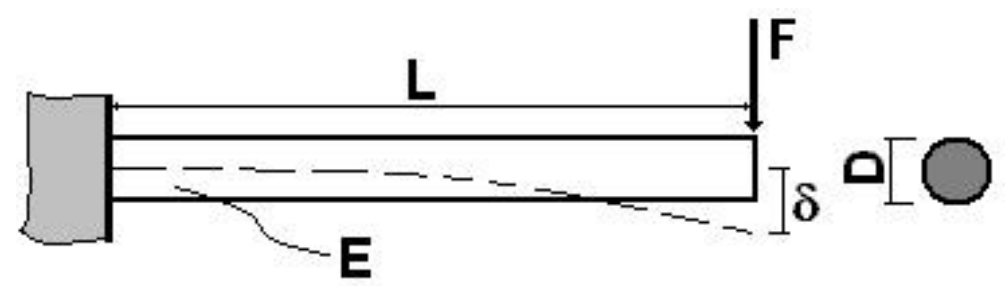

Figura 27 - Barra em balanço carregada transversalmente por uma força concentrada.

Uma possível escolha para a matriz dimensional do problema esquematizado acima é apresentada na Tabela 4.

Tabela 4 - Matriz dimensional para barra uniforme em balanço.

\begin{tabular}{|c|c|c|c|c|c|}
\hline Base [FL] & $\delta$ & $F$ & $L$ & $E$ & $I(D)$ \\
\hline$[\mathrm{m}]$ & 1 & 0 & 1 & -2 & 4 \\
\hline$[\mathrm{N}]$ & 0 & 1 & 0 & 1 & 0 \\
\hline
\end{tabular}

Da escolha acima, resultam três grupos adimensionais. Confira Szirtes (1997, p.423):

$$
\Pi_{1}=\frac{\delta}{L} ; \quad \Pi_{2}=\frac{F}{E \cdot L^{2}} ; \quad \Pi_{3}=\frac{I}{L^{4}}
$$


Podemos formar um monômio a partir das eq.(41), como segue:

$$
\Pi_{1}=c \cdot\left(\Pi_{2}\right)^{\beta_{1}} \cdot\left(\Pi_{3}\right)^{\beta_{2}}
$$

Se a forma monomial definida pela eq.(42) for possível, a constante $c$ e os expoentes $\beta_{\mathrm{i}}$ devem ser determinados por experimentação, análise ou raciocínio heurístico.

Para o caso do problema ilustrado pela Figura 27, Tabela 4, podemos supor que o deslocamento seja diretamente proporcional à força aplicada e inversamente proporcional ao momento de inércia da seção transversal da barra, o que torna $\beta_{1}=1$ e $\beta_{2}=-1$, restando apenas encontrar o valor de $c$. Para pequenos deslocamentos, obtém-se $c=1 / 3$. Logo:

$$
\delta=\frac{F \cdot L^{3}}{3 \cdot E \cdot I}
$$

Ou seja, partindo de considerações dimensionais e raciocínio inquisitivo, descobrimos quais combinações de variáveis deveriam ser consideradas para definição do comportamento estrutural do modelo, eq. (43).

Quando figuram nas equações governantes de um problema diversas grandezas do mesmo tipo, uma delas é escolhida como "representativa" e as demais são substituídas por sua relação com aquela. Este tipo especial de variável adimensional é denominado "fator de forma", por analogia com as relações entre comprimentos, adimensionais, que são necessários para descrever a geometria de um corpo, referindo-os a uma dimensão representativa.

Às vezes, é necessário recorrer a funções, expressas em forma adimensional, para descrever a distribuição contínua de grandezas físicas de um mesmo tipo. Por analogia com a descrição de um contorno geométrico em função de suas coordenadas, expressa em forma adimensional, essas funções são chamadas "funções de forma". Equações que definem a geometria das partes curvas de um corpo e equações constitutivas são exemplos de funções de forma.

Uma das principais aplicações da análise dimensional é o estabelecimento das condições de semelhança física, que devem relacionar os protótipos com os modelos utilizados em experiências. Para que um modelo possa representar o protótipo, isto é, para que os resultados obtidos em ensaios com modelos possam ser estendidos aos protótipos, é preciso 
que haja semelhança, ou correspondência, entre eles. A Fig. 28 traz um exemplo de modelamento em escala.
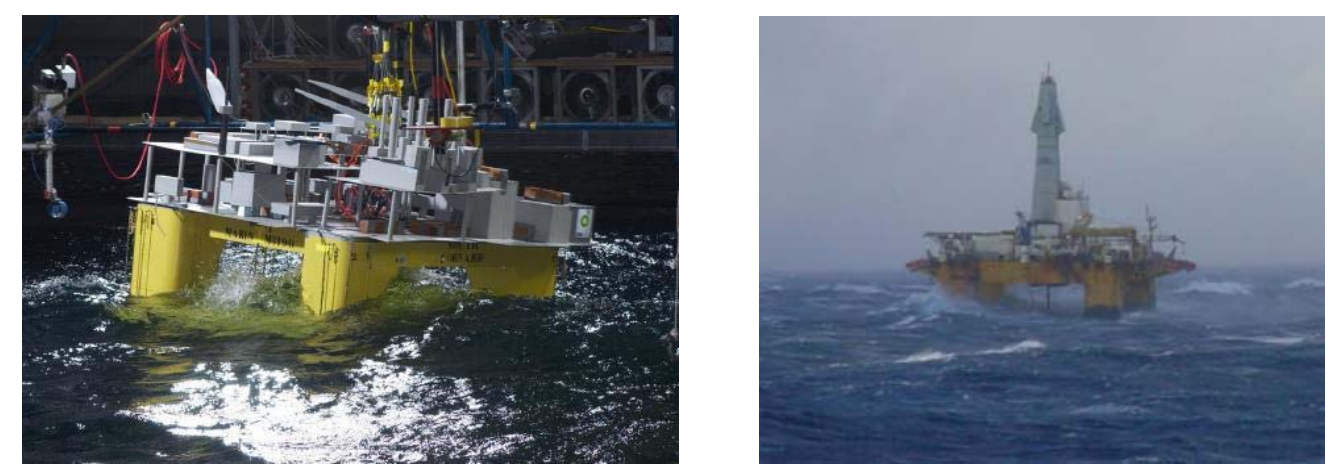

Figura 28 - Modelo e protótipo. Cortesia: Marin Inc.

Em tese, todos os números $\Pi$, fatores de forma e funções de forma devem ter no modelo os mesmos valores que apresentam no protótipo. Em muitos casos, todavia, introduzem-se distorções, isto é, adotam-se no modelo escalas diferentes para grandezas de um mesmo tipo e as conseqüências destas distorções devem ser cuidadosamente analisadas, para evitar erros de interpretação dos resultados.

Szirtes (1997) alerta para o fato de que alguns problemas são, geralmente, inapropriados para experimentação com modelos. Por exemplo:

- Propagação de rachaduras em estruturas;

- Efeitos de fluência;

- Efeitos adesivos (bond-splitting);

- Processos de encolhimento, anisotrópicos em geral, tal como ocorre com a madeira em função da variação da umidade.

Há ainda, segundo Szirtes (1997), algumas restrições no uso de modelos, a saber:

- Para modelar, é necessário entender a estrutura física básica do fenômeno a ser modelado, a ponto de somente as variáveis relevantes, mas todas as variáveis relevantes do problema serem consideradas. O conhecimento analítico detalhado de como as variáveis influenciam os resultados não é necessário - e isto é uma das características mais atraentes do método;

- O custo da experimentação com modelos deve ser realisticamente estimado;

- Se houver uma teoria que pode ser aplicada para prever confiavelmente o resultado da experimentação, então modelar é um esforço desnecessário;

- É possível modelar? Nem todos os fenômenos da natureza podem ser modelados. 
$\mathrm{Na}$ experimentação com modelos geralmente define-se como fator de escala, $S$, eq.(44), à relação entre a magnitude da grandeza $q$ no modelo e no protótipo. Se o modelo é reduzido, a escala geométrica é menor que a unidade.

$$
S_{q}=\frac{q_{m}}{q_{p}}=\frac{1}{\left(q_{p} / q_{m}\right)}=1:\left(q_{p} / q_{m}\right)
$$

Note-se que o fator de escala sempre se refere a um parâmetro particular. Não existe um "fator de escala do modelo". Existe, sim, por exemplo, fator de escala do coeficiente de Poisson, fator de escala da densidade, etc. Por outro lado, há uma relação, ou conjunto de relações, entre os fatores de escala relevantes para cada caso de modelamento - denominada, por definição, Lei do Modelo. Apesar de poder haver mais de uma relação entre os fatores de escala, há apenas uma Lei do Modelo. O uso de letras maiúsculas se deve à sua unicidade em caracterizar uma particular inter-relação entre o protótipo e seu modelo.

Langhaar (1951), por exemplo, obteve os seguintes grupos adimensionais para um modelo de barra esbelta sujeita a grandes deformações, tendo escolhido a força $F$, o momento $M$, o coeficiente de Poisson $v$, o módulo de elasticidade $E$, o comprimento $L$ e o deslocamento $\delta$ como parâmetros relevantes para o fenômeno:

$$
\prod_{1}=v \quad ; \quad \Pi_{2}=\frac{F}{E \cdot L^{2}} \quad ; \quad \prod_{3}=\frac{M}{F \cdot L}=\frac{M}{E \cdot L^{3}} \quad ; \quad \Pi_{4}=\frac{\delta}{L}
$$

A partir deste conjunto de adimensionais, eq.(45), obteve a seguinte Lei do Modelo, eq.(46), para barras esbeltas sujeitas a grandes deslocamentos:

$$
S_{v}=1 ; \quad S_{F}=S_{E} \cdot S_{L}^{2} ; \quad S_{M}=S_{F} \cdot S_{L}=S_{E} \cdot S_{L}^{3} ; \quad S_{\delta}=S_{L}
$$

Observe, mais uma vez, que a única variável dependente é o deslocamento $\delta$ e que ela aparece em apenas um dos números $\Pi$. Todas as outras devem ser conhecidas. Carneiro (1993) alerta para o fato de que escolher um conjunto errado de variáveis, ou pior, adicionar variáveis - ou constantes físicas - que não influenciam realmente o problema resultará em números adimensionais falsos que conduzirão, naturalmente, a conclusões erradas.

No estudo da mecânica temos usualmente duas possibilidades para formar o sistema de unidades: massa, comprimento, tempo [MLT] e força, comprimento, tempo [FLT]. No caso 
de processos dinâmicos, o uso de qualquer dos dois sistemas de três grandezas fundamentais é possível e satisfatório. Em processos estáticos, entretanto, as grandezas fundamentais independentes são apenas duas e a utilização de sistemas triplos requer alguns cuidados, como se verá adiante. Note que, por conveniência, Langhaar utilizou o sistema duplo [FL] - força, comprimento - para definição das eq.(45) - (46).

No estudo de deflexões estáticas de enrijecedores à flexão, sem considerar o peso próprio da estrutura, poder-se-ia construir a matriz dimensional da Tabela 5, na qual $L$ é um comprimento representativo. Tomando, então, duas variáveis independentes ( $E_{B S}$ e $L$, por exemplo) como fundamentais, um método prático é empregado para obtenção dos números adimensionais do problema. Veja, por exemplo, Szirtes (1997, p.163 e 474) para o método matricial ilustrado na Tabela 5.

Tabela 5 - Matriz dimensional para estudo estático de enrijecedores.

\begin{tabular}{|c|c|c|c|c|c|}
\hline Base [FL] & $F$ & $I_{B S}$ & $\kappa$ & $E_{B S}$ & $L$ \\
\hline $\mathrm{F}$ & 1 & 0 & 0 & 1 & 0 \\
\hline $\mathrm{L}$ & 0 & 4 & -1 & -2 & 1 \\
\hline$\Pi_{1}$ & 1 & 0 & 0 & -1 & -4 \\
\hline$\Pi_{2}$ & 0 & 1 & 0 & 0 & 1 \\
\hline$\Pi_{3}$ & 0 & 0 & 1 & 0 & -4 \\
\hline
\end{tabular}

Ou, ainda:

(a) $\quad \Pi_{1}=\left(E_{B S}\right)^{a_{1}} \cdot L^{a_{2}} \cdot F^{a_{3}}$

(b) $\quad \Pi_{2}=\left(E_{B S}\right)^{b_{1}} \cdot L^{b_{2}} \cdot\left(I_{B S}\right)^{b_{3}}$

(c) $\Pi_{3}=\left(E_{B S}\right)^{c_{1}} \cdot L^{c_{2}} \cdot \kappa^{c_{3}}$

De (a), temos:

$$
\begin{aligned}
& \Pi_{1}=\left(\mathrm{F}^{1} \cdot \mathrm{L}^{-2}\right)^{a_{1}} \cdot\left(\mathrm{L}^{1}\right)^{a_{2}} \cdot\left(\mathrm{F}^{1}\right)^{a_{3}}=\left[\mathrm{F}^{0} \cdot \mathrm{L}^{0}\right] \\
& \mathrm{F}^{\left(a_{1}+a_{3}\right)} \cdot \mathrm{L}^{\left(-2 \cdot a_{1}+a_{2}\right)}=\mathrm{F}^{0} \cdot \mathrm{L}^{0}
\end{aligned}
$$

Igualando os expoentes de mesma base, obtém-se um sistema de equações:

$$
\begin{aligned}
& a_{1}+a_{3}=0 \\
& -2 \cdot a_{1}+a_{2}=0
\end{aligned}
$$

Adota-se, então, para solução do sistema acima, $a_{1}=-1$ (por conveniência). Daí resulta: $a_{3}=1$ a $a_{2}=2$. Logo: $\Pi_{1}=\frac{F}{E_{B S} \cdot L^{2}}$. 
Adotando procedimento análogo para $\Pi_{2}$ e $\Pi_{3}$, e lembrando que $\theta_{L}$ é uma variável relevante do problema, obtém-se os números adimensionais do problema, eq. (47):

$$
\Pi_{1}=\frac{F}{E_{B S} \cdot L^{2}} \quad ; \quad \Pi_{2}=\frac{I_{B S}}{L^{4}} \quad ; \quad \Pi_{3}=\kappa \cdot L \quad ; \quad \Pi_{4}=\theta_{L}
$$

Apesar de não comparecer na matriz dimensional, pois é adimensional, $\theta_{L}$ forma naturalmente um número $\Pi\left(\Pi_{4}\right.$, que como cada um dos outros, deverá ser o mesmo no modelo e no protótipo). Note ainda que o número $\Pi_{2}$ indica que a escala do momento de inércia da seção transversal do modelo deverá ser proporcional à quarta potência da escala geométrica geral do protótipo, independente da forma da seção. E esta é a única restrição quanto à escolha da seção transversal do modelo, uma vez que a área resistente à cortante não foi listada como variável relevante na matriz dimensional do problema.

É possível utilizar-se uma base tripla para o estudo do mesmo problema, desde que se considere o peso próprio da estrutura e se especifique a massa específica do material e a aceleração da gravidade, separadamente, quando da construção da matriz dimensional.

Uma possível escolha para a matriz dimensional assim formada é apresentada na Tabela 6, a seguir.

Tabela 6 - Matriz dimensional para estudo estático de enrijecedores, considerando seu peso próprio.

\begin{tabular}{|c|c|c|c|c|c|c|c|}
\hline Base [MLT] & $F$ & $I_{B S}$ & $\rho$ & $\kappa$ & $E_{B S}$ & $g$ & $L$ \\
\hline $\mathrm{M}$ & 1 & 0 & 1 & 0 & 1 & 0 & 0 \\
\hline $\mathrm{L}$ & 1 & 4 & -3 & -1 & -1 & 1 & 1 \\
\hline $\mathrm{T}$ & -2 & 0 & 0 & 0 & -2 & -2 & 0 \\
\hline$\Pi_{1}$ & 1 & 0 & 0 & 0 & -1 & 0 & -2 \\
\hline$\Pi_{2}$ & 0 & 1 & 0 & 0 & 0 & 0 & -4 \\
\hline$\Pi_{3}$ & 0 & 0 & 1 & 0 & -1 & 1 & 1 \\
\hline$\Pi_{4}$ & 0 & 0 & 0 & 1 & 0 & 0 & 1 \\
\hline
\end{tabular}

Para a obtenção dos números $\Pi$, adotamos $E_{B S}, g$ e $L$, por exemplo, como variáveis fundamentais. Daí resulta:

$$
\Pi_{1}=\frac{F}{E_{B S} \cdot L^{2}} ; \quad \Pi_{2}=\frac{\rho \cdot g \cdot L}{E_{B S}} ; \quad \Pi_{3}=\frac{I_{B S}}{L^{4}} ; \quad \Pi_{4}=\kappa \cdot L ; \quad \Pi_{5}=\theta_{L}
$$


Observe que a utilização do artifício (necessário) de separação do peso próprio $\gamma$ em duas outras variáveis (massa específica $\rho$ e aceleração da gravidade $g$ ) na construção da matriz dimensional evitou que ela se tornasse singular, o que equivale a dizer que se criou uma base tripla independente (necessária) a partir da qual se formaram os números $\Pi$ desejados.

O número $\Pi_{1}$ é conhecido por "número de Hooke", sendo um dos que comparecem na eq.(41); $\Pi_{2}$ é o "número de Galileu modificado" e deverá ser descartado se o peso da estrutura for negligenciado. Neste caso, como esperado, a eq.(48) passa a ter os mesmos adimensionais da eq.(47).

O número de Galileu vem do estudo da resistência das estruturas, em que a incógnita é o conjunto de forças aplicadas capaz de provocar a ruína da estrutura. Em tal contexto, o número de Galileu, dado por $N_{G a l}=\frac{\rho \cdot g \cdot L}{\sigma}=\frac{\gamma \cdot L^{3}}{\sigma \cdot L^{2}}$, mede a influência do peso próprio da estrutura (forças aplicadas), que cresce ao cubo com suas dimensões, mais rapidamente que sua resistência, que cresce com suas dimensões apenas ao quadrado.

Os números $\Pi$, e também outros números adimensionais (fatores de forma, normalizações, etc.) podem e devem ser utilizados para a apresentação gráfica de resultados de pesquisas teóricas ou experimentais. Como o número de gráficos requeridos para ilustrar um determinado problema varia com o expoente do seu número de variáveis representativas, a economia é significativa.

Além disso, a comparação entre resultados torna-se imediata, permitindo, por exemplo, a sobreposição de gráficos análogos (impossível de outro modo), fazendo com que a análise paramétrica que se apresenta no próximo capítulo se torne de fácil compreensão e muito mais proveitosa. 


\section{ANÁLISE PARAMÉTRICA}

\subsection{CONSIDERAÇÕES GERAIS}

O código proposto neste trabalho, aliado à apresentação gráfica adimensional dos dados, permite a avaliação paramétrica de enrijecedores à flexão complexos, mostrando os efeitos da variação de cada um de seus parâmetros geométricos na resposta estrutural do conjunto linha flexível e enrijecedor à flexão. Neste capítulo analisaremos a geometria típica de um enrijecedor à flexão cônico complexo, conforme ilustrado na Fig. 29 e cujos dados encontram-se especificados na Tabela 7.

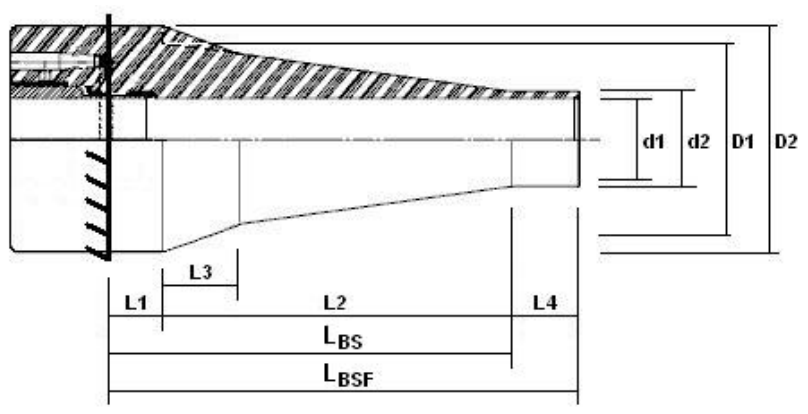

Figura 29 - Enrijecedor de geometria complexa.

Tabela 7 - Enrijecedor à flexão hipotético.

\begin{tabular}{llll}
\hline Propriedades & Símbolo & Valor & Unidade \\
\hline Rigidez à Flexão da Linha & $E I_{P}$ & 10 & {$\left[\mathrm{kNm}^{2}\right]$} \\
Módulo de Young do Enrijecedor & $E_{B S}$ & 45 & {$[\mathrm{MPa}]$} \\
Comprimento Total do Modelo & $L$ & 3,262 & {$[\mathrm{~m}]$} \\
Comprimento da $1^{\text {a }}$ Seção Cilíndrica & $L_{1}$ & 0,200 & {$[\mathrm{~m}]$} \\
Comprimento da Seção Cônica & $L_{2}$ & 1,775 & {$[\mathrm{~m}]$} \\
Comprimento da $1^{\text {a Seção Cônica }}$ & $L_{3}$ & 1,076 & {$[\mathrm{~m}]$} \\
Comprimento da $2^{\text {a }}$ Seção Cilíndrica & $L_{4}$ & 0,350 & {$[\mathrm{~m}]$} \\
Diâmetro Máx. Original do Enrijecedor & $D_{1}$ & 0,650 & {$[\mathrm{~m}]$} \\
Diâmetro Máx. Aumentado do Enrijecedor & $D_{2}$ & 0,737 & {$[\mathrm{~m}]$} \\
Diâmetro Externo da Linha & $d_{1}$ & 0,180 & {$[\mathrm{~m}]$} \\
Diâmetro Ext. do Enrijecedor na Extremidade Livre & $d_{2}$ & 0,234 & {$[\mathrm{~m}]$} \\
Força Máx. Aplicada em $s=L$ & $F_{\max }$ & 500 & {$[\mathrm{kN}]$} \\
Força Min. Aplicada em $s=L$ & $F_{\min }$ & 62,5 & {$[\mathrm{kN}]$} \\
Ângulo entre $F$ e o eixo $x$ & $\theta_{L}$ & 45 & {$\left[{ }^{\circ}\right]$} \\
Limite de Curvatura da Linha Flexível & $\kappa_{l i m}$ & 0,500 & {$[1 / \mathrm{m}]$} \\
\hline
\end{tabular}


Observe que o comprimento total do modelo, $L$, é a soma do comprimento total do enrijecedor, $L_{B S F}$, com o comprimento "suficiente", $l_{s}$, necessário para garantir a precisão desejada nos cálculos. $\mathrm{O}$ valor de $L$ indicado na Tabela 7 é portanto um valor para referência, resultante daquele conjunto particular de dados. Nos cálculos feitos nas análises que se seguem, $L$ variou entre 2,907 m (para o menor valor $L_{2}$ ) e 3,617 m (para o maior valor de $L_{2}$ ). O valor de $L$ é dado pela eq.(49) e o comprimento suficiente $l_{s}$ é dado pela eq.(9).

$$
L=L_{B S F}+l_{s}
$$

As relações geométricas entre os outros comprimentos e diâmetros podem ser obtidas na Fig. 29. Cumpre ressaltar, por fim, que se adotou que não há folga entre a linha flexível e o enrijecedor.

\subsection{LEVANTAMENTO DOS ADIMENSIONAIS DO PROBLEMA}

$\mathrm{Na}$ análise estrutural de enrijecedores à flexão, as seguintes variáveis podem ser apontadas como relevantes: $L, L_{1}, L_{2}, L_{3}, L_{4}, L_{B S}, L_{B S F}, l_{s}, D_{1}, D_{2}, d_{1}, d_{2}, E_{B S}, E I_{P}, F, \theta_{L}, \kappa$. Destas variáveis, apenas uma é dependente - a curvatura $\kappa$. Todos as outras são independentes - dados do problema, portanto.

Note que figuram na lista acima grandezas do mesmo tipo, logo podemos reduzi-la a apenas sete variáveis representativas: $L, D, E_{B S}, E I_{P}, F, \theta_{L}, \kappa$. Além disso, para manutenção da coerência com o restante do trabalho, adota-se o sistema de unidades do SI - [MLT] triplo, portanto - o que não influencia negativamente nos resultados, como mostrado no Capítulo 5, eq.(47) - (48). A matriz dimensional do problema se torna então semelhante àquela da Tabela 6, com a adição da rigidez flexional do tubo, $E I_{P}$, aqui considerada. Poder-se-ia adotar a mesma base $\left(E_{B S}, g\right.$ e $\left.L\right)$ e obter os mesmos adimensionais lá obtidos, mais um.

Este processo, todavia, não será repetido aqui, já que para a apresentação dos gráficos da análise paramétrica que se segue, interessa-nos notar que números adimensionais podem ser obtidos a partir de outros adimensionais e que, por exemplo, o adimensional $\kappa / \kappa_{\text {lim }}$ é mais interessante que o adimensional original $\kappa \cdot L_{B S}$ na apresentação dos dados de curvatura pois aponta diretamente se a curvatura limite da linha está sendo ultrapassada, ou não.

A eq. (50) mostra como $\kappa / \kappa_{\text {lim }}$ decorre da razão de dois outros adimensionais: 


$$
\Pi_{4}=\kappa \cdot L \Rightarrow \frac{\kappa \cdot L_{B S}}{\kappa_{L I M} \cdot L_{B S}}=\frac{\kappa}{\kappa_{L I M}}
$$

Optou-se então por mostrar resultados de curvatura normalizados pela curvatura máxima de projeto da linha (como descrito acima) - em função do comprimento de arco $s$ normalizado pelo comprimento original do enrijecedor. Esta normalização facilita a comparação deste trabalho com outros, sobre o mesmo tema, e mostra-se mais informativo devido a características do próprio enrijecedor, como se verá adiante.

\subsection{INFLUÊNCIA DO PARÂMETRO $L_{4}$ NA RESPOSTA DO CONJUNTO}

A avaliação paramétrica é iniciada pelo comportamento do conjunto em face de mudanças na extremidade não engastada.

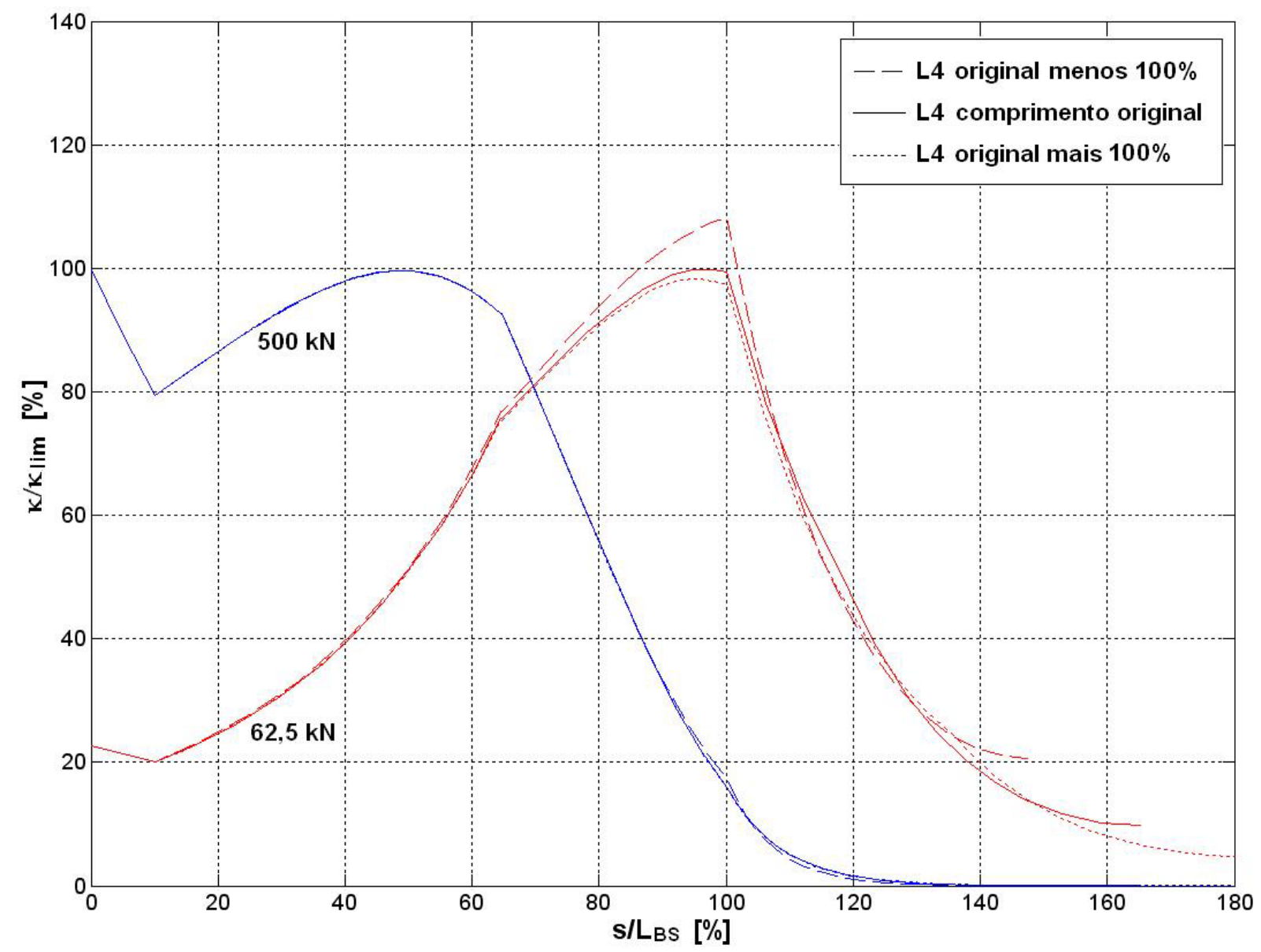

Figura 30 - Efeito da variação do parâmetro $L_{4}$ na curvatura do conjunto. 
A Fig. 30 mostra que a variação do parâmetro $L_{4}$ tem efeito localizado na curvatura do conjunto especificado na Tabela 7. Mesmo com uma variação de $100 \%$ no comprimento $L_{4}$, não houve alteração significativa no comportamento de curvatura para $F_{\text {máx }}$. Ou seja, apenas para o menor valor de $F$ pôde-se observar alguma variação na curvatura do conjunto. Para entender melhor este comportamento, a Fig. 31 traz o resultado de vários cômputos do código $\operatorname{com} F=F_{\min }=62,5 \mathrm{kN}=$ constante, e diferentes comprimentos do parâmetro $L_{4}$, adicionados à extremidade não-engastada do enrijecedor, com $L_{4}=0$, inicialmente, e outras variáveis, como indicado na Tabela 7.

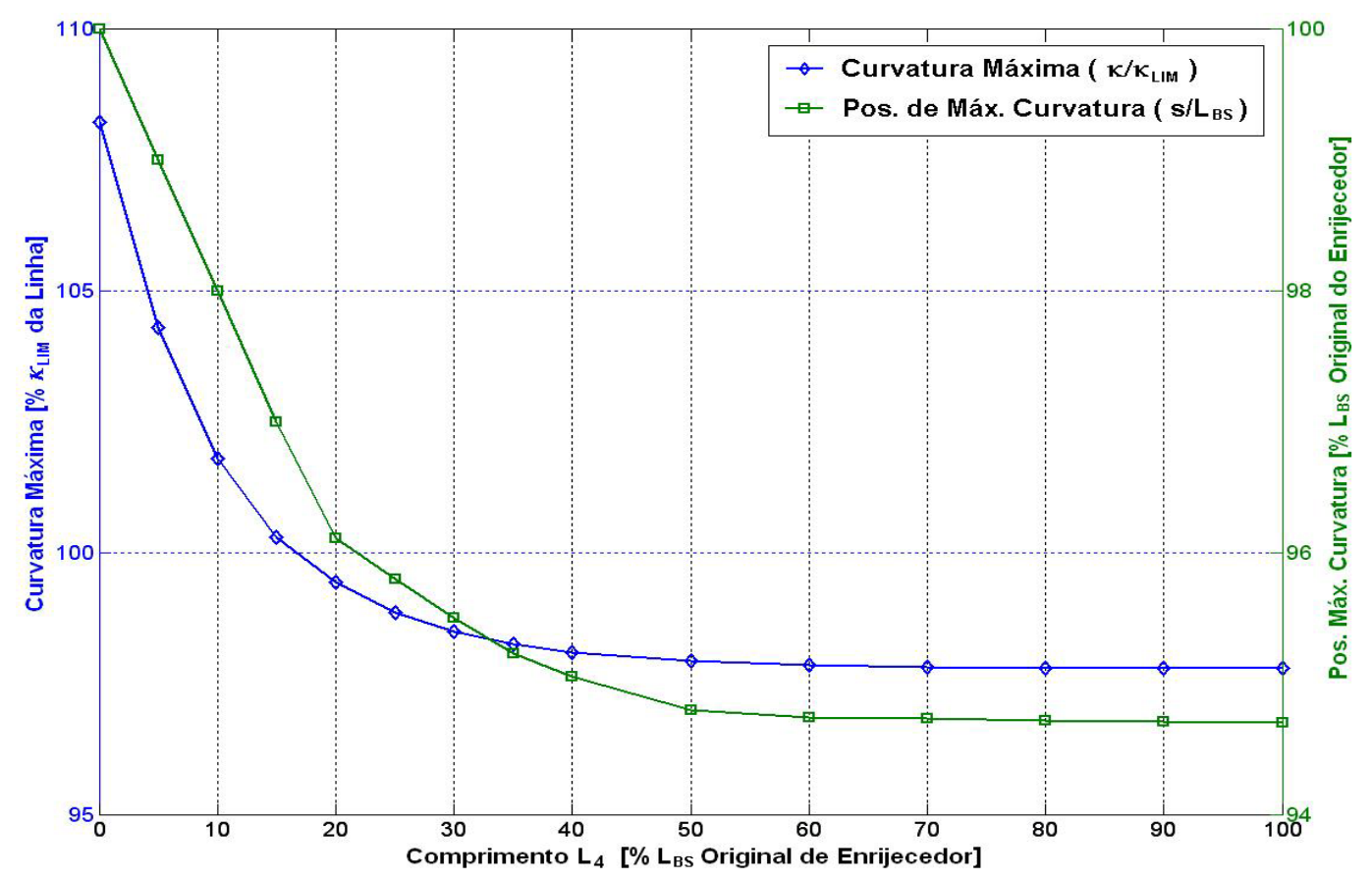

Figura 31 - Efeito da extensão cilíndrica $L_{4}$ na curvatura do conjunto com $F=F_{\min }$.

Como podemos observar na Fig. 31, o aumento do comprimento $L_{4}$ permite uma pequena redução na curvatura máxima do conjunto, porém suficiente para evitar que a curvatura máxima seja excedida. Observa-se também que se tomarmos $L_{4} / L_{B S} \cong 0,2$ já teremos uma redução significativa na curvatura máxima, havendo pouco benefício para valores maiores de $L_{4} / L_{B S}$. Além disto, também é possível verificar que a posição em que ocorre a máxima curvatura é em torno da extremidade não-engastada do enrijecedor, o que nos permite concluir que o propósito da extensão $L_{4}$ é proteger a instalação contra flexão excessiva próximo a esta região, quando o conjunto é submetido a pequenos valores de tração. Mostrase também que a posição de máxima curvatura não muda significantemente com a inserção da seção $L_{4}$, tendo movido aproximadamente $5 \%$ em direção à extremidade engastada. 


\subsection{CONSIDERAÇÕES SOBRE O COMPRIMENTO $L_{B S}$ DO ENRIJECEDOR}

Antes de se prosseguir com a avaliação dos demais parâmetros, algumas considerações são necessárias: Boef e Out (1990) propuseram que um enrijecedor à flexão deve ter um comprimento total mínimo, eq.(51), e em sua formulação assumiram que a configuração deformada final do conjunto aproxima-se daquela de um setor de circunferência, sugerindo que um enrijecedor "ideal" tornaria constante a curvatura do conjunto ao longo do comprimento do enrijecedor.

$$
L_{B S_{\min }} \geq \frac{\theta_{L}}{\kappa_{\text {lim }}}
$$

Note, entretanto, que a eq.(37) indica que a integração da curvatura ao longo do comprimento total do modelo deve ser igual a $\theta_{L}$; assim, uma proposição adicional é possível: otimizar a seção cônica do enrijecedor de forma que os gráficos de curvatura para ambos os casos extremos de carregamento abarquem a maior área possível dentro do comprimento $L_{B S}$ do enrijecedor.

Admite-me, neste caso, que o comprimento $L_{1}$ seja fixo e determinado pela configuração da instalação, mais especificamente pela configuração do "capacete". Admite-se como aproximação que a seção que contém o toróide (Fig. 12 e 29) corresponda à seção de engastamento do conjunto. Assim, restam basicamente dois parâmetros de comprimento com que trabalhar: $L_{2}$ e $L_{3}$.

Os dois valores extremos de $F$ serão considerados em todas as análises pois, como pudemos notar pela Fig. 30, $F_{\text {máx }}$ está associado aos maiores valores de curvatura junto ao engastamento, enquanto $F_{\min }$ está associado aos maiores valores de curvatura junto à extremidade livre do enrijecedor.

\subsection{INFLUÊNCIA DO PARÂMETRO $L_{2}$ NA RESPOSTA DO CONJUNTO}

Neste item, analisaremos o efeito de mudanças no parâmetro $L_{2}$ no comportamento estrutural do conjunto. Como ponto de partida para nossa análise, consideremos o enrijecedor, hipoteticamente ótimo, especificado na Tabela 7 e ilustrado na Fig. 32. 


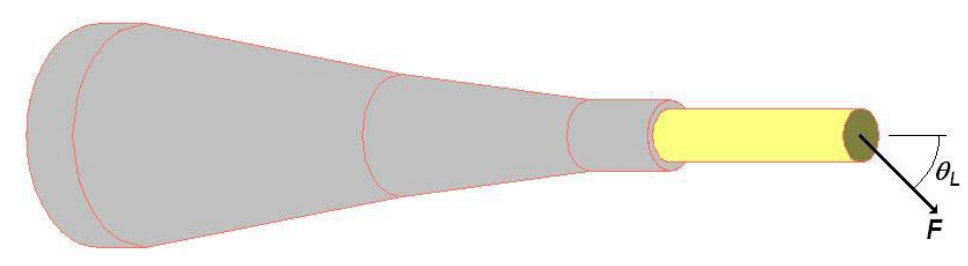

Figura 32 - Perspectiva do enrijecedor especificado na Tabela 7.

O efeito da variação do parâmetro $L_{2}$ é mostrado na Fig. 33, a seguir, obtida a partir dos resultados de análise para três valores distintos de $L_{2}$.

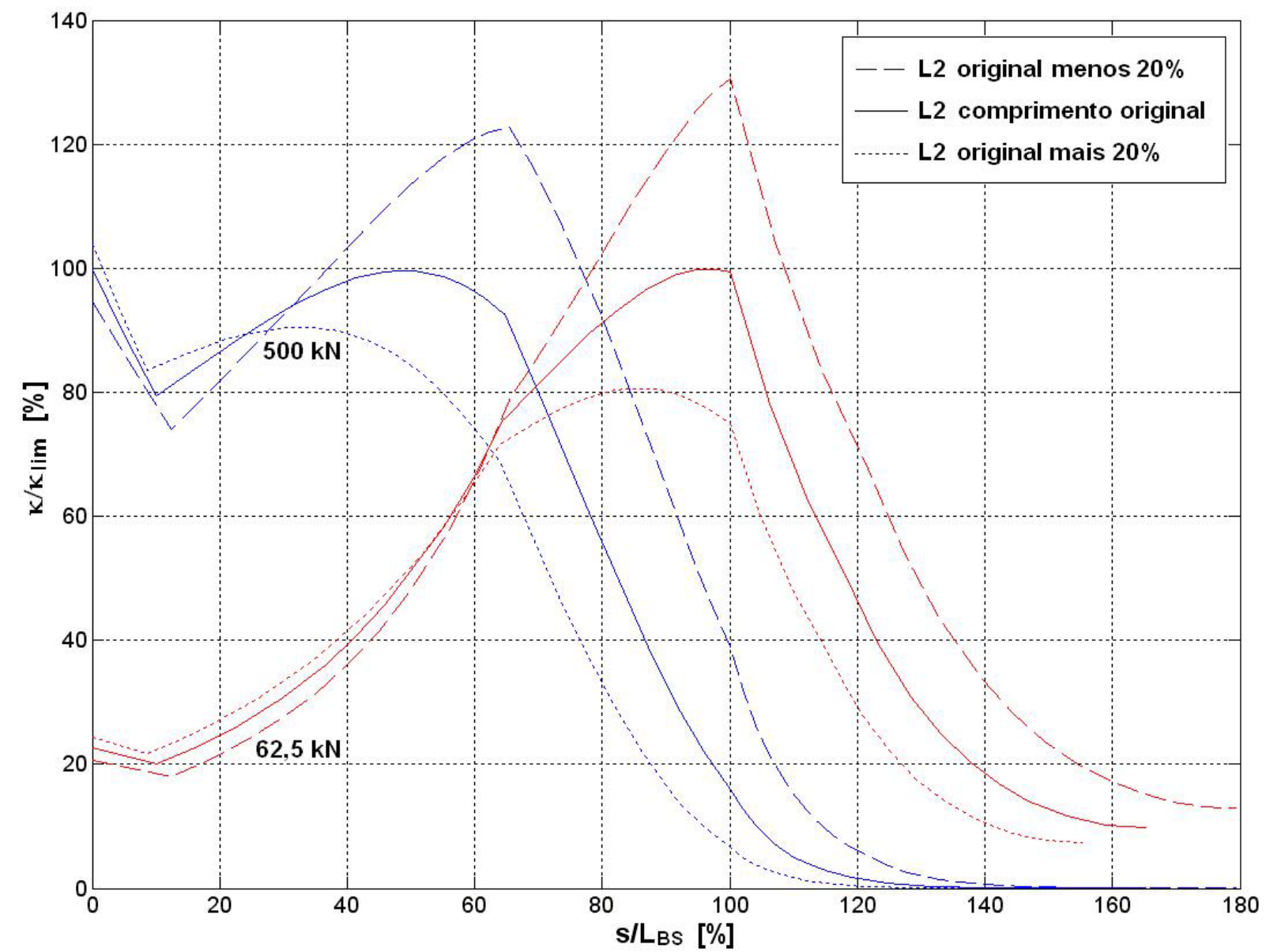

Figura 33 - Efeito da variação do parâmetro $L_{2}$ na curvatura do conjunto.

Deve-se observar que o comprimento $L_{2}$ compreende toda a porção cônica do enrijecedor e, como podemos observar da Fig. 33, a distribuição de curvatura ao longo do eixo central é bastante sensível a variações deste parâmetro. Mais especificamente, a Fig. 33 mostra que, quando $L_{2}$ foi encurtado em $20 \%$ de seu comprimento original, ambos os picos de curvatura cresceram entre $20 \%$ e $30 \%$. O oposto ocorreu para $L_{2}$ aumentado, com picos de curvatura entre $10 \%$ e $20 \%$ menores (na região compreendida por $L_{2}$ ). Note-se ainda que há um pequeno aumento da curvatura, próximo ao engastamento, para ambos os casos. 
Deve-ser ressaltar ainda que a análise acima considera $L_{2}$ e $L_{3}$ como variáveis independentes. Assim, a mudança do parâmetro $L_{2}$ altera não só o comprimento do enrijecedor, mas também a "razão de aspecto" de sua seção cônica. É possível, naturalmente, alterar o programa para manter a razão de aspecto da seção cônica fazendo $L_{3}=L_{2} / n$, sendo $n$ um parâmetro a ser usado para definir o comprimento $L_{3}$.

\subsection{INFLUÊNCIA DO PARÂMETRO $L_{3}$ NA RESPOSTA DO CONJUNTO}

O parâmetro $L_{3}$ altera o perfil - ou a "razão de aspecto" - da seção cônica do enrijecedor, mantendo inalterado seu comprimento total, já que $L_{3}$ é uma fração do comprimento $L_{2}$, o qual define o comprimento total da seção cônica. Seu efeito na distribuição de curvaturas pode ser avaliado através da Fig. 34, a seguir.

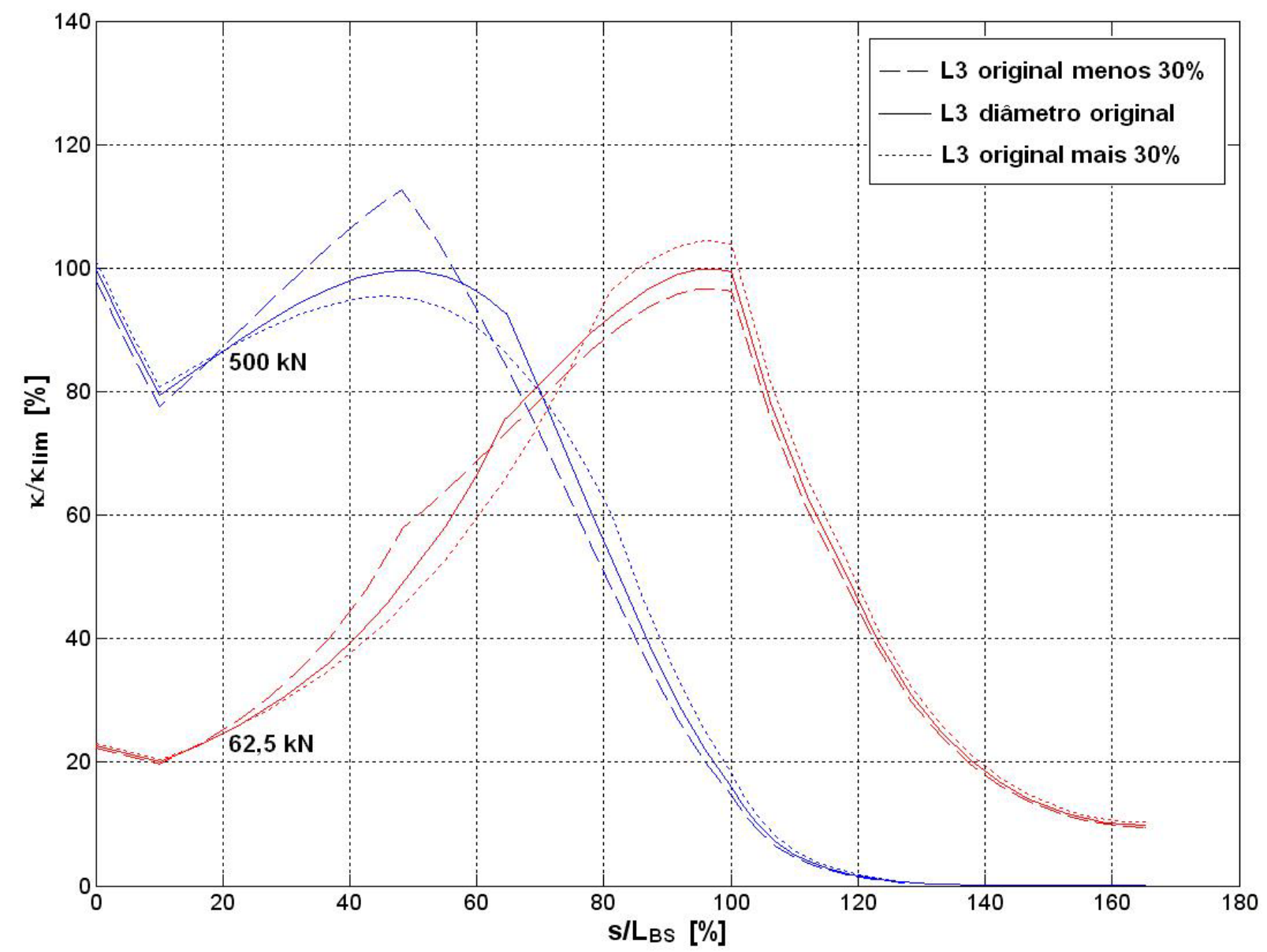

Figura 34 - Efeito da variação do parâmetro $L_{3}$ na curvatura do conjunto.

A Fig. 34 mostra que uma redução de $30 \%$ no parâmetro $L_{3}$ faz com que o pico de curvatura cresça aproximadamente $10 \%$ para o maior carregamento, e decresça aproximadamente $3 \%$ para o menor valor de $F$. Comportamento inverso (mas não 
proporcional) é observado para um aumento de $30 \%$ no comprimento $L_{3}$. Os resultados obtidos indicam, portanto, que a relação $L_{3} / L_{2} \cong 0,6$ (ou $L_{3} / L_{\mathrm{BS}} \cong 0,54$ ) original (dados da Tabela 7), leva a uma melhor distribuição de curvaturas, considerando os dois carregamentos extremos $\left(F_{\text {máx }}\right.$ e $\left.F_{\text {min }}\right)$. Deve-se observar ainda que não houve mudanças significativas nos valores da curvatura, próximo ao engastamento.

\subsection{INFLUÊNCIA DO PARÂMETRO $D_{2}$ NA RESPOSTA DO CONJUNTO}

Adicionalmente aos parâmetros de comprimento longitudinal, os diâmetros do enrijecedor também podem ser alterados e seus efeitos na distribuição da curvatura, analisados. Assim, considerando fixos os demais parâmetros, verifiquemos inicialmente a influência do diâmetro $D_{2}$ (diâmetro aumentado do enrijecedor) na distribuição de curvatura.

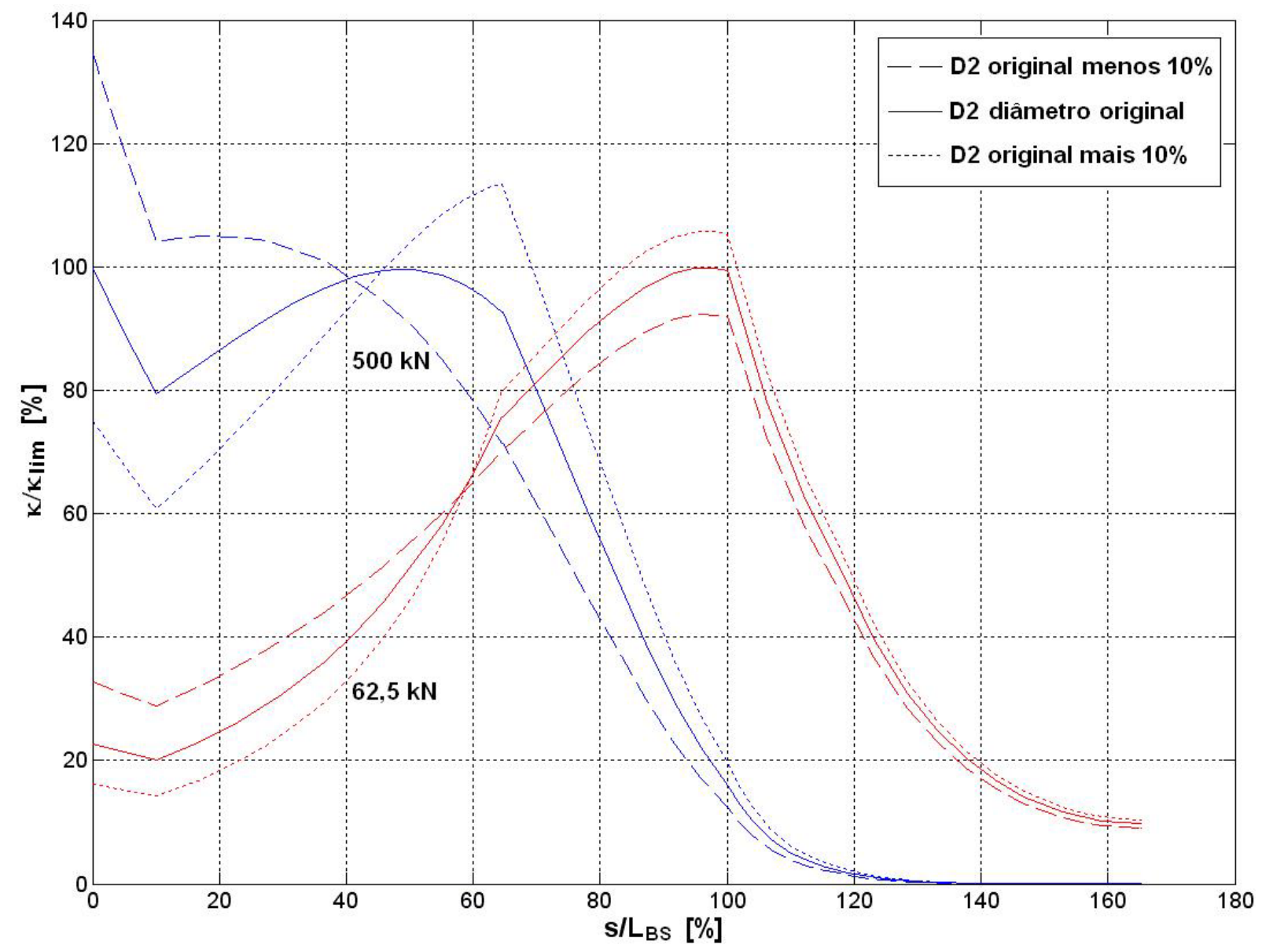

Figura 35 - Efeito da variação do parâmetro $D_{2}$ na curvatura do conjunto. 
Como pode ser observado na Fig. 35, variações da ordem de 10\%, para mais ou para menos, no valor de $D_{2}$ já geram mudanças significativas na distribuição de curvatura, principalmente junto ao engastamento do conjunto.

É importante notar que um aumento em $D_{2}$ não é necessariamente benéfico: apesar de o valor de curvatura no engastamento ter diminuído bastante com o aumento de $10 \%$ no valor original de $D_{2}$, seu pico para $F_{\text {máx }}$ excedeu o limite de curvatura da linha flexível na posição aproximada de $60 \%$ de seu comprimento, i.e. na seção de transição entre as duas partes cônicas. Observa-se ainda que um aumento no diâmetro $D_{2}$ também não favorece a distribuição de curvaturas para o caso em que a força $F_{\text {min }}$ é aplicada, uma vez que a curvatura limite é ultrapassada nas proximidades de $s=L_{B S}$.

Com relação aos efeitos da diminuição no diâmetro $D_{2}$, pode-se observar que tal diminuição favorece a distribuição de curvatura para o caso em que $F=F_{\min }$, mas é bastante prejudicial quando $F=F_{m a ́ x}$, aumentando a curvatura máxima em mais de $30 \%$ além da curvatura limite neste caso.

Os resultados obtidos parecem apontar que o diâmetro $D_{2}$ original (ligado ao adimensional $D_{2} / L_{\mathrm{BS}} \cong 0,37$ ) leva a uma melhor distribuição de curvaturas nos casos extremos de força.

\subsection{INFLUÊNCIA DO PARÂMETRO $D_{1}$ NA RESPOSTA DO CONJUNTO}

Avaliam-se, em seguida, os efeitos do parâmetro $D_{1}$ 


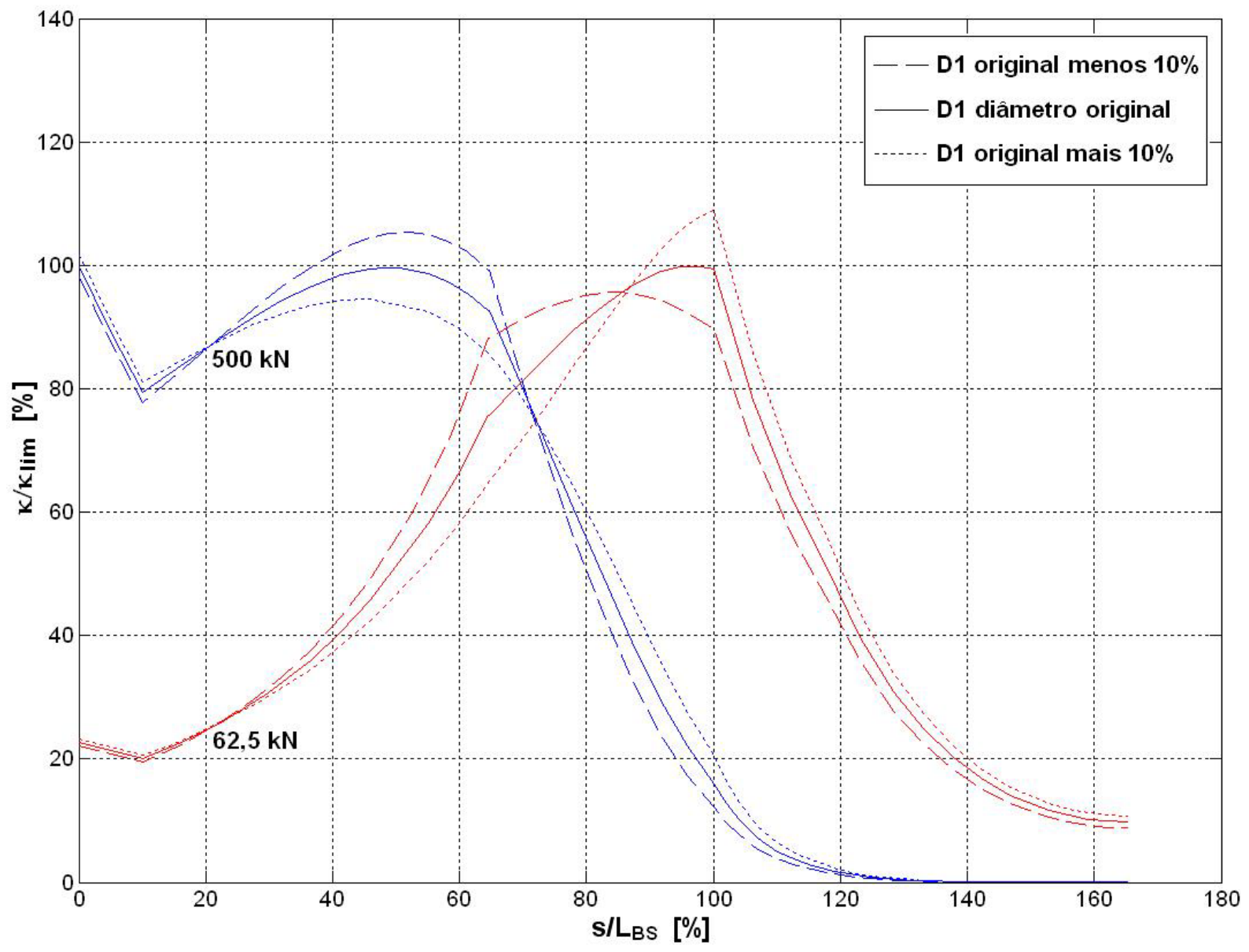

Figura 36 - Efeito da variação do parâmetro $D_{1}$ na curvatura do conjunto.

O aumento de $10 \%$ no parâmetro $D_{1}$ mostrado na Fig. 36 resultou em um aumento no pico de curvatura para o menor carregamento, e em diminuição do pico para o carregamento de maior valor - sem variação apreciável no valor de curvatura junto ao engastamento, em ambos os casos. Note que seus efeitos são semelhantes àqueles provocados por variações em $L_{3}$, com a diferença que o pico mais acentuado tem ocorrência inversa - com $L_{3}$ ele se dá com $F_{\text {máx }}$ e $\operatorname{com} D_{1}, \operatorname{com} F_{\min }$.

\subsection{INFLUÊNCIA DO PARÂMETRO $d_{2}$ NA RESPOSTA DO CONJUNTO}

Passando agora para uma avaliação do efeito da variação do parâmetro $d_{2}$ na curvatura, observamos que a Fig. 37, a seguir, mostra que uma diminuição de $20 \%$ no diâmetro original da extremidade não engastada do enrijecedor gerou curvas mais suaves, todavia com um aumento de aproximadamente $10 \%$ nos valores dos picos de curvatura para ambos os casos de carregamento analisados. $\mathrm{O}$ aumento do diâmetro da extremidade não 
engastada do enrijecedor, por outro lado, gerou resposta de curvatura bastante irregular para o carregamento de menor valor e ligeiro aumento no valor de curvatura junto ao engastamento.

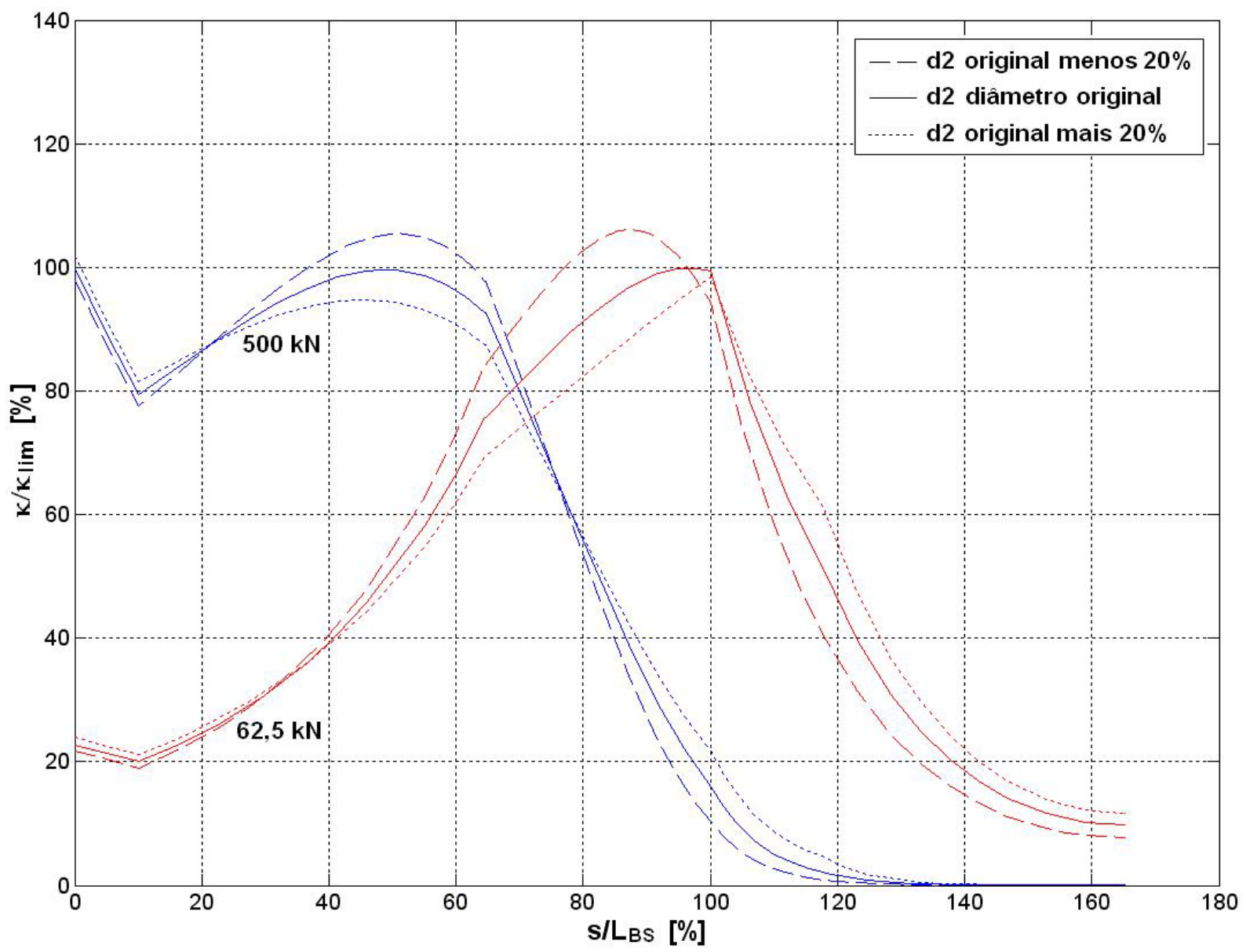

Figura 37 - Efeito da variação do parâmetro $d_{2}$ na curvatura do conjunto.

Observa-se, então, que a distribuição da curvatura do conjunto estudado (linha e enrijecedor), submetido a casos extremos de carregamento, é afetada de forma mais significativa por apenas dois dos parâmetros geométricos estudados: seu comprimento total $L_{2}$ e seu diâmetro máximo $D_{2}$.

Não obstante, as contribuições dos demais parâmetros geométricos não devem ser descartadas. Ao contrário, as sutilezas das respostas indicam oportunidades para otimização da geometria do enrijecedor à flexão que, nas aplicações práticas, depende também de outras variáveis além da distribuição da curvatura, apenas.

\subsection{INFLUÊNCIA DO PARÂMETRO $E_{B S}$ NA RESPOSTA DO CONJUNTO}

Por fim, é importante observar que toda a formulação aqui apresentada, e implementada no código utilizado na avaliação paramétrica geométrica acima, foi feita 
considerando material elástico linear, com módulo de elasticidade fixo (igual ao módulo secante à curva tensão-deformação do material em $10 \%$ da deformação). É igualmente importante, então, verificar quais as implicações desta hipótese. Neste sentido, para completude desta análise, apresenta-se a seguir o efeito da variação do módulo de elasticidade na curvatura.

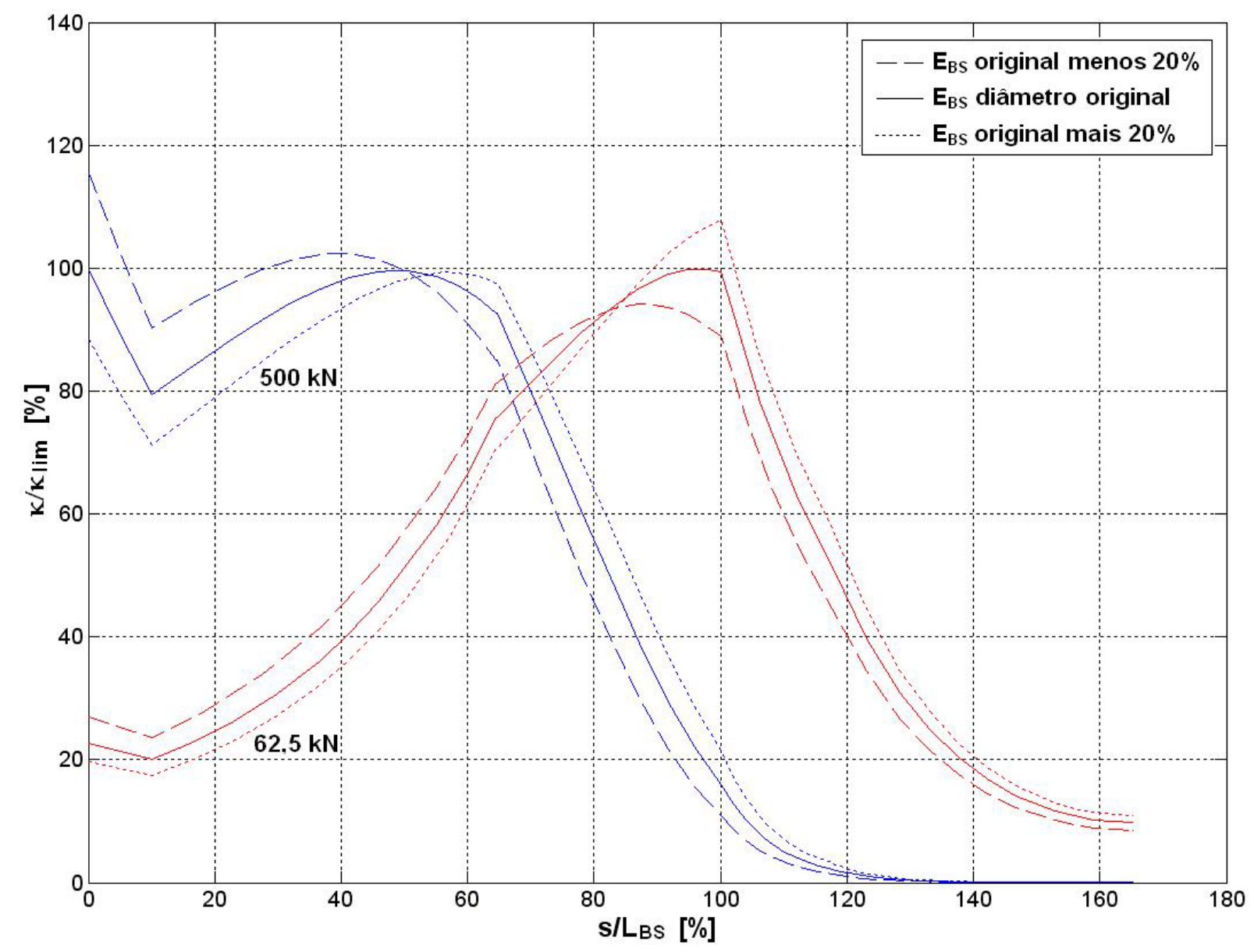

Figura 38 - Efeito da variação do parâmetro $E_{\mathrm{BS}}$ na curvatura do conjunto.

Nota-se, a partir da Fig. 38, que há significativas alterações nos valores de curvatura frente às mudanças em $E_{B S}$ e verifica-se que um aumento no valor do módulo de elasticidade não leva necessariamente a um menor pico de curvatura, como podemos verificar na distribuição de curvatura obtida para o caso em que $F=F_{\min }$ (com aumento de cerca de $8 \%$ em relação ao pico obtido para o módulo de elasticidade inicialmente adotado).

Nota-se, desta forma, que correta estimativa do módulo de elasticidade é essencial para a análise estrutural de enrijecedores à flexão e suas implicações devem ser cuidadosamente avaliadas. 


\section{CONCLUSÕES}

Este trabalho apresentou uma revisão da formulação analítica para a avaliação estrutural linear elástica de enrijecedores à flexão submetidos a carregamentos extremos; Examinou também questões normativas e aspectos de análise dimensional relacionados ao projeto destes acessórios.

Notou-se que o modelo proposto é governado por uma equação diferencial ordinária não-linear de segunda ordem com coeficientes variáveis, resultando em um problema matemático de valor de contorno cuja solução analítica não é conhecida.

Um novo código escrito em Matlab® para solução numérica do problema de valor de contorno assim produzido (sem necessidade de convertê-lo em problema de valor inicial equivalente) fora então apresentado e sua robustez, comprovada. Com este código, procedeuse a uma avaliação estrutural paramétrica (geométrica) de um enrijecedor à flexão de geometria complexa em uma instalação típica, sujeita a carregamentos extremos.

O resultado desta avaliação mostra que, dos sete parâmetros geométricos de um enrijecedor cônico complexo típico, dois têm influência mais significativa na distribuição da curvatura do conjunto linha-enrijecedor: seu comprimento total $L_{2}$ e seu diâmetro máximo $D_{2}$. A avaliação mostrou, por outro lado, sutilezas de comportamento que podem, eventualmente, ser utilizadas para otimizar o projeto destes equipamentos.

Este trabalho não avaliou efeitos não lineares do comportamento do material do enrijecedor ou o dimensionamento da extremidade não engastada para resistir ao rasgamento do material ou, ainda, como prevê a norma, a ovalização naquela extremidade. Não obstante, é possível melhorar o código e implementar, por exemplo, a formulação para materiais que não seguem a lei de Hooke, sugerida por Timoshenko (1975, p.336), e as equações para mudança no diâmetro de anéis circulares, encontradas em Young e Budinas (2002, p.325). Estas implementações, a propósito, ficam como sugestão para trabalhos futuros. Sugere-se, ainda, como objeto de novas pesquisas, a comparação dos resultados obtidos com o código assim implementado com análises mais modernas com elementos finitos.

Um dos atrativos do código apresentado, além de sua robustez, é a facilidade com que permite avaliar novas geometrias, mesmo as não-cônicas ou com variações bruscas. Para averiguar a viabilidade de uma nova proposta rapidamente, basta inserir as novas equações de forma e suas derivadas nas linhas do código. O resultado é produzido em segundos. 


\section{REFERÊNCIAS}

AMERICAN PETROLEUM INSTITUTE. API RP 17B: recommended practice for flexible pipe. Houston, 2002. 166 p.

AMERICAN PETROLEUM INSTITUTE. API SPEC 17J: specification for unbonded flexible pipe. Houston, 1999. 52 p.

BATHE, K-J. Finite element procedures. $1^{\text {st }}$ ed. New Jersey: Prentice-Hall, 1996. 1037 p.

BARLTROP, N. D. P. (Ed.). Floating Structures: a guide for design and analysis. CMPT - The Centre for Marine and Petroleum Technology. Houston: Oilfield Publications, 1998. 2v.

BOEF, W. J. C.; OUT, J. M. M. Analysis of a flexible riser top connection with bend restrictor. In: PROCEEDINGS OF THE $22^{\text {ND }}$ ANNUAL OFFSHORE TECHNOLOGY CONFERENCE, 1990, Houston: OTC 6436. p.131-142.

CAIRE, M. Análise de enrijecedores à flexão. 2005. 115 p. Dissertação (Mestrado) - COPPE, Universidade federal do Rio de Janeiro, Rio de Janeiro, 2005.

CAIRE, M.; VAZ, M. A. The effect of flexible pipe non-linear bending stiffness behavior on bend stiffener analysis. In: PROCEEDINGS OF THE $26^{\mathrm{TH}}$ INTERNATIONAL CONFERENCE ON OFFSHORE MECHANICS AND ARCTIC ENGINEERING, 2007, San Diego: OMAE 2007 - 29108. Disponível em: <http://www.ooae.org>. Acesso em: 30 jun. 2007.

CARNEVAL, R. de O.; MARINHO, M. G. Flexible line inspection. In: PROCEEDINGS OF THE $9^{\text {TH }}$ EUROPEAN CONFERENCE ON NDT, 2006, Berlim: ECNDT 2006. Poster 106, p.1-11. Disponível em:

<http://www.ndt.net/search/docs.php3?MainSource=40>. Acesso em: 28 maio 2007. 
DEMANZE, F. et al. Fatigue analysis of polyurethane bending stiffeners. In: PROCEEDINGS OF THE $24^{\text {TH }}$ INTERNATIONAL CONFERENCE ON OFFSHORE MECHANICS AND ARCTIC ENGINEERING, 2005, Halkidiki: OMAE 2005-67506.

DeRUNTZ, J. A. Jr. End effect bending stresses in cables. Journal of Applied Mechanics, Transactions of the ASME, p.750-756. December, 1969. Presented at The American Society of Mechanical Engineers Winter Annual Meeting. Los Angeles, 1969.

FALTINSEN, O. M. Sea loads on ships and offshore structures. $1^{\text {st }}$ ed. Cambridge: Cambridge University Press, 1990. 328 p.

CARNEIRO, F. L. Análise dimensional e teoria da semelhança e dos modelos. 2. ed. Rio de Janeiro: UFRJ Editora, 1993. 256 p.

KIEPPER, B. de O. Análise estrutural estática via elementos finitos do segmento tubo flexível-enrijecedor. 2004. 95 p. Dissertação (Mestrado) - COPPE, Universidade Federal do Rio de Janeiro, Rio de Janeiro, 2004.

LANE, M. et al. Bend stiffeners for flexible risers. In: PROCEEDINGS OF THE $27^{\text {TH }}$ ANNUAL OFFSHORE TECHNOLOGY CONFERENCE, 1995, Houston: OTC 7730. p.345-353.

LANGHAAR, H. L. Dimensional analysis and theory of models. New York: John Wiley \& Sons, 1951. $166 \mathrm{p}$.

LEMOS, C. A. D. de. Análise de fadiga em risers flexíveis. 2005. 248 p. Tese (Doutorado) - COPPE, Universidade Federal do Rio de Janeiro, Rio de Janeiro, 2005.

MACHADO, A. C. Um elemento finito de tubo tridimensional para análise geometricamente não linear de dutos. 2006. 85 p. Dissertação (Mestrado) Centro de Tecnologia, Universidade Federal de Alagoas, Maceió, 2006. 
MALVERN, L. E. Introduction to the Mechanics of a Continuous Medium. Upper Saddle River: Prentice Hall, 1969. 713 p.

MBAYE, M. Implementação de ferramentas para análise local de linhas flexíveis pelo método dos elementos finitos. 2006. 96 p. Dissertação (Mestrado) - COPPE, Universidade Federal do Rio de Janeiro, Rio de Janeiro, 2006.

MSC.Software Corporation. MSC.Marc and MSC.Marc Mentat: Installation and Operations Guide: Version 2005. Documentação do programa. Santa Anna, 2004.

PETROBRAS. Rio de Janeiro. A Petrobras, Plataformas, Águas Profundas.

Disponível em: <http://www2.petrobras.com.br/portugues/ads/ads Petrobras.html>. Acesso em: 19 jun. 2007.

PESCE, C. P. Mecânica de cabos e tubos submersos lançados em "catenária": uma abordagem analítica. 1997. 354 p. Tese (Livre Docência) - Escola Politécnica, Universidade de São Paulo, São Paulo, 1997.

PESCE, C. P. et al. Dynamic curvature in catenary risers at the touch down point: an experimental study and the analytical boundary-layer solution. In: PROCEEDINGS OF THE SEVENTH INTERNATIONAL OFFSHORE AND POLAR ENGINEERING CONFERENCE, 1997, Honolulu: ISSN 1098-6189, p. 656-665.

RAMOS, R. Jr. Modelos analíticos no estudo do comportamento estrutural de tubos flexíveis e cabos umbilicais. 2001. 367 p. Tese (Doutorado) - Escola Politécnica, Universidade de São Paulo, São Paulo, 2001.

SENRA, S. F. Metodologias de análise e projeto integrado de sistemas flutuantes para exploração de petróleo offshore. 2004. 316 p. Tese (Doutorado) COPPE, Universidade Federal do Rio de Janeiro, Rio de Janeiro, 2004.

SHAMPINE, L. F.; KIERZENKA, J.; REICHELT, M. W. Solving Boundary Value Problems for Ordinary Differential Equations in MATLAB with bvp4c. 2000. 27p. Disponível em: 
< http://www.mathworks.com/matlabcentral/fileexchange/loadFile.do?objectld=3819\& objectType=file>. Acesso em: 01 ago. 2007.

SZIRTES, T. Applied dimensional analysis and modeling. $2^{\text {nd }}$ ed. Burlington: Butterworth-Heinemann, 1997. 820 p.

TIMOSHENKO, S. P. Resistência dos materiais. 3. ed. Tradução de José Rodrigues de Carvalho. Rio de Janeiro: LTC, 1979. v. 1. 451 p.

TIMOSHENKO, S. P. Resistência dos materiais. 3. ed. Tradução de Domício Falcão Moreira. Rio de Janeiro: LTC, 1975. v. 2. 518 p.

TIMOSHENKO, S. P.; GOODIER, J. N. Theory of elasticity. 3 ed. Singapure: McGraw-Hill International Editions, 1970. 567 p.

YOUNG, W. C.; BUDYNAS, R. G. Roark's Formulas for Stress and Strain. $7^{\text {th }}$ ed. New York. McGraw-Hill, 2002. 851 p. 


\section{APÊNDICE A - Código para Solução de Problema de Valor de Contorno em Matlab ${ }^{\circledR}$}

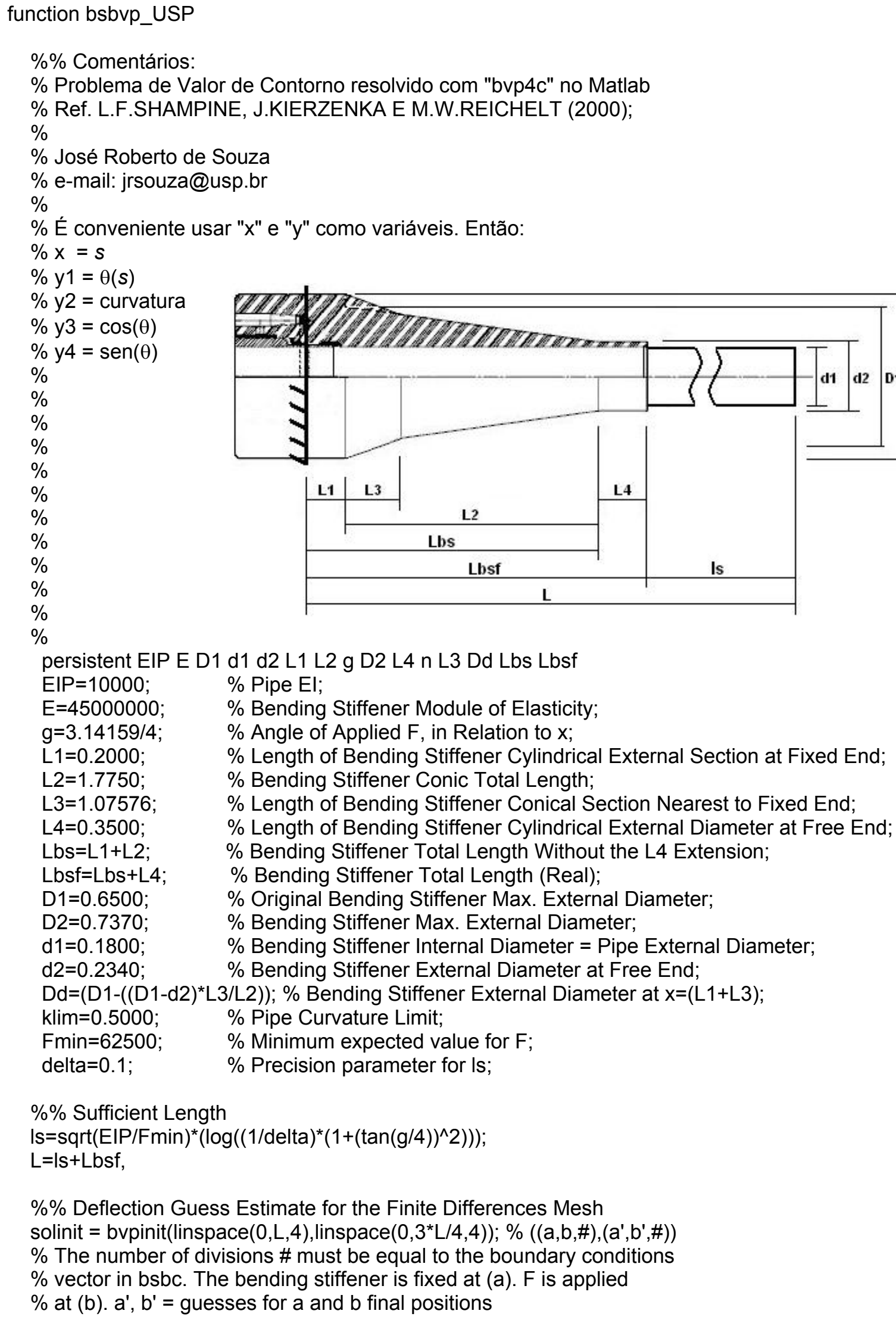


$\% \%$ Options: precision RelTol (default 1e-3), mesh size NMax (default 1000), etc. options=bvpset('RelTol',1e-4);

$\% \%$ Solution

sol1 = bvp4c(@bsbvp1,@bsbc,solinit,options);

sol2 = bvp4c(@bsbvp2,@bsbc,solinit,options);

sol3 = bvp4c(@bsbvp3,@bsbc,solinit,options);

sol4 = bvp4c(@bsbvp4,@bsbc,solinit,options);

$\%$ Curvature, $\mathrm{k}$

subplot(2,2,[1 3]);

\%plot(100*sol1.x/Lbs,100*sol1.y(2,:)/klim,'b'); hold on, grid on;\%F=500 kN subplot(2,2,[1 3]);

plot(100*sol2.x/Lbs, 100*sol2.y(2,:)/klim,'b:'); hold on, grid on;\%F=250 kN

subplot(2,2,[1 3]);

plot(100*sol3.x/Lbs, 100*sol3.y(2,:)/klim,'m:'); hold on, grid on;\%F=125 kN

subplot(2,2,[1 3]);

\%plot(100*sol4.x/Lbs, $100^{*}$ sol4.y(2,:)/klim,'r'); hold on, grid on;\%F=62.5kN

title('Curvature'); hold on, grid on

xlabel('s/Lbs [\%]'); hold on, grid on

ylabel('k/klim [\%]'); hold on, grid on

$\%$ Angle, teta

subplot(2,2,2);plot(100*sol1.x/Lbsf,sol1.y(1,:),'r'); hold on, grid on

subplot(2,2,2);plot(100*sol2.x/Lbsf,sol2.y(1,:),'b'); hold on, grid on

subplot(2,2,2);plot(100*sol3.x/Lbsf,sol3.y $\left.(1,:),{ }^{*} \mathrm{~m}^{\prime}\right)$; hold on, grid on

subplot(2,2,2);plot(100*sol4.x/Lbsf,sol4.y(1,:),'g'); hold on, grid on

title('Angle'); hold on, grid on

xlabel('s/Lbs [\%]'); hold on, grid on

ylabel('teta [rad]'); hold on, grid on

$\%$ Deflection: y

subplot(2,2,4);plot(100*sol1.y(3,:)/Lbsf, 100*sol1.y(4,:)/Lbsf,'r'); hold on, grid on subplot(2,2,4);plot(100* sol2.y(3,:)/Lbsf, 100*sol2.y(4,:)/Lbsf,'b'); hold on, grid on subplot(2,2,4);plot(100*sol3.y(3,:)/Lbsf, 100*sol3.y(4,:)/Lbsf,'m'); hold on, grid on subplot(2,2,4);plot(100*sol4.y(3,:)/Lbsf, 100*sol4.y(4,:)/Lbsf,'g'); hold on, grid on title('Displacement'); hold on, grid on

xlabel('x/Lbs [\%]'); hold on, grid on ylabel('y/Lbs [\%]'); hold on, grid on

$\% \%$ Embedded Functions

$\% \%$ ODEs

function dyds $=\operatorname{bsbvp} 1(x, y)$

$\%$ Non-Linear Ordinary Differential Equations of First Order with

$\%$ Variable Coeficients (dsdy):

EIP;E;D1;d1;d2;L1;L2;g;D2;L4;L3;Dd;Lbs;Lbsf; \%Recall of Variables

$\mathrm{F}=500000 ; \quad \%$ Applied Force in (b);

$\mathrm{D}=\mathrm{D} 2-((\mathrm{D} 2-\mathrm{Dd}) / \mathrm{L} 3)^{*}(\mathrm{x}-\mathrm{L} 1)$;

$\%$ Variable diameter for $\mathrm{L} 1<\mathrm{x}<=(\mathrm{L} 1+\mathrm{L} 3)$;

$d=D 1-((D 1-d 2) / L 2)^{*}(x-L 1)$;

$\%$ Variable diameter for $(\mathrm{L} 1+\mathrm{L} 3)<\mathrm{x}<=\mathrm{Lt}$;

Elbs $0=E^{\star}(3.1416 / 64)^{\star}\left(\mathrm{D} 2^{\wedge} 4-\mathrm{d} 1^{\wedge} 4\right)$;

\% Bending stiffener $\mathrm{El}(\mathrm{x})$ within first cylindrical part;

Elbs1 $=E^{*}(3.1416 / 64)^{*}\left(D^{\wedge} 4-d 1^{\wedge} 4\right)$;

$\%$ Bending stiffener $\mathrm{EI}(\mathrm{x})$ within first conical part; 


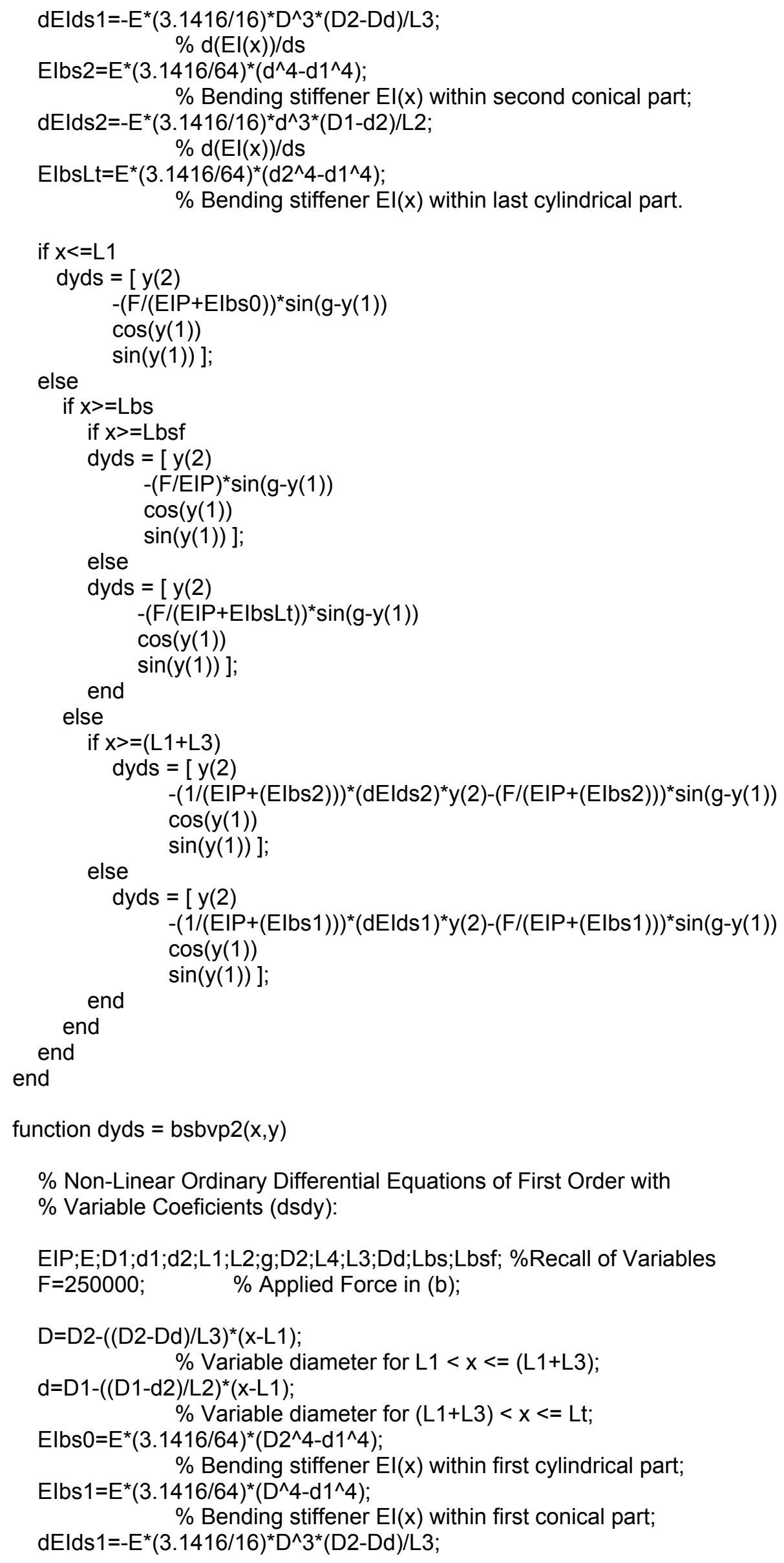




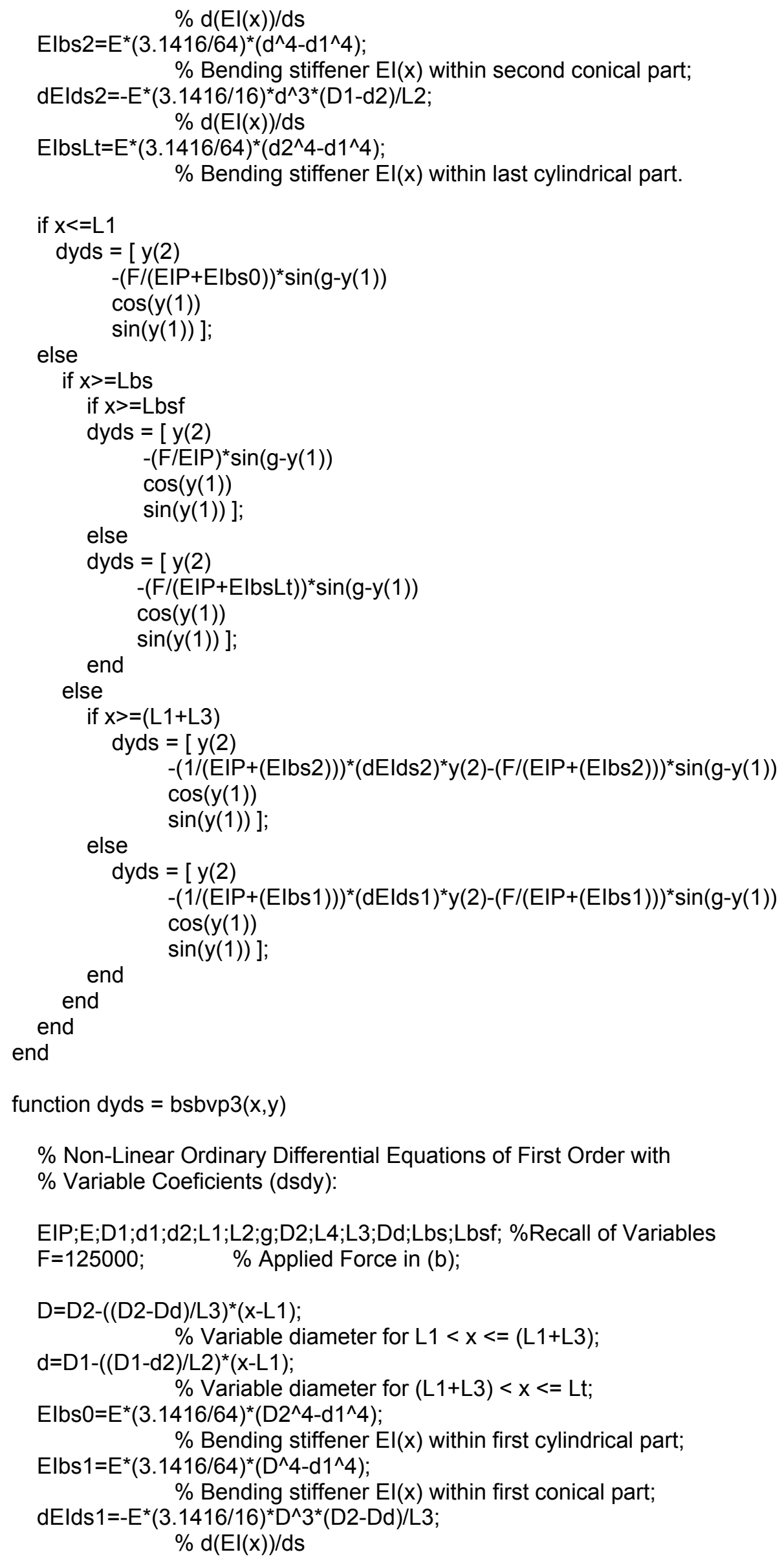




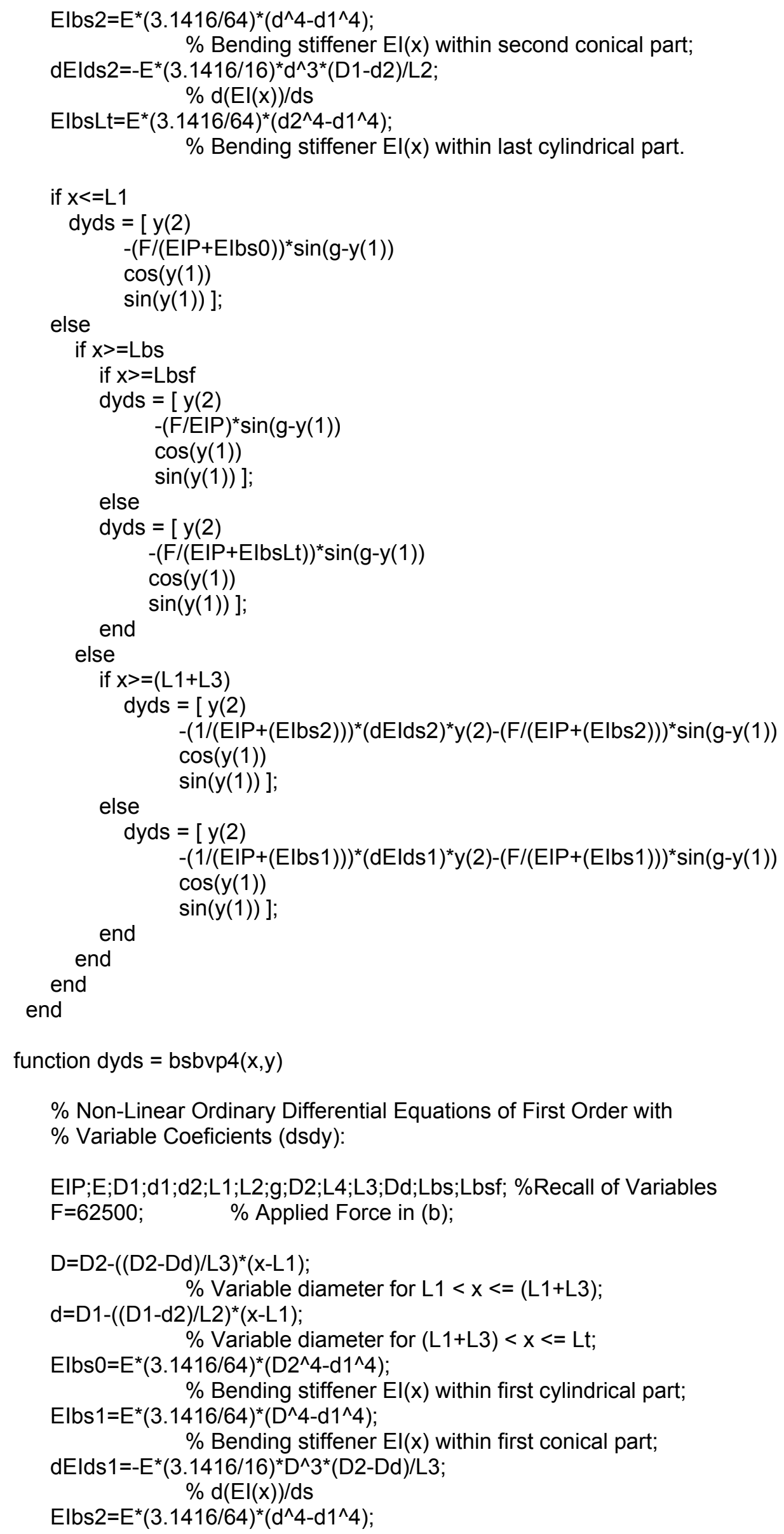




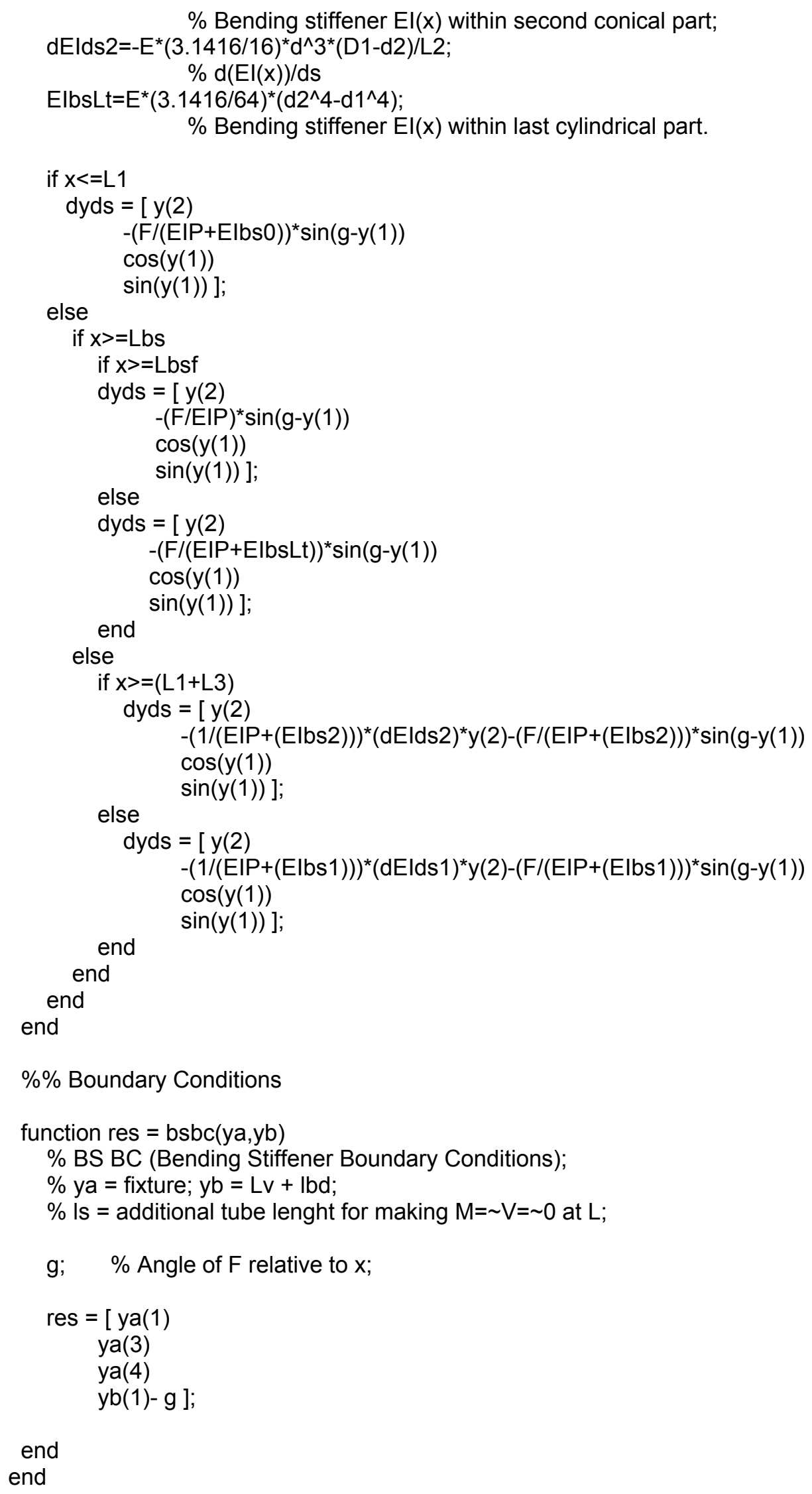

